This is a self-archived - parallel published version of this article in the publication archive of the University of Vaasa. It might differ from the original.

\title{
Optimal charge scheduling of electric vehicles in solar energy integrated power systems considering the uncertainties
}

Author(s): Sadati, S. Muhammad Bagher; Moshtagh, Jamal; Shafie-Khah, Miadreza; Rastgou, Abdollah; Catalão, João P. S.

Title: Optimal charge scheduling of electric vehicles in solar energy integrated power systems considering the uncertainties

Year: $\quad 2020$

Version: Accepted manuscript

Copyright C)2020 Springer Nature Switzerland. This is a post-peer-review, pre-copyedit version of an article published in Ahmadian, A., Mohammadi-ivatloo, B., \& Elkamel, A. (eds), Electric vehicles in energy systems modelling, integration, analysis, and optimization. The final authenticated version is available online at: http://dx.doi.org/10.1007/978-3-030-34448-1_4.

\section{Please cite the original version:}

Sadati S.M.B., Moshtagh J., Shafie-Khah M., Rastgou A., \& Catalão J.P.S. (2020), Optimal charge scheduling of electric vehicles in solar energy integrated power systems considering the uncertainties. In: Ahmadian, A., Mohammadi-ivatloo, B., \& Elkamel, A. (eds), Electric vehicles in energy systems modelling, integration, analysis, and optimization (pp. 73128). Springer, Cham. https://doi.org/10.1007/978-3-03034448-1_4 


\title{
Chapter 4
}

\section{Optimal charge scheduling of electric vehicles in solar energy integrated power systems considering the uncertainties}

\author{
S. Muhammad Bagher Sadati \\ National Iranian Oil Company (NIOC), Iranian Central Oil Fields Company (ICOFC), West Oil and \\ Gas Production Company (WOGPC), Kermanshah, Iran. \\ Email: bagher_sadati@yahoo.com \\ Jamal Moshtagh \\ Department of Electrical Engineering, Faculty of Engineering, University of Kurdistan, Sanandaj, \\ Kurdistan, Iran. \\ Email: j.moshtagh@uok.ac.ir \\ Miadreza Shafie-khah \\ School of Technology and Innovations, University of Vaasa, Finland. \\ Email: miadreza@gmail.com

\begin{abstract}
Abdollah Rastgou
Department of Electrical Engineering, Kermanshah Branch, Islamic Azad University, Kermanshah, Iran.

Email: a.rastgou@iauksh.ac.ir
\end{abstract}

João P. S. Catalão

Faculty of Engineering of the University of Porto and INESC TEC, Porto, Portugal.

Email: catalao@fe.up.pt

\begin{abstract}
Nowadays, vehicle to grid (V2G) capability of the electric vehicle (EV) is used in the smart distribution network (SDN). The main reasons for using the EVs, are improving air quality by reducing greenhouse gas emissions, peak demand shaving and applying ancillary service, and etc. So, in this chapter, a non-linear bi-level model for optimal operation of the SDN is proposed where one or more solar based-electric vehicle parking lots (PLs) with private owners exist. The SDN operator (SDNO) and the PL owners are the decision-makers of the upper-level and lower-level of this model, respectively. The objective functions at two levels are the SDNO's profit maximization and the PL owners' cost minimization. For transforming this model into the single-level model that is named mathematical program with equilibrium constraints (MPEC), firstly, Karush-Kuhn-Tucker (KKT) conditions are used. Furthermore, due to the complementary constraints and non-linear term in the upper-level objective function, this model is linearized by the dual theory and Fortuny-Amat and McCarl linearization method. In the following, it is assumed that the SDNO is the owner of the solar-based EV PLs. In this case, the proposed model is a single-level model. The uncertainty of the EVs and the solar system, as well as two programs, are
\end{abstract}


considered for the EVs, i.e., controlled charging (CC) and charging/discharging schedule (CDS). Because of the uncertainties, a risk-based model is defined by introducing a Conditional Value-at-Risk (CVaR) index. Finally, the bi-level model and the single-level model are tested on an IEEE 33-bus distribution system in three modes; i.e., without the EVs and the solar system, with the EVs by controlled charging and with/ without the solar system, and with the EVs by charging/discharging schedule and with / without the solar system. The main results are reported and discussed.

Keywords: Smart Distribution Network, Operational Scheduling, Solar Based-Electric Vehicles Parking Lots, Bi-level Model.

\subsection{Introduction}

Nowadays, air pollution and dependence on fossil fuel resources are worldwide concerns. These issues are most taken into account in the transportation sectors and electricity generation system as the main consumers of fossil fuels. Electric vehicles (EVs) with the capability of Vehicle-to-Grid (V2G) are a solution to answer these concerns. Of course, most of the EVs, which will be added in the distribution system in the future, would highly consume energy, which leads to more energy production and consequently, increased the greenhouse gas emissions. However, this problem can be solved by charging/discharging schedule of the EVs as well as the usage of renewable-energy resources (RERs) such as the solar system.

Because of uncontrolled charging, controlled charging and charging/discharging schedule of the EVs, the planning and operation of the smart distribution network (SDN) have been intricated. Uncontrolled charging of the EVs has inappropriate results such as increasing power losses and demand [1-4], imbalanced demand [5, 6], voltage drop [7], increasing of total harmonic distortion [8, 9], decreasing of cable and transformer life [10, 11], etc.. However, by using the controlled charging and charging/discharging schedule, as well as V2G capability of the EVs; the performance of the SDN is improved and is obtained some benefit such as ancillary service [12], peak load shaving [13, 14], emission's reduction [15], support for the integration of RERs [16, 17], losses reduction [18], improving voltage profile [19] and maximizing the profit [20, 21].

In addition, in $[22,23]$ are proved that charging of the EVs with only traditional power plants leads to unfit environmental impact. So, using of RERs along with traditional power plants is unavoidable. For this reason, charging of the EVs is explored with RERs i.e. solar system, wind turbine and both of them [24-29].

In addition, due to the uncertainties of the EVs, especially their availability and ensuring of the discharging power as well as the uncertainty of output power of the solar system, the SDN faces uncertainties. Therefore, it is necessary to introduce the risk-based model. Usually, risk control is done by using the risk measures. Value-at-risk $(\mathrm{VaR})$ and conditional value-at-risk $(\mathrm{CVaR})$ are the most important examples of risk measures. Due to the linear form of $\mathrm{CVaR}$, this index is widely applied in the power system problems [30].

Although, the optimal operation of the SDN has been evaluated in different studies over the past few years; however, in this chapter, the operational scheduling of the SDN in the presence of solar-based EV PLs, within the bi-level framework has been investigated. The most important questions that are answered in this chapter, as follows:

1. What is the main aim of the optimal operation of the SDN?

2. What is the appropriate model with the PL owners as a new decision-maker?

3. What time the EVs will be charged and discharged?

4. How much is the total charging/discharging power of the EVs?

5. What is the amount of purchasing power from the wholesale market (WM) for the EVs and customers with regard to $\mathrm{V} 2 \mathrm{G}$ capability?

6. what is the effect of the uncertainties on the SDN?

7. How does the risk effect on operational scheduling of the SDN?

8. What are the most important affecting factors on the SDN?

9. What is the proper method for solving the offered model?

The modeling of the EVs and the solar system are explained in sections 4.2 and 4.3, respectively. Section 4.4 gives modeling of operational scheduling of the SDN, i.e., bi-level model and single-level model. In section 4.5 simulation results are presented. At last, conclusions are reported in section 4.6. 


\subsection{Modeling of the EVs}

The EVs can be categorized into three groups of battery-electric vehicles, hybrid-electric vehicles, and fuel cell electric vehicles. All these EVs have a battery as well as the V2G capability. Therefore, in the near future, EVs are widely used. With increasing the EVs, the batteries of them can provide a high-availability storage system for the SDN. In this way, the EVs can act as an active element during the parked times. So, the power stored in the batteries, particularly at the on-peak hours sells to the SDNO. The initial state of energy (SOE), arrival time/departure time of the EVs to/from the PLs, are the main uncertainties of each EV. Some studies are shown that the behavior of the EVs can be modeled with appropriate probability distribution function (PDF) such as a truncated Gaussian distribution [21]. Thus, the modeling of EVs is shown by Eqs. (4.1) - (4.3).

$$
\begin{array}{ll}
S O E_{E V}^{i n i}=f_{T G}\left(X ; \mu_{S O E} ; \sigma_{S O E}^{2} ;\left(S O E_{E V}^{i n i, \min } ; S O E_{E V}^{i n i, \max }\right)\right) & \forall E V \\
t_{E V}^{a v}=f_{T G}\left(X ; \mu_{a v} ; \sigma_{a v}^{2} ;\left(t_{E V}^{a v, \text { min }} ; t_{E V}^{a v, \max }\right)\right) & \forall E V \\
t_{E V}^{d e p}=f_{T G}\left(X ; \mu_{d e p} ; \sigma_{d e p}^{2} ;\left(\max \left(t_{E V}^{d e p, \min }, t_{E V}^{a v v}\right) ; t_{E V}^{d e p, \max }\right)\right) & \forall E V
\end{array}
$$

Due to the large number of the EVs are in the PLs every day, the more energy is needed for charging of the EVs. Furthermore, due to the V2G capability, the performance of the SDN can be improved. Since the EVs are considered a load/source at the off-peak and mid-peak hours/during the on-peak hours, a complexity is created in the operation and planning of the SDN. Accordingly, proper PL's operation will only be possible if there is an energy management system (EMS) that be capable of controlling the process of charging and discharging of the EVs. Fig. 4.1 illustrates the flowchart of charging or charging/discharging schedule of the EVs, and the power exchanged between the PLs and the SDNO. Based on this flowchart, after the entrance of the EVs to the PL, required data such as initial and desired SOE of the EVs, the battery specifications and departure time are obtained from the EV owners. By computing the energy needed for each EV, the EMS determines the time and charging/discharging power of the EVs.

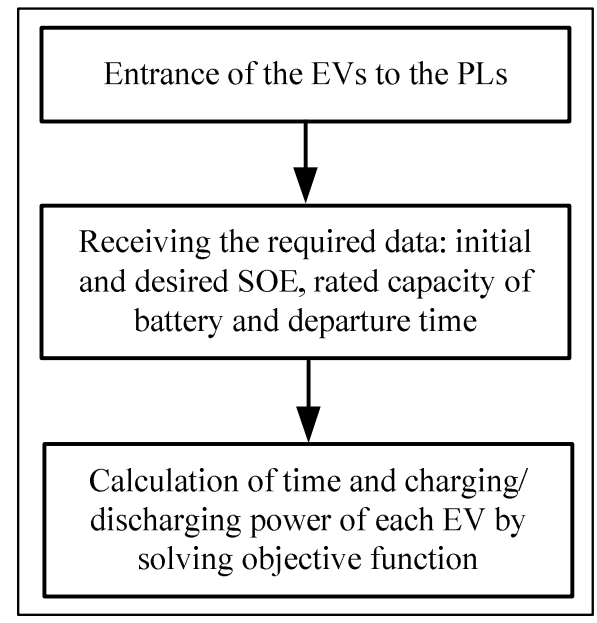

Fig. 4.1. The Flowchart of each EV's operation

\subsection{Modeling of the solar system}

Several cells create the solar system. This system transforms solar irradiance energy into electrical energy. The number of cells, the weather conditions, the direction of cells and the temperature are the main affecting factor of the power generated of the solar system. Of course, this power is an uncertain value due to the uncertainty of solar irradiance. The most usable PDF for modeling of solar irradiance is the Beta function that is explained in Eqs. (4.4) to (4.6). In these equations, $\theta$ is the solar irradiance $\left(\mathrm{kW} / \mathrm{m}^{2}\right)$. Also, by using the mean $(\mu)$ and variance $(\sigma$ ) of solar irradiance, $\alpha$ and $\beta$ are computed [31]. 


$$
\begin{aligned}
& f(\theta)=\left\{\begin{array}{lc}
\frac{\Gamma(\alpha+\beta)}{\Gamma(\alpha)+\Gamma(\beta)} \times \theta^{\alpha-1} \times(1-\theta)^{\beta-1} & 0 \leq \theta \leq 1, \alpha \geq 0, \beta \geq 0 \\
0 & \text { otherwise }
\end{array}\right. \\
& \beta=(1-\mu) \times\left(\frac{\mu \times(1+\mu)}{\sigma^{2}}-1\right) \\
& \alpha=\frac{\mu \times \beta}{1-\mu}
\end{aligned}
$$

The power generated of the solar system can be calculated by Eqs. (4.7) to (4.11).

$$
\begin{aligned}
& P_{\theta}=N \times F F \times V_{y} \times I_{y} \\
& F F=\frac{V_{M P P} \times I_{M P P}}{V_{O C} \times I_{S C}} \\
& V_{y}=V_{O C}-\left(K_{v} \times T_{C}\right) \\
& I_{y}=\theta \times\left(I_{S C}+K_{C} \times\left(T_{C}-25\right)\right) \\
& T_{C}=T_{a}+\left(\theta \times \frac{T_{N}-20}{0.8}\right)
\end{aligned}
$$

Where voltage at the maximum power point and open circuit voltage are $\mathrm{V}_{\mathrm{MPP}}$ and $\mathrm{V}_{\mathrm{oc}}$, respectively. $\mathrm{I}_{\mathrm{MPP}}$ and $\mathrm{I}_{\mathrm{sc}}$ are current at the maximum power point and short circuit current. The cell temperature is $\mathrm{T}_{\mathrm{c}}$ in ${ }^{\circ} \mathrm{C}$. The ambient and nominal operating temperatures are $\mathrm{T}_{\mathrm{a}}$ and $\mathrm{T}_{\mathrm{N}}$ in ${ }^{\circ} \mathrm{C} . \mathrm{k}_{\mathrm{v}}$ and $\mathrm{k}_{\mathrm{c}}$ (in $\mathrm{V} /{ }^{\circ} \mathrm{C}$ and $\mathrm{A} /{ }^{\circ} \mathrm{C}$ ) are the voltage temperature and the current temperature coefficient, respectively. $\mathrm{N}$ is the number of cells, $\mathrm{P}_{\theta}$ is the power generated of the solar system, and FF is the fill factor [31].

\subsection{Modeling of operational scheduling of the SDN}

A bi-level model proposes when two decision-makers exist in the optimization problems. In this model, the upper-level and the lower-level are leader and follower, respectively. In this chapter, the SDNO as the leader and the PL owner as a follower are considered. The aims of the objective functions for leader and follower are maximizing the profit and minimizing the cost, respectively. The presented bi-level model investigates in two-parts. In the first part, the EVs only charge (controlled charging), and in the second part, the EVs participate in charging/charging schedule. The structure of the bi-level model shows in Fig. 4.2. Also, Fig. 4.3 shows how the decision-makers interact in this model. Based on Fig. 4.3, the power exchanged between the SDNO and the PL owners as well as the price of this power are considered as the decision variables of these two levels (in the controlled charging part, charging power and price, i.e. $\mathrm{P}^{\mathrm{ch}}$ and $\mathrm{Pr}^{\mathrm{ch}}$, in the charging/discharging schedule part, charging/discharging power and price, i.e. $\mathrm{P}^{\mathrm{ch}}, \mathrm{Pr}^{\mathrm{ch}}$ and $\left.{ }^{\mathrm{Pdch}} \mathrm{Pr}^{\mathrm{dch}}\right)$. The PL owner decides on the offered price for the power exchanged with the SDNO, which depends on the ability to charging or charging/discharging of the EVs. This decision affects the offered price, and the SDNO may change this price. The changing this price will also change the exchanging power. This action repeats several times in order to the problem reach the point of equilibrium. 
Operation of the SDN Problem

aim: Maximization of the Profit

subject to: upper-level constraints

\section{Operation of the PLs Problem}

aim: Minimization of the cost

subject to: lower-level Problem

Fig. 4.2. Structure of the bi-level model

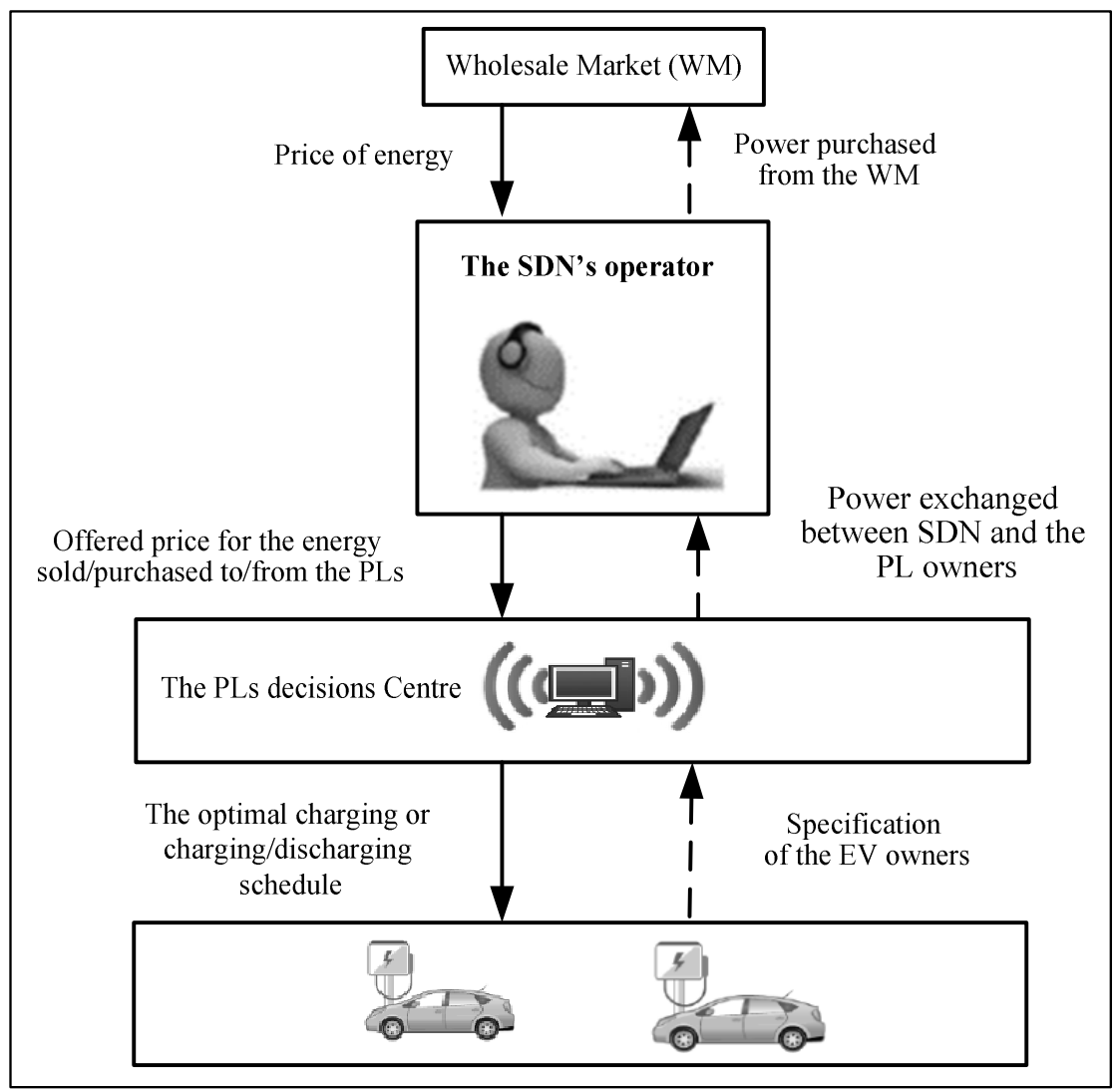

Fig. 4.3. Interaction with the SDNO and the PL owners in the bi-level model

\subsubsection{Bi-level model with controlled charging}

The proposed bi-level model with controlled charging of the EVs is defined in Eqs. (4.12) to (4.27). The goal of the upper-level is to maximize the profit of SDNO. Eqs. (4.12) to (4.18) describe this level. The objective function is explained in Eq. (4.12). The decision variables of this level are the purchasing power from the WM, and the offered energy sold price to the PL owners. The parts of the objective function are as follows:

Part 1. Selling energy to the customers (as an income term).

Part 2. Purchasing energy from the WM (as a cost term).

Part 3. The expected value of energy sold to the PL owner at off-peak/mid-peak hours (as an income term).

Eq. (4.13) is the linear load flow, and is fully explained in [31] (see Appendix-1.A). Eq. (4.14) shows also the maximum price of the energy sold to the PL owners. It should be noted that in the next section, firstly, the price of the energy sold to customers calculates regardless of the EVs, so the maximum price of the energy sold to the PL owners is equal to this amount. The Eq. (4.15) is the maximum power purchased of the SDNO from the WM. 
This maximum limit is equal to the total power for supplying the customers' demand and charging of all EVs. According to Eq. (4.16), the amount of line current due to the capacity and the permissible thermal must be limited to its maximum value. Also, Eq. (4.17) limits the voltage of each bus between the maximum and minimum values, i.e., 1.05 and 0.95 per unit (p.u.). The power balance limit, i.e., equivalence the total power generated with the total power consumed, is shown in Eq. (4.18). The amount of loss in Eq. (4.18) is equal to multiply the value of the electrical resistance between the two lines and the squared of current between these lines, and is also linearized in [31].

Eqs. (4.19) to (4.27) describe the lower-level. The cost minimization of the PL owners is the target of this level. At this level, the PL owners provide the optimal SOE of each EV at exiting time by charging the batteries of the EVs. The decision variables are the power purchased from the SDNO for charging of the EVs, the SOE of each $\mathrm{EV}$, and the charging power of the EVs by the solar system. The objective function of this level is defined in Eq. (4.19), which minimizes the cost of the purchasing energy from the SDNO for EVs' charging during the off-peak and mid-peak hours.

To optimize the power purchased from the SDNO, it is necessary to be created proper scheduling for the charging power and charging time of the EVs. In fact, in the interval time between the arrival/departure time from/to the PLs, at the low energy prices, i.e. at the off-peak and mid-peak hours, the EVs should be charge so that the EVs leaves the PLs with the desired SOE. The time interval, i.e. charging/discharging time of the EVs and the customers' demand, is 1 hour $(\Delta \mathrm{t}=1)$. Therefore, in these Eqs, $\Delta \mathrm{t}$ is neglected. The SOE of each EV, based on Eq. (4.20), should be less than its maximum value. Also, the total power purchased from the SDN and the power generated of the solar system for the EVs charging, according to Eq. (4.21) during the off-peak and mid-peak hours is limited to maximum and minimum values. According to Eq. (4.22), the EVs must not charge through the SDNO at the on-peak hours. Eq. (4.23) also shows that the EVs' charging power with the solar system at the on-peak hours should be limited to maximum and minimum values. Based on Eqs. (4.24) and (4.25), the SOE of each EV at each hour time is depended on to the remained SOE of the EV from the previous hour, the power purchased from the SDNO and the power generated by the solar system, charging efficiency, and the initial SOE of each EV. Based on Eq. (4.26), the SOE of the EVs reaches the desired SOE at the departure time. Eq. (4.27) also shows that the power required for charging of the EVs through the solar system at each time is equal to the power generated of the solar system at the same time. Dual variables for the equal and unequal constraints of the lower-level problem are shown by $\lambda$. Fig 4.4 shows the proposed framework of this model.

$$
\begin{aligned}
& \text { Maximize } \\
& \sum_{t=1}^{24}\left(\sum_{b=2}^{N_{b}}\left(P_{b, t}^{L} \times \operatorname{Pr}_{t}^{L}\right)-\sum_{s b=1}^{N_{s b}}\left(P_{s b, t}^{W h 2 G} \times \operatorname{Pr}_{t}^{W h 2 G}\right)\right) \\
& +\sum_{P L=1}^{N_{P L}} \sum_{E V=1}^{N_{E V}} \sum_{t=1}^{24}\left(\hat{P}_{P L, E V, t^{\text {mid loff - peak }}}^{c h-\text { grid }} \times \operatorname{Pr}_{t^{\text {mid loff }- \text { peak }}}^{G 2 P L}\right)
\end{aligned}
$$

\section{Subject to:}

Liner power flow

$$
\begin{aligned}
& 0<\operatorname{Pr}_{t^{\text {midloff-peak }}}^{G 2 P L} \leq \operatorname{Pr}_{t^{\text {mid loff }- \text { peck }}}^{G 2 P L, \text { max }} \\
& 0<\mathrm{P}_{t}^{W h 2 G} \leq \mathrm{P}_{t}^{W h 2 G, \max } \\
& 0 \leq I_{b, t, s} \leq I_{b, t}^{\max } \\
& V^{\min } \leq V_{b, t, s} \leq V^{\max } \\
& P_{s b, t}^{W h 2 G} \times \eta^{\text {Trans }}=P_{b, t}^{L}+P_{t, s}^{\text {Loss }}+\sum_{E V} \hat{P}_{P L, E V, t^{\text {midl loff - peak }}}^{\text {ch-grid }}
\end{aligned}
$$


Minimize

$$
\sum_{s=1}^{N_{s}} \rho_{s} \sum_{P L=1}^{N_{P L}} \sum_{E V=1}^{N_{E V}} \sum_{t=1}^{24}\left(P_{P L, E V, t^{\text {mid loff }- \text { peak }}, s}^{\text {ch-grid }} \times \operatorname{Pr}_{t^{\text {mid loff }- \text { peak }}}^{G 2 P L}\right)
$$

\section{Subject to}

$$
\begin{aligned}
& S O E_{P L, E V, t, s} \leq S O E_{E V}^{\max } \quad \forall \mathrm{PL}, \mathrm{EV}, \mathrm{t}, \mathrm{s} \quad \lambda_{\mathrm{PL}, \mathrm{EV}, \mathrm{t}, \mathrm{s}}^{1}
\end{aligned}
$$

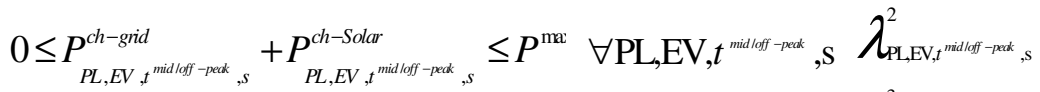

$$
\begin{aligned}
& \lambda_{\mathrm{PLEV}, t^{\text {mid } l \text { off-peat }}, \mathrm{S}}^{3} \\
& P_{P L, E V, t^{\text {on-peak }}, s}^{\text {ch-grid }}=0 \quad \forall \mathrm{PL}, \mathrm{EV}, t^{\text {on-peak }}, \mathrm{S} \\
& 0 \leq P_{P L, E V, t^{\text {on-peak }}, s}^{\text {ch-Solor }} \leq P^{\max } \quad \forall \mathrm{PL}, \mathrm{EV}, t^{\text {on-peak }}, \mathrm{S} \quad \lambda_{\mathrm{PL}, \mathrm{EV}, t^{\text {on-peak }}, \mathrm{s}}^{4}, \lambda_{\mathrm{PL}, \mathrm{EV}, t^{\text {on-peak }}, \mathrm{s}}^{5} \\
& S O E_{\mathrm{PL}, \mathrm{EV}, \mathrm{t}, \mathrm{s}}=S O E_{\mathrm{PL}, \mathrm{EV}, \mathrm{t}-1, \mathrm{~s}} \quad \forall \mathrm{PL}, \mathrm{EV}, \mathrm{t} \succ \mathrm{t}^{a r v} \quad \lambda_{\mathrm{PL}, \mathrm{EV}, \mathrm{t} \succ \mathrm{t}^{a v}, \mathrm{~s}}^{6} \\
& +\left(P_{P L, E V, t, s}^{c h-\text { grid }}+P_{P L, E V, t, s}^{c h-S o l a r}\right) \times \eta^{c h} \\
& S O E_{\mathrm{PL}, \mathrm{EV}, \mathrm{t}, \mathrm{s}}=\mathrm{SOE}_{E V}^{\mathrm{arv}} \quad \forall \mathrm{PL}, \mathrm{EV}, \mathrm{t}^{a v v}, \lambda_{\mathrm{PL}, \mathrm{EV}, \mathrm{t}^{a v}, \mathrm{~s}}^{7} \\
& +\left(P_{P L, E V, t, s}^{c h-g i d}+P_{P L, E V, t, s}^{c h-S o l a r}\right) \times \eta^{c h} \\
& S O E_{P L, E V, t, s}=S O E_{E V}^{d e p} \quad \forall \mathrm{PL}, \mathrm{EV}, \mathrm{t}^{d e p}, \mathrm{~s} \quad \lambda_{\mathrm{PL}, \mathrm{EV}, \mathrm{t}^{d e p}, \mathrm{~s}}^{8} \\
& \sum_{E V} P_{P L, E V, t, s}^{\text {ch-Solar }}=P_{P L, t, s}^{\text {Solar }} \quad \forall \mathrm{PL}, \mathrm{EV}, \mathrm{t}, \mathrm{s} \quad \lambda_{\mathrm{PL}, \mathrm{EV}, \mathrm{t}, \mathrm{s}}^{9}
\end{aligned}
$$




\section{Inputs:}

1. Specifications of the solar system as well as the EVs including arrival time, depurate time, initial and desired SOE, charging rate and battery capacity.

2. Real characteristics of the network such as the customers' demand, ohmic and inductive resistance, and power factor.

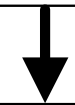

Upper -Level: Operational Scheduling of the SDN

Objective function: Maximizing the profit of the SDNO

Variables: The power purchased from the WM, the proposed energy sold price to the PL owners.

Limitations: Linear load flow, maximum and minimum the power purchased from the WM, maximum and minimum of the energy price, power balance, line capacity and bus voltage.

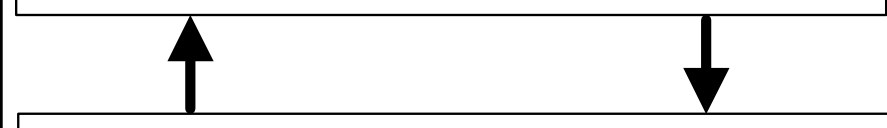

Lower-level: operation of the PLs

objective function: Minimizing the cost of the PLs

Variables: The power purchased from the SDNO for charging of the EVs, charging power of the EVs with the solar system, the SOE of the EVs.

Limitations : $\mathrm{SOE}$, charging rate.

\section{Outputs:}

1- The energy sold price to the PL owners.

2- Charging scheduling of the EVs.

3- The power sold to the PLs.

4- Operational scheduling of the SDN.

Fig .4.4. The proposed bi-level model framework with controlled charging.

\subsubsection{Bi-level model with the charging/discharging Schedule}

The presented bi-level model with the charging/discharging schedule of the EVs is described in Eqs. (4.28) to (4.45). In this case, the SDNO at the on-peak hours uses the discharging power of the EVs as well as the power generated of the solar system for supplying the customers' demand. The goal of the upper-level is to maximize the profit of SDNO. This level is defined by Eqs. (4.28) to (4.34). The objective function is presented in Eq. (4.28). The decision variables of this level are the power purchased from the WM, the energy purchased price from the PL owners. The energy sold price to the PL owners is calculated from the previous part and is considered as a parameter. The parts of this objective function are as follows:

Part 1. Selling energy to the customers (as an income term).

Part 2. Purchasing energy from the WM (as a cost term).

Part 3. The expected value of energy sold to the PL owners at off-peak/mid-peak hours (as an income term). 
Part 4. The expected value of purchasing energy from the PL owners at the on-peak hours (as a cost term).

Part 5. The expected value of purchasing energy from the power generated of the solar system at the on-peak hours (as a cost term).

Eqs. (4.29) to (4.34) are the constraints of this level. Except Eq. (4.30), reminded Eqs. are explained in section 4.4.1. Eq. (4.30) shows the maximum price of the energy purchased from the PL owners.

Eqs. (4.35) to (4.45) describe the lower-level. The aim of this level is to minimization the cost of the PL owners. At this level, the PL owners provide the optimal SOE of each EV at the departure time by charging/discharging schedule of the EVs. The decision variables are the power exchanged between the SDNO and the PL owners, the $\mathrm{SOE}$ of each EV, and the charging power of the EVs by the solar system. The objective function of this level is described in Eq. (4.35). The parts of this objective function are as follows:

1. Purchasing energy from the SDNO for EVs' charging during the off-peak/mid-peak hours.

2. Purchasing energy from the EV owners at the on-peak hours for selling to the SDNO. In this case, it is supposed that half of this income is paid to the EV owners to encourage them to attend the V2G program.

3. The cost of battery depreciation that is paid to the EV owners due to many times discharging. This term is calculated by the exchanging power between each EV and the PL owner [21].

The constraints of this level explain in Eqs. (4.36) to (4.45). Based on the previous part, proper scheduling for the power and the time of the EVs charging/discharging is needed. In fact, in the interval time between the arrival/departure time from/to the PLs, at the low energy prices, i.e. the off-peak and mid-peak hours, the EVs should be charge and at the high energy prices, i.e. the on-peak hours, the EVs should be discharge. Also, the EVs leaves the PLs with the desired SOE. The SOE of each EV, based on the Eq. (4.36), should be between the minimum and maximum value. Eqs. (4.37) and (4.38) are explained in the previous part. Eq. (4.39) shows that the power generated of the solar system for charging of the EVs not used at the on-peak hours. In fact, at these hours, the discharging power of the EVs and the power generated of the solar system are applied in order to supply the customers' demand. The amount of discharging power of the EVs for selling to the SDNO at the on-peak hours is also limited between the maximum and minimum values, based on Eq. (4.40). According to Eq. (4.41), the discharging power must be zero during the off-peak /mid-peak hours. Eqs. (4.42) to (4.45) are also explained in the previous part. $\lambda$ are dual variables for the equal and unequal constraints of the lower-level problem. Fig 4.5 shows the proposed framework for this model.

$$
\begin{aligned}
& \text { Maximize } \\
& \sum_{t=1}^{24}\left(\sum_{b=2}^{N_{b}}\left(P_{b, t}^{L} \times \operatorname{Pr}_{t}^{L}\right)-\sum_{s b=1}^{N_{s b}}\left(P_{s b, t}^{W h 2 G} \times \operatorname{Pr}_{t}^{W h 2 G}\right)\right) \\
& +\sum_{P L=1}^{N_{P L}} \sum_{E V=1}^{N_{E V}} \sum_{t=1}^{24}\left(\begin{array}{l}
\left(\begin{array}{l}
\hat{P}_{P L, E V, t^{\text {mid loff - peak }}}^{\text {ch-gid }} \times \operatorname{Pr}_{t^{\text {mid loff - peak }}}^{G 2 P L} \\
-\left(\hat{P}_{P L, E V, t^{\text {on-peak }}}^{d c h} \times \operatorname{Pr}_{t^{\text {on-peak }}}^{P L 2 G}\right.
\end{array}\right)
\end{array}\right) \\
& -\sum_{P L=1}^{N_{P L}} \sum_{t=1}^{24}\left(\hat{P}_{P L, t^{\text {on-peak }}}^{\text {Solor }} \times \operatorname{Pr}_{t^{\text {on-peak }}}^{P L 2 G}\right)
\end{aligned}
$$

\section{Subject to:}

Liner power flow

$$
\begin{aligned}
& 0<\operatorname{Pr}_{t^{\text {on-peak }}}^{\text {PL } 2 G} \leq \operatorname{Pr}_{t^{\text {on-peak }}}^{\text {PL 2G, max }} \\
& 0<\mathrm{P}_{t}^{W h 2 G} \leq \mathrm{P}_{t}^{W h 2 G, \text { max }}
\end{aligned}
$$




$$
\begin{aligned}
& 0 \leq I_{b, t, s} \leq I_{b, t}^{\max } \\
& V^{\min } \leq V_{b, t, s} \leq V_{\max } \\
& P_{s b, t}^{W h 2 G} \times \eta^{\text {Trans }}+\sum_{E V} \hat{P}_{P L, E V, t^{\text {on-peak }}}^{\text {dch }}+\hat{P}_{P L, t^{\text {on-peak }}}^{\text {Solar }}=P_{b, t}^{L}+P_{t, s}^{\text {Loss }}+\sum_{E V} \hat{P}_{P L, E V, t^{\text {mid lof }- \text { peak }}}^{\text {ch-grid }}
\end{aligned}
$$

Minimize

$$
\sum_{s=1}^{N_{s}} \rho_{s} \sum_{P L=1}^{N_{P L}} \sum_{E V=1}^{N_{E V}} \sum_{t=1}^{24}\left(\left(P_{P L, E V, t^{\text {mid loff - peak }}, s}^{c h-\text { irid }} \times \operatorname{Pr}_{t^{\text {mid loff }- \text { peeak }}}^{G 2 P L}\right)+\left(P_{P L, E V, t^{\text {on-peak }}, s}^{d c h} \times\left(0.5 \operatorname{Pr}_{t^{\text {on-peak }}}^{P L 2 G}+C^{c d}\right)\right)\right)
$$

\section{Subject to:}

$$
\begin{aligned}
& S O E_{E V}^{\min } \leq S O E_{P L, E V, t, s} \leq S O E_{E V}^{\max } \quad \forall \mathrm{PL}, \mathrm{EV}, \mathrm{t}, \mathrm{s} \quad \lambda_{\mathrm{PL}, \mathrm{EV}, \mathrm{t}, \mathrm{s}}^{1}, \lambda_{\mathrm{PL}, \mathrm{EV}, \mathrm{t}, \mathrm{s}}^{2}
\end{aligned}
$$

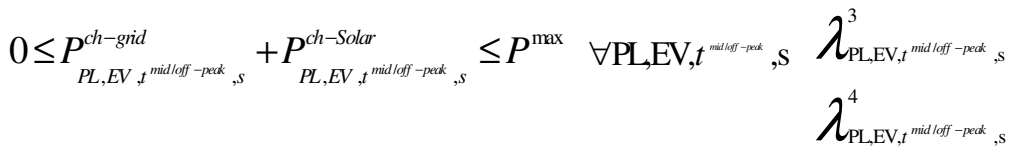

$$
\begin{aligned}
& P_{P L, E V, t^{\text {on-peed }}, s}^{\text {ch-grid }}=0 \quad \forall \mathrm{PL}, \mathrm{EV}, t^{\text {on-peek }} \\
& P_{P L, E V, t^{\text {on-peak }}, s}^{\text {ch-Solar }}=0 \quad \forall \mathrm{PL}, \mathrm{EV}, t^{\text {an-pauk }}, \mathrm{s} \\
& 0 \leq P_{P L, E V, t^{\text {on-peak }}, s}^{d c h} \leq P^{\max } \quad \forall \mathrm{PL}, \mathrm{EV}, t^{\text {on-peat }}, \subseteq \lambda_{\mathrm{PL}, \mathrm{EV}, t^{\text {on-peak }}, \mathrm{s}}^{5} \\
& \lambda_{\mathrm{PL}, \mathrm{EV}, t^{\text {on-peak }}, \mathrm{s}}^{6} \\
& P_{P L, E V, t^{\text {mid loff }- \text { peak }}, s}^{d c h}=0 \quad \forall \mathrm{PL}, \mathrm{EV}, t^{\text {mid hoff }- \text { peec }} \\
& S O E_{\mathrm{PL}, \mathrm{EV}, \mathrm{t}, \mathrm{s}}=S O E_{\mathrm{PL}, \mathrm{EV}, \mathrm{t}-1, \mathrm{~s}}-\left(\frac{P_{P L, E V, t, \mathrm{~s}}^{d c h}}{\eta^{d c h}}\right) \forall \mathrm{PL}, \mathrm{EV}, \mathrm{t} \succ \mathrm{t}^{a v} \quad \lambda_{\mathrm{PL}, \mathrm{EV}, \mathrm{t} \succ \mathrm{t}{ }^{a v}, \mathrm{~s}}^{7} \\
& +\left(P_{P L, E V, t, s}^{c h-g r i d}+P_{P L, E V, t, s}^{c h-S o l a r}\right) \times \eta^{c h} \\
& S O E_{\mathrm{PL}, \mathrm{EV}, \mathrm{t}, \mathrm{s}}=\mathrm{SOE}_{E V}^{\mathrm{arv}}-\left(\frac{P_{P L, E V, t, \mathrm{~s}}^{d c h}}{\eta^{d c h}}\right) \quad \forall \mathrm{PL}, \mathrm{EV}, \mathrm{t}^{a v n}, \mathrm{~s} \quad \lambda_{\mathrm{PL}, \mathrm{EV}, \mathrm{t}^{a v}, \mathrm{~s}}^{8} \\
& +\left(P_{P L, E V, t, s}^{c h-g r i d}+P_{P L, E V, t, s}^{c h-S o l a r}\right) \times \eta^{c h} \\
& S O E_{P L, E V, t, s}=S O E_{E V}^{d e p} \quad \forall \mathrm{PL}, \mathrm{EV}, \mathrm{t}^{d e p}, \mathrm{~S} \quad \lambda_{\mathrm{PL}, \mathrm{EV}, \mathrm{t}{ }^{d e p}, \mathrm{~s}}^{9} \\
& \sum_{E V} P_{P L, E V, t^{\text {mid loff }- \text { peak }}, s}^{\text {ch-Solar }}=P_{P L, t^{\text {mid loff-peak }}, s}^{\text {Solar }} \quad \forall \mathrm{PL}, \mathrm{EV}, t^{\text {mid loff-pece }} \quad \lambda_{\mathrm{PL}, \mathrm{EV}, t^{\text {mid loff-peak }}, \mathrm{s}}^{10}
\end{aligned}
$$




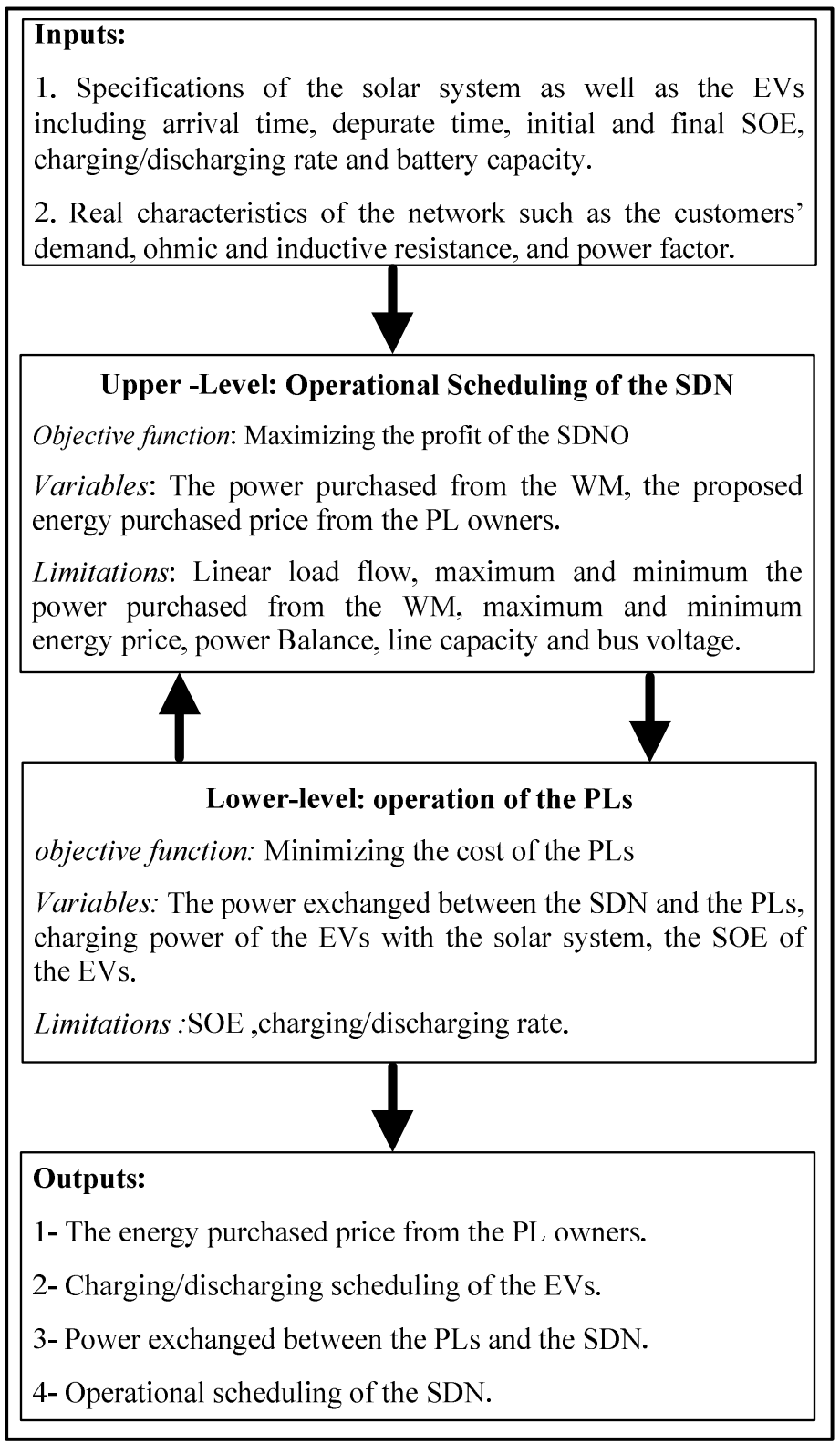

Fig.4.5. The proposed bi-level model framework with charging/discharging schedule.

\subsubsection{A bi-level problem solving method}

The KKT conditions and the dual theory are applied to solve the non-linear bi-level model. The single-level steps and linearization of the bi-level model are as follows [21, 32]:

1. The energy sold price to PL owners in the controlled charging model as well as the energy purchased price from the PL owners in the charging/discharging schedule model; those are as variables in the upper-level, are considered as parameters in the lower-level. Therefore, the lower-level problem that is linear and continuous is replaced by KKT conditions.

2. With the using of the KKT conditions, the problem is still non-linear due to the multiplication of two variables. Therefore, by using the dual theory, the linear expressions of these non-linear parts are calculated and replaced.

The linear single-level model, whose steps are described in Appendix-1. B, are expressed in Eqs. (4.46) to (4.50) for controlled charging. 
Maximize

$$
\begin{aligned}
& \mathrm{OF}_{1}+\sum_{s=1}^{N_{s}} \rho_{s} \times \mathrm{OF}_{2}=\sum_{t=1}^{24}\left(\sum_{b=2}^{N_{b}}\left(P_{b, t}^{L} \times \operatorname{Pr}_{t}^{L}\right)-\sum_{s b=1}^{N_{s b}}\left(P_{s b, t}^{W h 2 G} \times \operatorname{Pr}_{t}^{W h 2 G}\right)\right)
\end{aligned}
$$

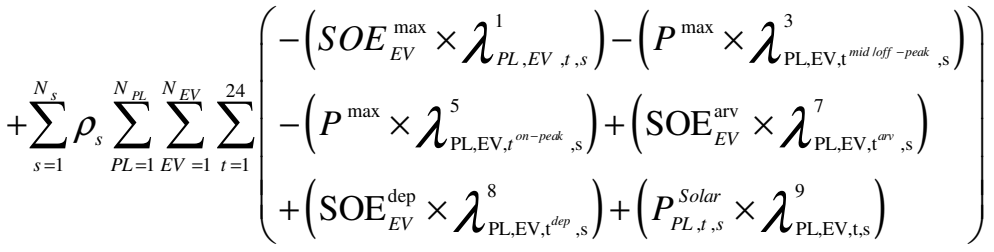

\section{Subject to:}

$$
\begin{aligned}
& \text { (4.13) to (4.18) } \\
& \text { (4.20) to (4.27) } \\
& \text { (I.11) to (I.13) } \\
& \text { (I.20) to (I.24) }
\end{aligned}
$$

Also, the charging/discharging schedule model is explained in Eqs. (4.51) to (4.55).

$$
\begin{aligned}
& \text { Maximize } \mathrm{OF}_{3}+\sum_{s=1}^{N_{s}} \rho_{s} \times \mathrm{OF}_{4} \\
& =\sum_{t=1}^{24}\left(\sum_{b=2}^{N_{b}}\left(P_{b, t}^{L} \times \operatorname{Pr}_{t}^{L}\right)-\sum_{s b=1}^{N_{s b}}\left(P_{s b, t}^{W h 2 G} \times \operatorname{Pr}_{t}^{W h 2 G}\right)\right) \\
& +\sum_{P L=1}^{N_{P L}} \sum_{E V=1}^{N_{E V}} \sum_{t=1}^{24}\left(\hat{P}_{P L, E V, t^{\text {mid loff }- \text { peak }}}^{c h-\text { grid }} \times \operatorname{Pr}_{t^{\text {mid } l \text { off }- \text { peak }}}^{G 2 P L}\right) \\
& -\sum_{P L=1}^{N_{P L}} \sum_{t=1}^{24}\left(\hat{P}_{P L, t^{t o-p e a k}}^{\text {Solar }} \times \operatorname{Pr}_{t^{\text {on-peak }}}^{P L 2 G}\right)
\end{aligned}
$$

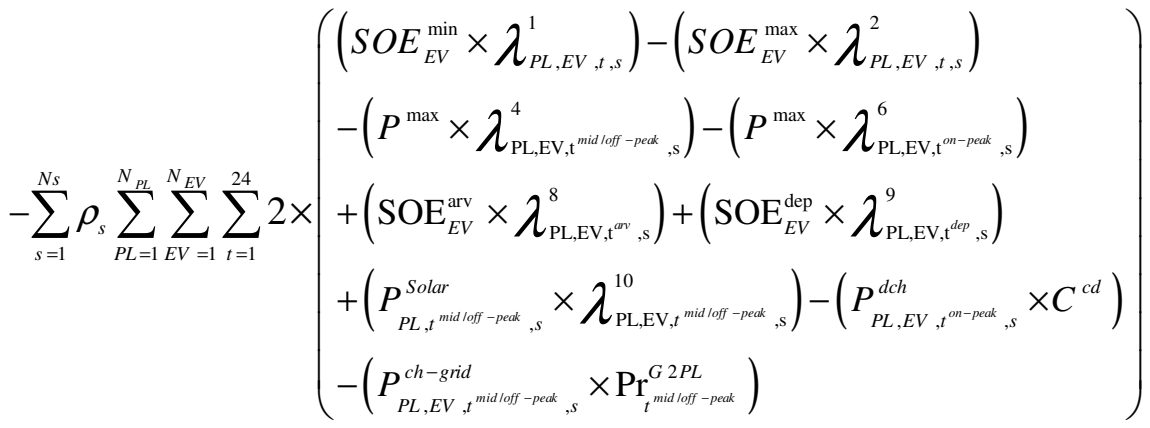

\section{Subject to:}

$$
\begin{aligned}
& \text { (4.29) to (4.34) } \\
& \text { (4.36) to (4.45) } \\
& \text { (II.12) to (II.15) } \\
& \text { (II.22) to (II.27) }
\end{aligned}
$$




\subsubsection{Single-level model}

In the single-level model, the SDNO also owns the PLs and the solar system; therefore, it must satisfy the owner of each EV in accordance with the limitations of the EVs. In fact, the constraints of the EVs that are described in the previous sections should be considered as the constraints of the SDNO.

\subsubsection{Single-level model with controlled charging}

In this case, the SDNO provides the total customers' demand and a part of the charging power of the EVs, from the WM. Also, the other part of the power needed for EVs' charging is provided through the power generated of the solar system. The single-level model is defined in Eqs. (4.56) to (4.59). The objective function of the model is similar to the bi-level model, except for the last part, where the income from the selling energy to the EVs with the power generated of the solar system. Moreover, the energy sold price to the EVs, in this case, is equal to the energy sold price to the customer. The proposed framework of this model shows in Fig. 4.6.

$$
\begin{aligned}
& \text { Maximize } \mathrm{OF}_{1}+\sum_{s=1}^{N_{s}} \rho_{s} \times \mathrm{OF}_{5} \\
& \sum_{t=1}^{24}\left(\sum_{b=2}^{N_{b}}\left(P_{b, t}^{L} \times \operatorname{Pr}_{t}^{L}\right)-\sum_{s b=1}^{N_{s b}}\left(P_{s b, t}^{W h 2 G} \times \operatorname{Pr}_{t}^{W h 2 G}\right)\right) \\
& +\sum_{s=1}^{N_{s}} \rho_{s} \sum_{P L=1}^{N_{P L}} \sum_{E V=1}^{N_{E V}} \sum_{t=1}^{24}\left(\begin{array}{l}
\left(\begin{array}{l}
P_{P L, E V, t^{\text {mid loff }- \text { peak }}, s}^{\text {ch-grid }} \times \operatorname{Pr}_{t}^{L}
\end{array}\right) \\
+\left(P_{P L, E V, t, s}^{\text {ch-Solar }} \times \operatorname{Pr}_{t}^{L}\right.
\end{array}\right)
\end{aligned}
$$

Subject to:

(4.13) and (4.15) to (4.18)

$$
P_{s b, t}^{W h 2 G} \times \eta^{\text {Trans }}+P_{P L, t, s}^{\text {solar }}=P_{b, t}^{L}+P_{t, s}^{\text {Loss }}+\sum_{E V} P_{P L, E V t^{\text {mid loff - peak }, s}}^{\text {ch-gird }}+\sum_{E V} P_{P L, E V, t, s}^{\text {ch-solar }}
$$

(4.20) to (4.27)

\subsubsection{Single-level model with charging/discharging schedule}

In this case, the SDNO provides a part of the customers' demand and a part of the charging power of the EVs from the WM. Furthermore, a part of the customers' demand during the on-peak hours is provided by the power purchased from the EV owners, and the power generated by the solar system. A part of the charging power is being provided during the off-peak/mid-peak hours by the power generated of the solar system. The energy sold price to the EVs is equale to the energy sold price to the customer. It is also assumed that the energy purchased price from the EVs is equal to the minimum electricity price of the WM at the on-peak hours, i.e. $140 \$ / \mathrm{MWh}$. The objective functions of this model are similar to the bi-level model, with two differences in the single-level model. The SDNO must pay the cost of depreciation of the battery to the EVs owners. Also, the SDNO gains the income from the selling energy to the EVs by the power generated of the solar system, so the single-level model is defined by the Eqs. (4.60) to (4.63). Fig. 4.7 shows the proposed framework of the single-level model. 


$$
\begin{aligned}
& \text { Maximize } \mathrm{OF}_{1}+\sum_{s=1}^{N_{s}} \rho_{s} \times \mathrm{OF}_{6} \\
& \sum_{t=1}^{24}\left(\sum_{b=2}^{N_{b}}\left(P_{b, t}^{L} \times \operatorname{Pr}_{t}^{L}\right)-\sum_{s b=1}^{N_{s b}}\left(P_{s b, t}^{W h 2 G} \times \operatorname{Pr}_{t}^{W h 2 G}\right)\right)
\end{aligned}
$$

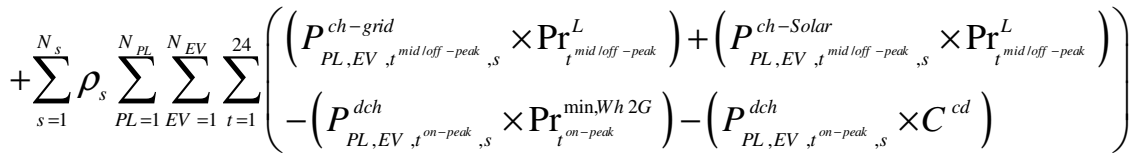

\section{Subject to:}

(4.29), (4.31) to (4.34)

$$
\begin{aligned}
& P_{s b, t}^{W h 2 G} \times \eta^{\text {Trans }}+\sum_{E V} P_{P L, E V, t^{\text {on-peak }}, s}^{d c h}+P_{P L, t, s}^{\text {Solar }}= \\
& P_{b, t}^{L}+P_{t, s}^{\text {Loss }}+\sum_{E V} P_{P L, E V, t^{\text {mid loff -peak }}, s}^{c h \text {-grid }}+\sum_{E V} P_{P L, E V, t^{\text {mid loff }- \text { peak }}, s}^{\text {ch-Solar }}
\end{aligned}
$$

\section{Inputs:}

1. Specifications of the solar system as well as the EVs including arrival time, depurate time, initial and final SOE, charging rate and battery capacity.

2. Real characteristics of the network such as the customers' demand, ohmic and inductive resistance, and power factor.

\section{Objective function: Maximizing the profit of the SDNO}

Variables: The power purchased from the WM, the power sold to the EVs.

Limitations: Linear load flow, maximum and minimum the power purchased from the WM, power Balance, line capacity, bus voltage, SOE, charging rate.

\section{Outputs:}

1- Charging scheduling of the EVs.

2- The power sold to the EVs.

3- Operational scheduling of the SDN.

Fig.4.6. The proposed single-level model framework with controlled charging. 


\begin{tabular}{l} 
Inputs: \\
1. Specifications of the solar system as well as the EVs \\
including arrival time, depurate time, initial and final SOE, \\
charging rate and battery capacity. \\
2. Real characteristics of the network such as the customers' \\
demand, ohmic and inductive resistance, and power factor. \\
Objective function: Maximizing the profit of the SDNO \\
Variables: The power purchased from the WM, the power \\
exchanged between the SDN and the EVs. \\
Limitations: Linear load flow, maximum and minimum the \\
power purchased from the WM, power Balance, line capacity, \\
bus voltage, SOE, charging/discharging rate. \\
3- Operational scheduling of the SDN. \\
2- The power purchased/sold from/to the EVs. \\
1- Charging/discharging scheduling of the EVs. \\
\hline
\end{tabular}

Fig.4.7. The proposed single-level model framework with charging/discharging schedule.

\subsubsection{Risk management}

Due to uncertainties of the EVs and the solar system in the proposed model, the SDNO is faced to risk that a determined value is admissible. For controlling the risk level, three strategies, i.e. risk-seeker, risk-neutral, and risk-averse are offered [33].

1. By ignoring uncertainties, the SDNO has faced no risk. The model in this situation is solved with one scenario, i.e. $s=1$.

2. By taking the several scenarios into account for uncertainties, i.e. Risk-neutral model, the optimal response is achieved by the expected value of scenarios.

3. If with considering scenarios, a term for controlling the risk of profit is added, the risk-averse model will be obtained. In this model, a non-suitable condition, e.g., a high probability of low profit is eliminated. Value-at-Risk (VaR) and Conditional Value-at-Risk (CVaR), are the most important of risk measures. In this chapter, $\mathrm{CVaR}$ is considered for risk measures because of the linear formulation. The $\mathrm{CVaR}$ at $\alpha$ confidence level is equal to the expected profit of the (1- $\alpha) 100 \%$ scenarios with the worst value of profit. The confidence level of $\mathrm{CVaR}$ is set close to 1 , so in this chapter is 0.95 . The CVaR is explained by Eqs. (4.64) to (4.66) [30]:

$$
\begin{aligned}
& B_{s}=\zeta-\frac{1}{1-\alpha} \sum_{s=1}^{N_{s}} \rho_{s} \eta_{s} \\
& -B_{s}+\zeta-\eta_{s} \leq 0 \\
& \eta_{s} \geq 0
\end{aligned}
$$

The risk-based models with CVaR index are introduced as follows. 


\subsubsection{Risk-based bi-level model}

The risk-based bi-level model with CVaR index, for controlled charging model is defined in Eqs. (4.67) to (4.70).

Maximize

$$
(1-\beta) \times\left(\mathrm{OF}_{1}+\sum_{s=1}^{N_{S}} \rho_{s} \times \mathrm{OF}_{2}\right)+\beta \times\left(\zeta-\frac{1}{1-\alpha} \sum_{s=1}^{N_{s}} \rho_{s} \eta_{s}\right)
$$

\section{Subject to:}

$$
\begin{aligned}
& \eta_{\mathrm{s}} \geq 0 \\
& \zeta-\eta_{\mathrm{s}}-\left(\mathrm{OF}_{1}+\mathrm{OF}_{2}\right) \leq 0
\end{aligned}
$$

Also, Eqs. (4.71) to (4.74) explain the risk-based bi-level model in charging/discharging schedule.

$$
\begin{aligned}
& \text { Maximize } \\
& \mathrm{OF}_{3}+\sum_{s=1}^{N_{s}} \rho_{s} \times \mathrm{OF}_{4}+\beta \times\left(\zeta-\frac{1}{1-\alpha} \sum_{s=1}^{N_{s}} \rho_{s} \eta_{s}\right)
\end{aligned}
$$

\section{Subject to:}

$$
\begin{aligned}
& \eta_{\mathrm{s}} \geq 0 \\
& \zeta-\eta_{\mathrm{s}}-\left(\mathrm{OF}_{3}+\mathrm{OF}_{4}\right) \leq 0
\end{aligned}
$$

\subsubsection{Risk-based single-level model}

The risk-based single-level model with CVaR index, for controlled charging model is described in Eqs. (4.75) to (4.78).

$$
\begin{aligned}
& \operatorname{Maximize} \\
& (1-\beta) \times\left(\mathrm{OF}_{1}+\sum_{s=1}^{N_{s}} \rho_{s} \times \mathrm{OF}_{5}\right)+\beta \times\left(\zeta-\frac{1}{1-\alpha} \sum_{s=1}^{N_{s}} \rho_{s} \eta_{s}\right)
\end{aligned}
$$

Subject to:

$$
\begin{aligned}
& \eta_{\mathrm{s}} \geq 0 \\
& \zeta-\eta_{\mathrm{s}}-\left(\mathrm{OF}_{1}+\mathrm{OF}_{5}\right) \leq 0
\end{aligned}
$$

Also, Eqs. (4.79) to (4.82) explain the risk-based bi-level model in charging/discharging schedule. 
Maximize

$(1-\beta) \times\left(\mathrm{OF}_{1}+\sum_{s=1}^{N_{s}} \rho_{s} \times \mathrm{OF}_{6}\right)+\beta \times\left(\zeta-\frac{1}{1-\alpha} \sum_{s=1}^{N_{s}} \rho_{s} \eta_{s}\right)$

Subject to:

(4.61) to $(4.63)$

$\eta_{\mathrm{s}} \geq 0$

$$
\zeta-\eta_{\mathrm{s}}-\left(\mathrm{OF}_{1}+\mathrm{OF}_{6}\right) \leq 0
$$

\subsubsection{The Problem Solving Process}

For solving the models, a flowchart based on stochastic programming is suggested, and is shown in Fig 4.8. Forasmuch as the models are mixed-integer linear programming (MILP) problems, the simulation is performed through CPLEX solver of GAMS. By using the Kantorovich distance approach, the scenarios for modeling of uncertainty are decreased to 8. The simulation is carried out in a laptop with Corei7 up to $3.5 \mathrm{GHz} \mathrm{CPU}, 12 \mathrm{~GB}$ RAM (DDR4), and 4 MB Cash.

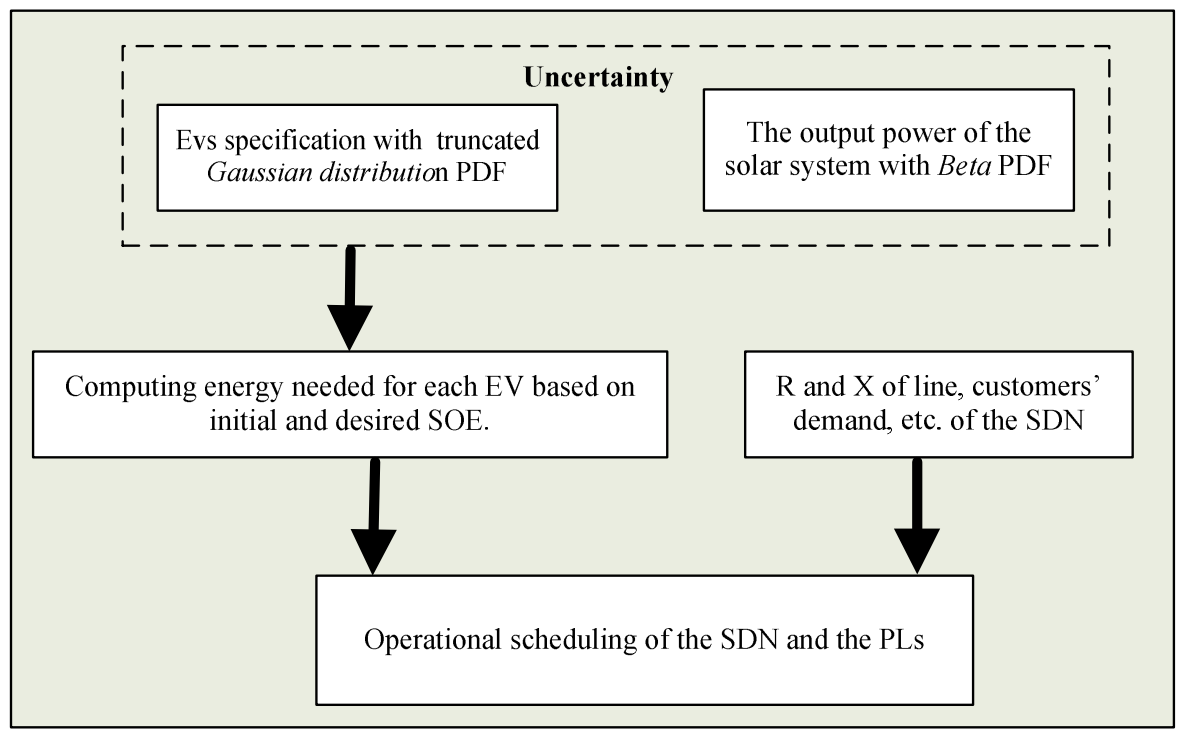

Fig. 4.8. The stochastic programming framework for optimal operation of the SDN

\subsection{Simulation results}

In the following, based on the proposed models, the simulations are carried out on an IEEE 33-bus distribution system. At first, the maximum profit of the SDNO is calculated without the EV. In this program, the price of the energy sold to the customer is also obtained. Additionally, the customers' demand and the power purchased from the WM are investigated. Then, considering the EVs and controlled charging and charging/discharging schedule with and without the solar system, in the single-level model and the bi-level model, different parts of the objective functions such as charging/discharging power of the EVs are evaluated over a 24-hours. The price of the energy sold to the PL owner (controlled charging mode), and the price of the energy purchased from the PL owner (charging/discharging schedule) are calculated by solving the bi-level problem. The risk level is more accurately investigated. Finally, the sensitivity analysis is performed by changing some parameters such as the number of the EVs, the EVs' battery capacity, the rated power of the solar system and the PL sitting. 


\subsubsection{Input data}

For proving the effectiveness of the models, the presented models are tested on an IEEE 33-bus distribution system, i.e. Fig. 4.9 that the specification is obtained from [34]. The power factor of the customers' demand is 0.95 lagging. Also, there is a PL with a capacity of up to $500 \mathrm{EVs}$ is installed on bus 20. The PL has a solar system that the requirements' data are given in Table 4.1 [35]. Fig. 4.10 is shown the solar irradiation [36]. The data for modeling the EVs' uncertainty is presented in Table 4.2 [21]. Accordingly, the number of the EVs entering the PL as well as the number of the EVs departing from the PL are shown in Tables 4.3 and 4.4. It should be noted that between 10:00 and 18:00, the number of the EVs in the PL is fixed i.e. 500 EVs. In addition, Fig. 4.11 is illustrated the initial SOE of the EVs in scenario 1. The desired SOE at the departure time is considered $90 \%$ of battery capacity [21]. The minimum and maximum values of SOE are set to $15 \%$ and $90 \%$ battery capacity, respectively. The charging/discharging efficiency, EVs' battery capacity, and the maximum charging/discharging rate are $90 \%, 95 \%, 50 \mathrm{kWh}$ and $10 \mathrm{kWh}$, respectively. The price of the battery depreciation of the EVs is 30 \$/MWh [21]. Moreover, Fig. 4.12 shows the electricity price of WM. Hours (1:00-8:00), (23:00-24:00) and (9:00-12:00), (19:00-22:00) and (13:00-18:00) are the off-peak, mid-peak and on-peak hours, respectively [34]. The price of energy sold to customers' demand is 80,120 and 240 at the off-peak, mid-peak and on-peak hours, respectively.

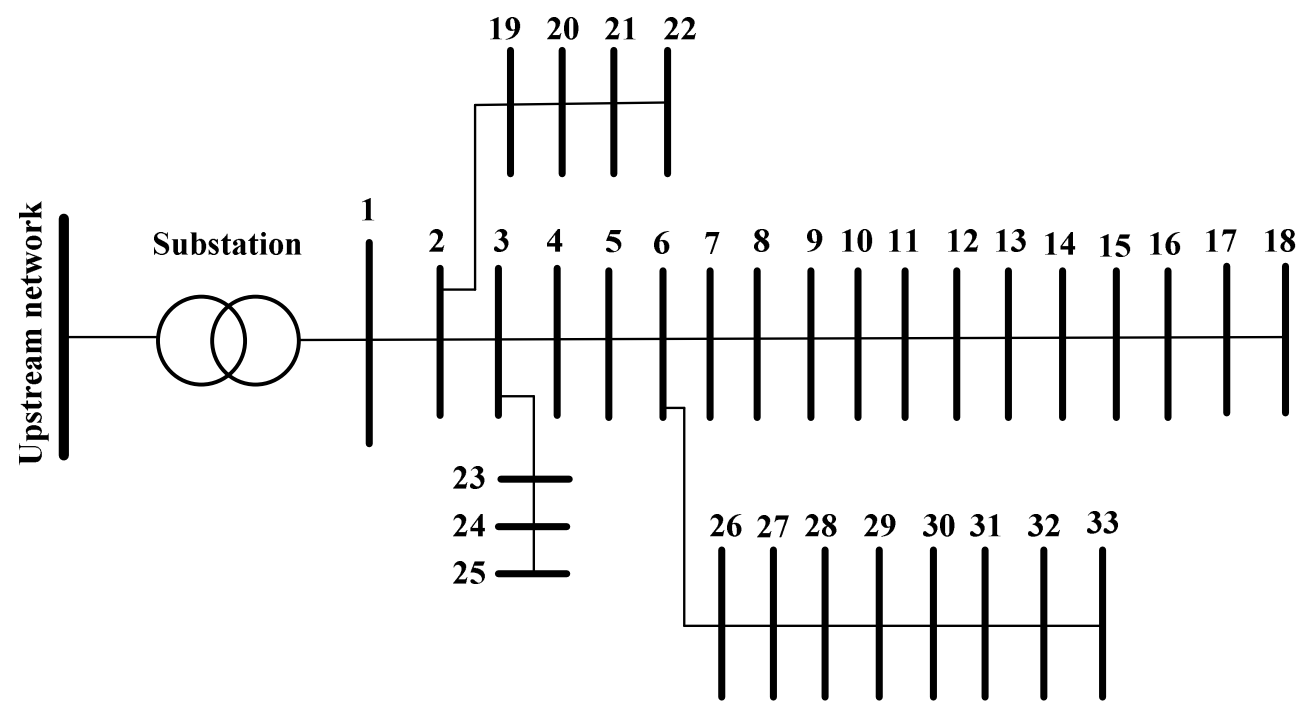

Fig. 4.9. The IEEE 33-bus distribution system

Table 4.1. The parameters of the solar system

\begin{tabular}{l|c|l|c}
\hline Parameters & Value & Parameters & Value \\
\hline Open circuit voltage (V) & 21 & Voltage temperature coefficient (V/c) & 0.088 \\
\hline Short circuit current (A) & 3.4 & Current temperature coefficient (A/c) & 0.0015 \\
\hline Voltage at maximum power (v) & 17.4 & Normal operating temperature $(\mathrm{c})$ & 34 \\
\hline Current at maximum power $(\mathrm{v})$ & 3.05 & Ambient temperature $(\mathrm{c})$ & 25 \\
\hline Cell number & 2000 & Rated power $(\mathrm{kW})$ & 400 \\
\hline
\end{tabular}




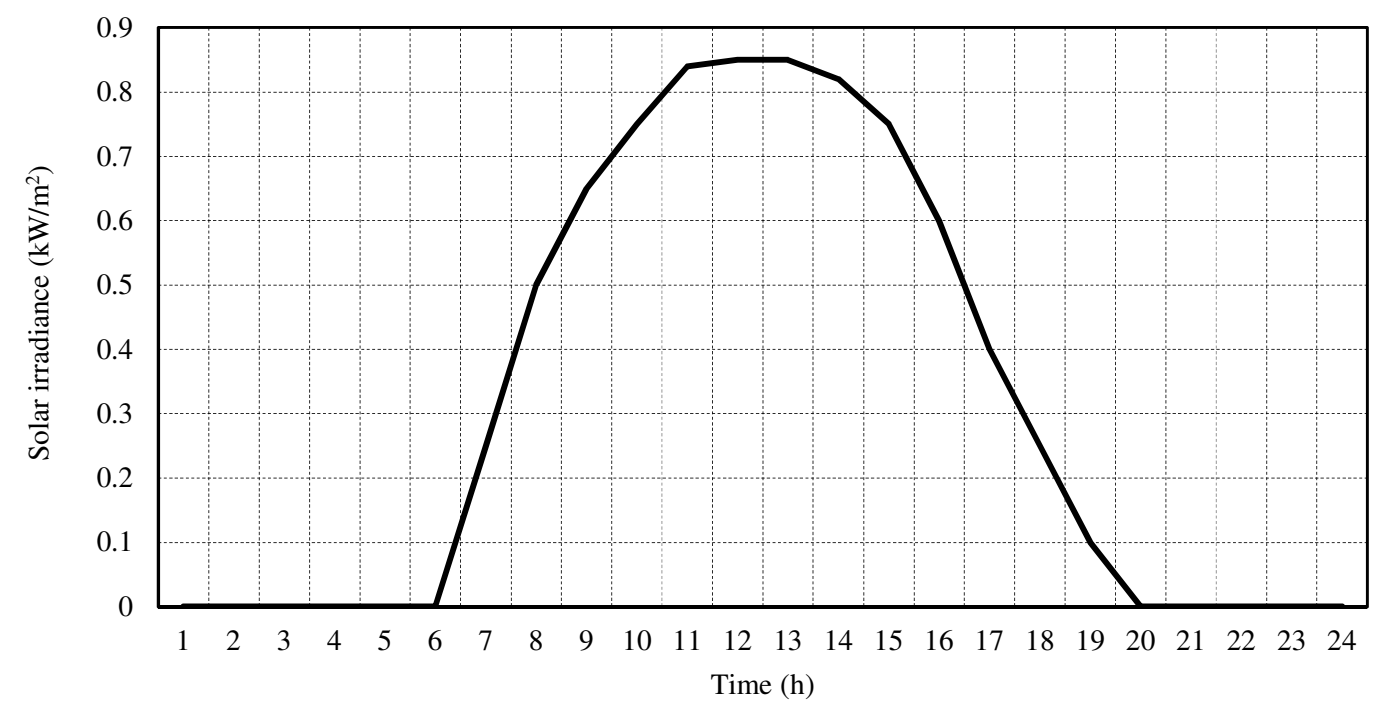

Fig. 4.10. The solar irradiance $\left(\mathrm{kW} / \mathrm{m}^{2}\right)$

Table 4.2. The required data for modeling of initial SOE, arrival/departure time of EVs

\begin{tabular}{c|c|c|c|c}
\hline & Mean & Standard Deviation & Minimum & Maximum \\
\hline Initial SOE (\%) & 50 & 25 & 30 & 60 \\
\hline Arrival Hours (h) & 8 & 3 & 7 & 10 \\
\hline Departure Hours (h) & 20 & 3 & 19 & 24 \\
\hline
\end{tabular}

Table 4.3. The number of entered the EVs to PL from 7:00 to 11:00

\begin{tabular}{c|c|c|c|c|c|c|c|c}
\hline Time $(\mathrm{h})$ & S1 & S2 & S3 & S4 & S5 & S6 & S7 & S8 \\
\hline 7 & 262 & 234 & 262 & 258 & 268 & 244 & 237 & 251 \\
\hline 8 & 57 & 65 & 54 & 68 & 58 & 76 & 70 & 80 \\
\hline 9 & 66 & 71 & 52 & 51 & 61 & 54 & 67 & 53 \\
\hline 10 & 115 & 130 & 132 & 123 & 113 & 126 & 126 & 116 \\
\hline
\end{tabular}

Table 4.4. The number of departed the EVs from PL from 19:00 to 24:00

\begin{tabular}{c|c|c|c|c|c|c|c|c}
\hline Time $(\mathrm{h})$ & S1 & S2 & S3 & S4 & S5 & S6 & S7 & S8 \\
\hline 19 & 235 & 233 & 268 & 245 & 243 & 255 & 259 & 233 \\
\hline 20 & 67 & 66 & 80 & 62 & 66 & 71 & 60 & 72 \\
\hline 21 & 73 & 63 & 50 & 54 & 68 & 49 & 56 & 59 \\
\hline 22 & 49 & 54 & 31 & 52 & 45 & 42 & 50 & 59 \\
\hline 23 & 33 & 34 & 30 & 27 & 34 & 38 & 35 & 30 \\
\hline 24 & 43 & 50 & 41 & 60 & 44 & 45 & 40 & 47 \\
\hline
\end{tabular}




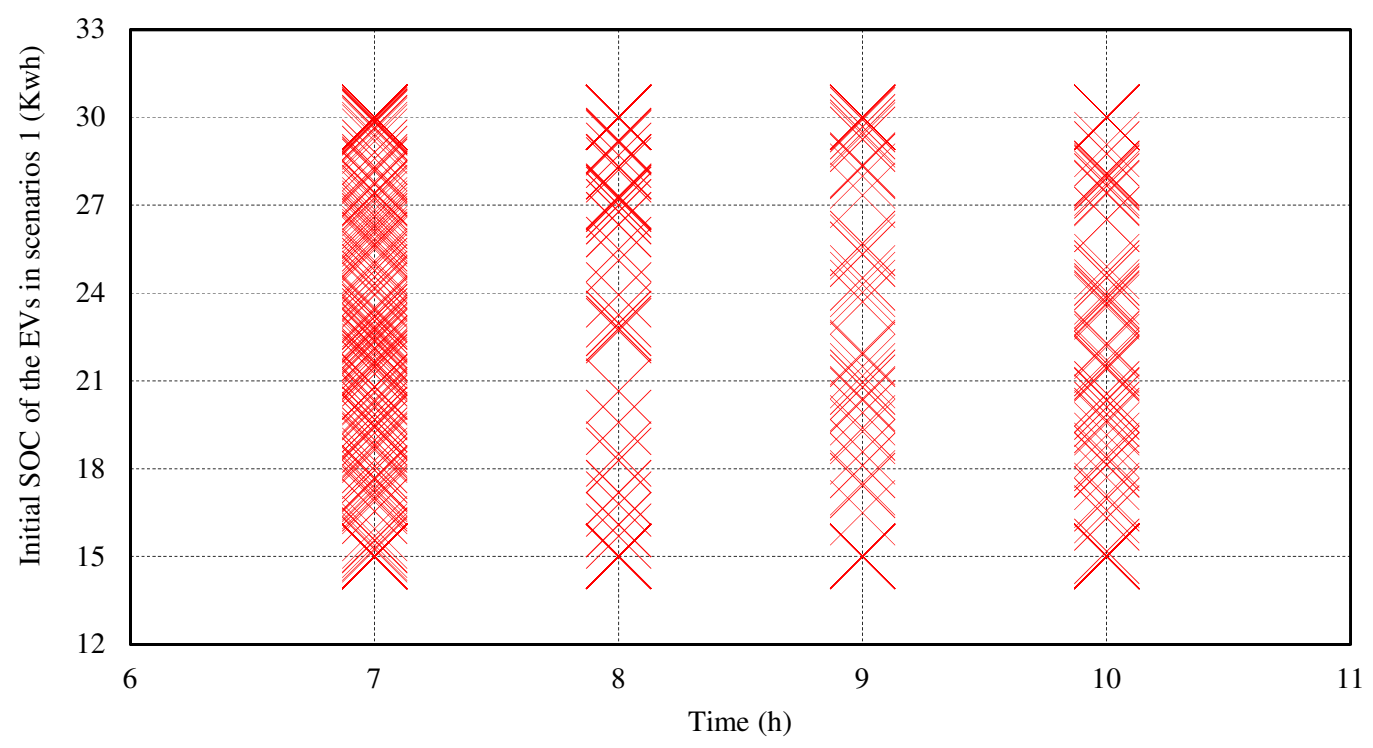

Fig. 4.11. The SOE of 500 EVs in scenario 1.

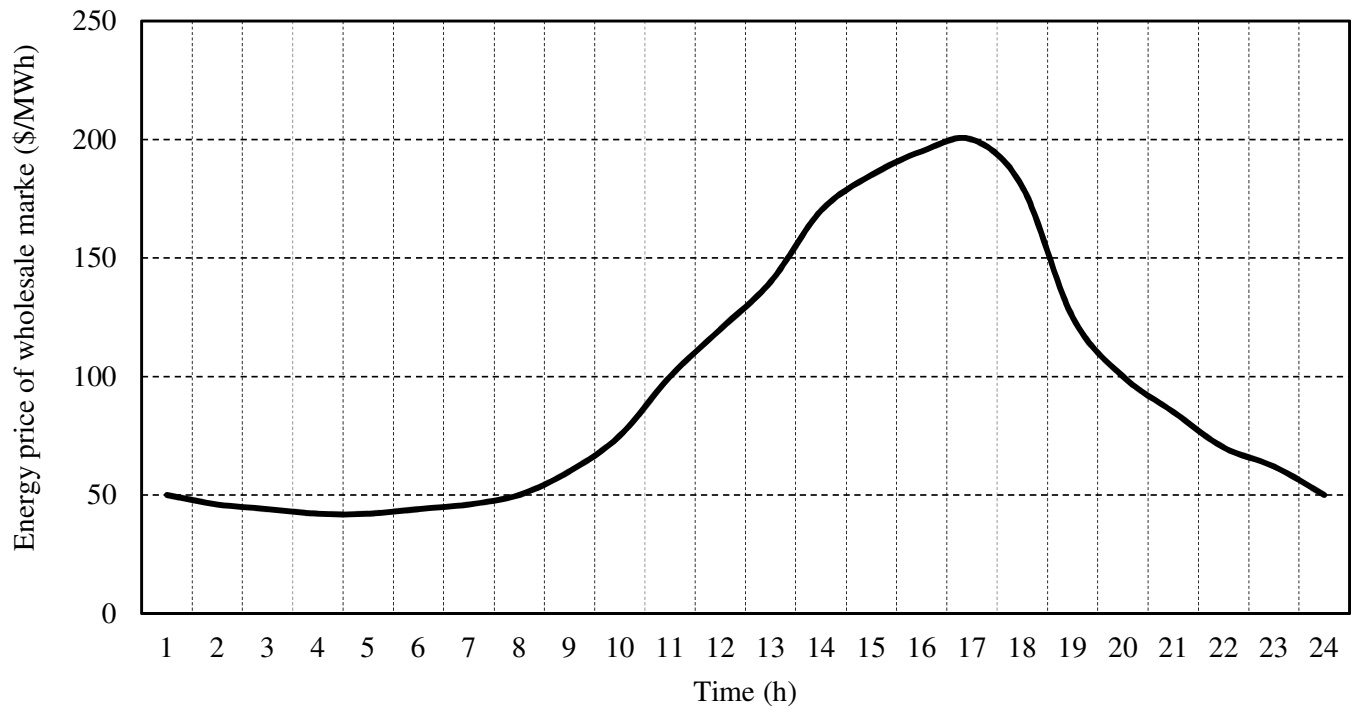

Fig. 4.12. The energy price of the WM.

\subsubsection{The system without the EVs and the Solar system}

Initially, the model is solved for a situation in which the EVs do not exist, in order to determine the maximum profit of the SDNO along with the optimal price of the energy sold to the customer. In addition in this section, the customers' demand and the power purchased from the WM are calculated.

1. The maximum profit of the SDNO

Table 4.5 shows the maximum profit of SDNO in the absence of the EVs. The solution time of each program is also given in Table 4.5 .

\section{Customers' demand}

Fig. 4.13 shows customers' demand. Table 4.6 shows the customers' demand at different time intervals. It is noted that the benefit of the SDNO from the energy sold to the customer is $24256.64 \$$. 


\section{Power purchased from the WM}

The power purchased from the WM, i.e. the sum of the customers' demand and network losses and also its cost are shown in Table 4.7. Moreover, the SDN loss is 7.415 MWh.

Table 4.5. The maximum profit of the SDNO

\begin{tabular}{c|c}
\hline Profit of the SDNO $(\$)$ & solution time (s) \\
\hline 5929.33 & 0.39 \\
\hline
\end{tabular}

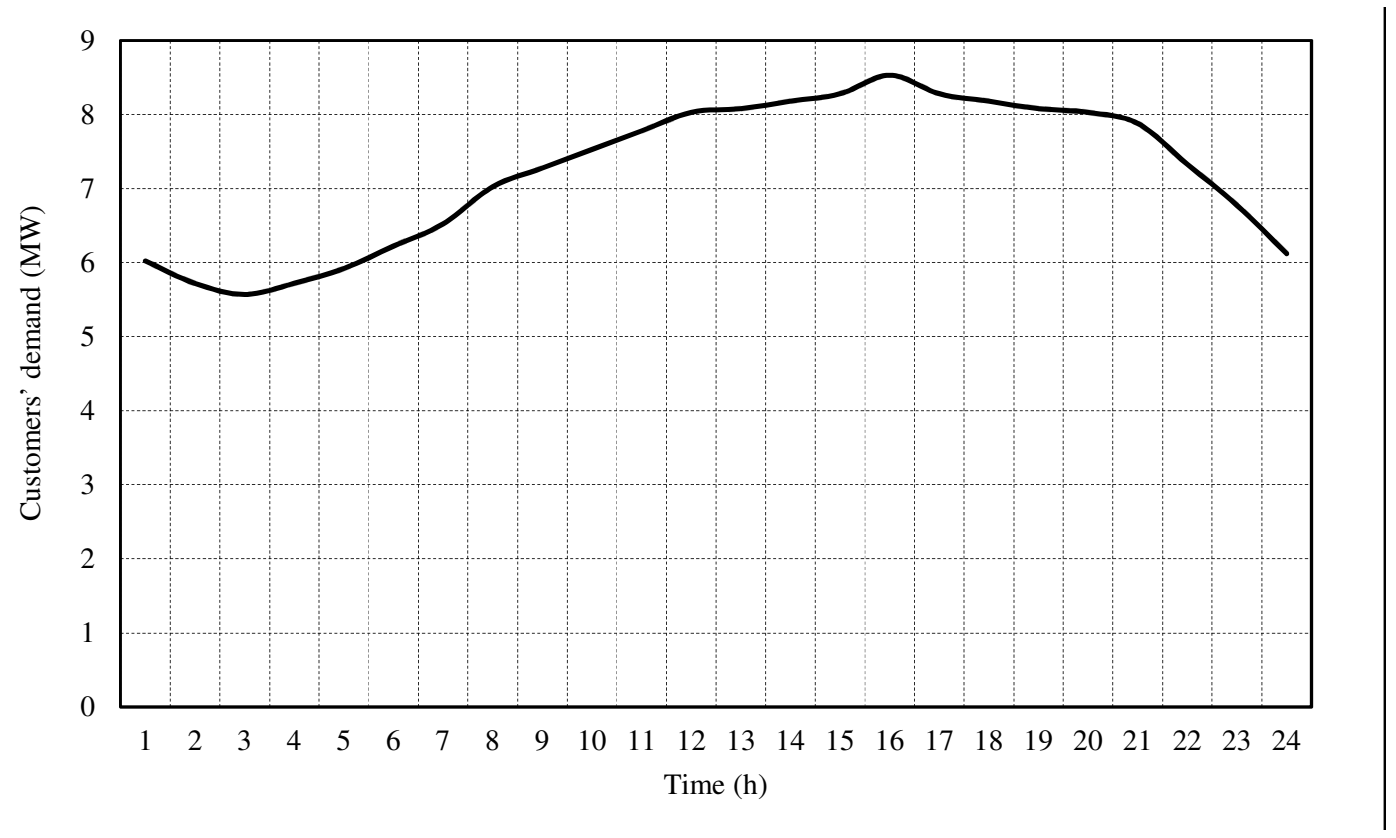

Fig. 4.13. The customers' demand in two models.

Table 4.6. The customers' demand at the interval time (MWh)

\begin{tabular}{c|c|c|c}
\hline Total Demand & off-peak hours & mid-peak hours & on-peak hours \\
\hline 173.139 & 61.646 & 61.946 & 49.547 \\
\hline
\end{tabular}

Table 4.7. The energy purchased from the wholesale and its cost without the EVs

\begin{tabular}{c|c}
\hline The energy purchased $(\mathrm{MWh})$ & The cost of the energy purchased $(\$)$ \\
\hline 180.554 & 18327.31 \\
\hline
\end{tabular}

\subsubsection{The system with the EVs (controlled charging) with/without the solar system}

In this section, the model is solved for a situation that the EVs are only charged i.e. controlled charging mode. The model is investigated in two parts: single-level and bi-level. Also, in each part, the effect of the solar system is evaluated. In the single-level model forasmuch as the SDNO is the owner of the PL and the solar system, the price of the energy sold to the EV owners is equal to the price of the energy sold to the customers. However, in the bi-level model, the price of the energy sold to the PL owner is calculated by solving the model. The charging power of the EVs and the power purchased from the WM are also examined in both models. It should be noted that the customers' demand, in this case, is the same as Fig. 4.13. 


\section{The maximum profit of SDNO}

Table 4.8 shows the maximum profit of the SDNO in the single-level and bi-level models with/without the solar system. The single-level model has more profit than the bi-level model. According to Tables 4.9 and 4.10, the main reason can be considered by the price of the energy sold to the EV owners and the PL owner. In the single-level model, this price is equal to the price of the energy sold to the customer; however, in the bi-level model, this price, due to the interaction between the two decision-makers, i.e. the SDNO and the PL owner, is lower than the price of the energy sold to the customer. The second reason is the revenue by the energy sold to the EV owners by the power generated of the solar system (in the single-level model, SDNO owns the solar system). The solution times are also presented in Table 4.8. With the presence of the EVs and the solar system, the solution time raise. Of course, in the bi-level model, due to the complexity of the problem, this time will be greatly increased.

Table 4.8. The maximum profit of the SDNO and solution time in all programs

\begin{tabular}{|c|c|c|}
\hline Program & Profit of the SDNO (\$) & Solution time (s) \\
\hline 1. Single-level model without the solar system & 6430.646 & 22.859 \\
\hline 2. Single-level model with the solar system & 6600.369 & 44.766 \\
\hline 3. bi-level model without the solar system & 6164.578 & 72.359 \\
\hline 4. bi-level model with the solar system & 6225.330 & 288.266 \\
\hline
\end{tabular}

Table 4.9. The selling energy price to the EV owners in the single-level model (\$/MWh)

\begin{tabular}{c|c}
\hline Hour & Energy Price \\
\hline $7: 00-8: 00$ & 80 \\
\hline $9: 00-12: 00$ and $19: 00-22: 00$ & 120 \\
\hline $23: 00-24: 00$ & 80 \\
\hline
\end{tabular}

Table 4.10. The selling energy price to the PL owner in the bi-level model ( $\$ / \mathrm{MWh})$

\begin{tabular}{c|c|c}
\hline \multirow{2}{*}{ Hour } & \multicolumn{2}{|c}{ Energy Price } \\
\cline { 2 - 3 } & With solar & Without solar \\
\hline $7: 00-8: 00$ & 71.6 & 72.2 \\
\hline 9:00-12:00 and 19:00-22:00 & 114 & 118 \\
\hline $23: 00-24: 00$ & 71.6 & 72.2 \\
\hline
\end{tabular}

\section{Charging power of the EVs}

Due to the controlled charging of the EVs, at the off-peak and mid-peak hours, the EVs are charged. The maximum charging rate of the EVs is $10 \mathrm{~kW}$.h. Forasmuch as at some hours, there are $500 \mathrm{EVs}$ in the PL, the maximum power that can be imposed on the system for charging of the EVs can be up to $5 \mathrm{MWh}$. In this regard, the charging power of the EVs by the SDNO and the solar system as well as the benefit of its, in both models in different programs are presented in Table 4.11 and 4.12. According to these Tables, the EVs' charging power in each program is equal because of the condition of each EV, such as arrival time, departure time and the initial and desired SOE is the same. The price of the energy sold to the EVs, the price of the energy purchased from the WM, as well as the number of the EVs in the PL, are the main factors in the charging power of the EVs.

Table 4.11. The power charged of the EVs in both models (MW)

\begin{tabular}{c|c|c|c}
\hline Program & $\begin{array}{c}\text { Total charging power } \\
\text { of the EVs }\end{array}$ & $\begin{array}{c}\text { Charging power of the EVs } \\
\text { by the SDNO }\end{array}$ & $\begin{array}{c}\text { Charging power of the EVs } \\
\text { by the solar system }\end{array}$ \\
\hline 1 & 11.903 & 11.903 & - \\
\hline 2 & 11.903 & 8.960 & 2.943 \\
\hline 3 & 11.903 & 11.903 & - \\
\hline 4 & 11.903 & 8.960 & 2.943 \\
\hline
\end{tabular}


Table 4.12. The revenue of the energy sold to the EV owners or the PL owner (\$)

\begin{tabular}{c|c}
\hline Program & EV owners or PL owner \\
\hline 1 & 1383.34 \\
\hline 2 & 1059.51 \\
\hline 3 & 1123.16 \\
\hline 4 & 937.547 \\
\hline
\end{tabular}

Also, Figs. 4.14 and 4.15 illustrate the total charging power of the EVs through the SDNO. Based on Fig. 4.14 in the single-level model, at the 7:00 and 8:00, the difference between the price of the energy purchased from the WM and the energy sold to EVs owner is low; therefore, at these times, the SDNO purchases less energy for charging of the EVs. However, at 9:00, 10:00, and 22:00, because of the higher difference between the two prices, the SDNO purchases high energy. Furthermore, in the bi-level model according to Fig. 4.15, the PL owner's decision is also effective, so SDNO purchases more energy for charging of the EVs at the 7:00 and 8:00 that the price of energy is low. In this situation, the SDNO gains more profit by the cheaper electricity price of the WM. Therefore, the purchasing behavior of the SDNO from the WM for charging of the EVs in this model is slightly different from the single-level model.

It is noted that the EVs will not be charged by the SDNO from 13:00 to 18:00 due to the on-peak hours. Additionally, at the 12:00 and 19:00, due to the difference between these two prices (purchasing from the WM and selling to the EV owners or the PL owner) is zero or negative and because of charging of the EVs by the solar system during the on-peak hours, no energy for charging of the EVs is purchased. Of course, in the system without the solar system, due to many EVs leave the PL at 19:00, and in accordance with the constraints, especially the EV owner's satisfaction (desired SOE), the energy is also purchased at 12:00 and 19:00. The power for charging of the EVs that is provided by the solar system is shown in Fig. 4.16.

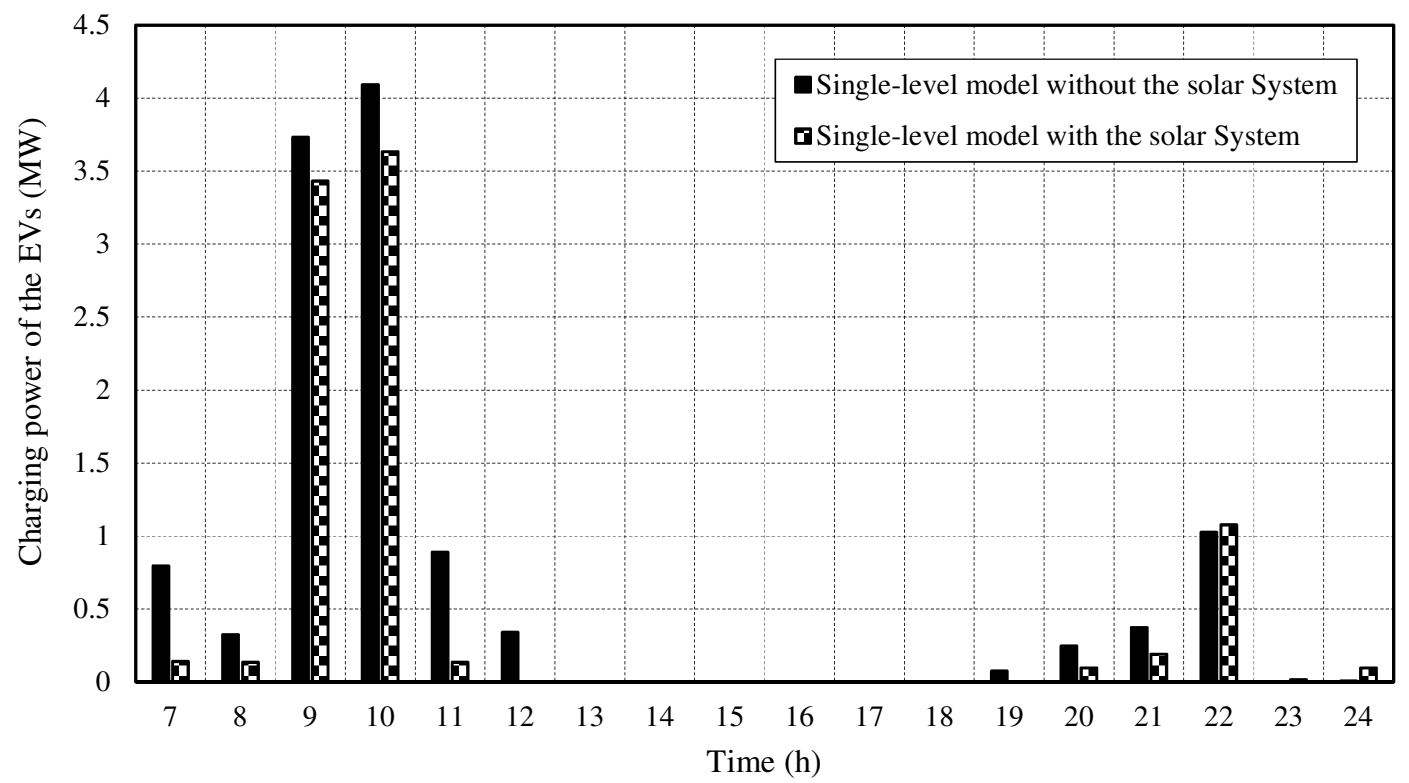

Fig. 4.14. The charging power of all EVs by the SDNO in the single-level model 


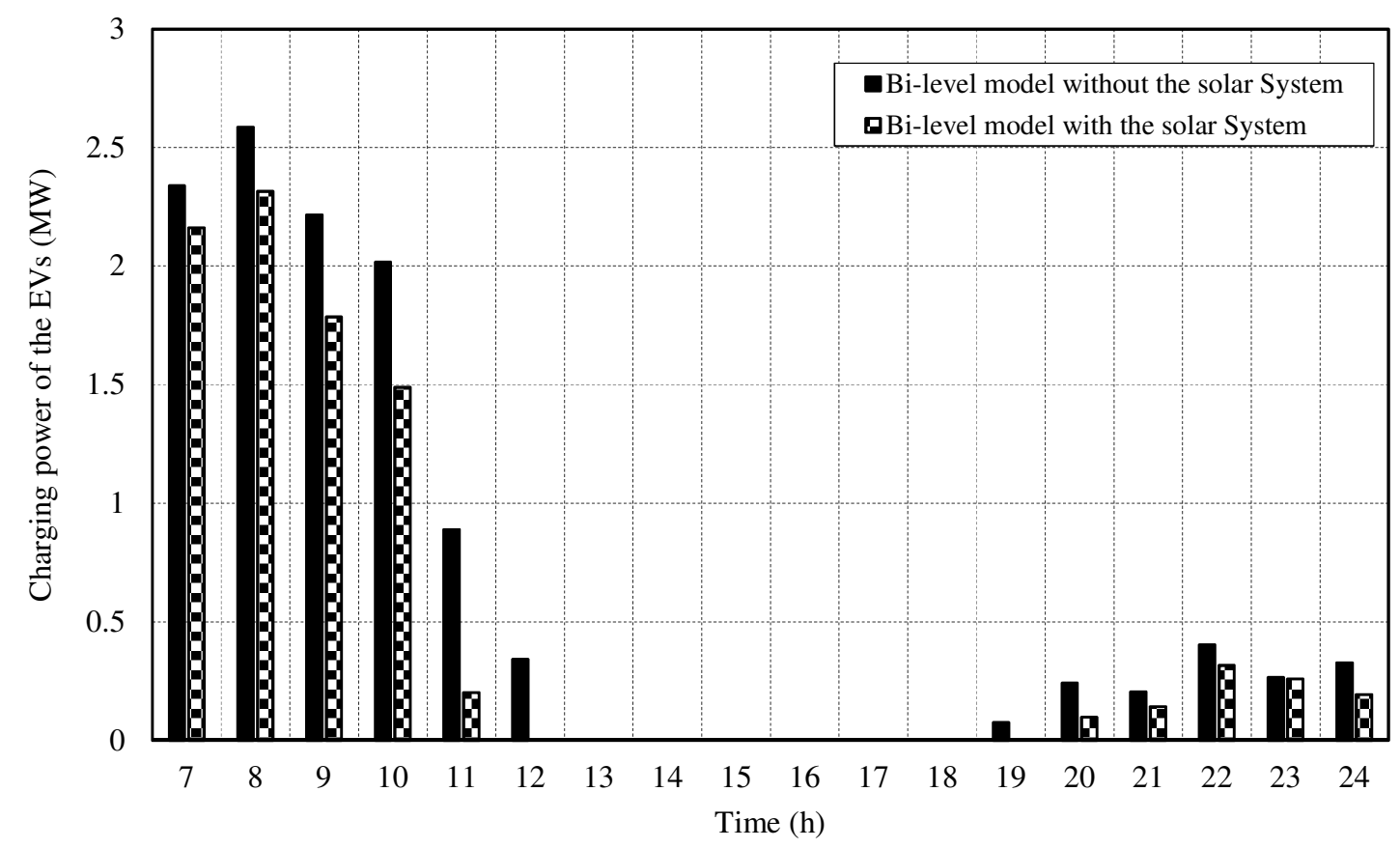

Fig. 4.15. The charging power of all EVs by the SDNO in the bi-level model

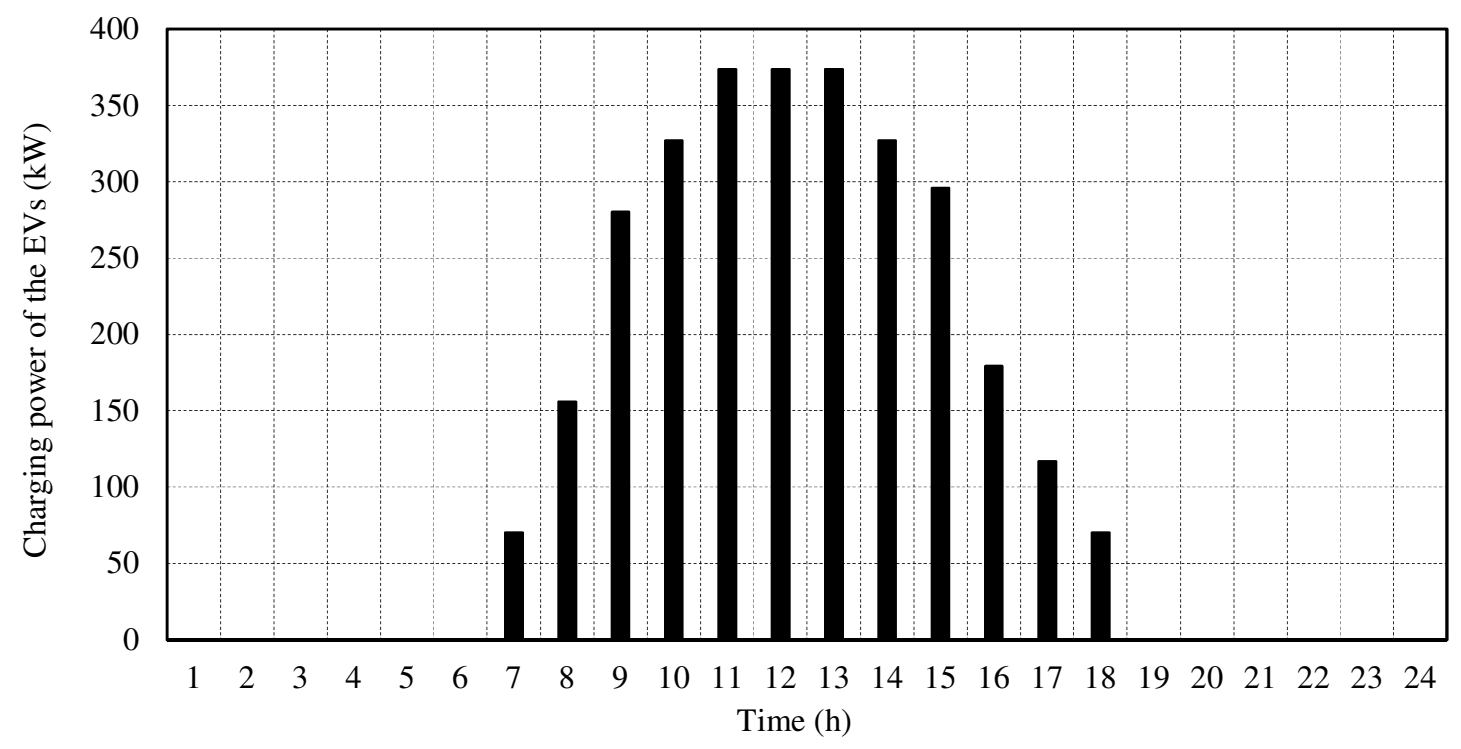

Fig. 4.16. The charging power of all EVs by the solar system in both models

\section{Power purchased from the WM}

The power purchased from the WM with regard to the customers' demand, network losses, the power generated of the solar system and charging power of the EVs, along with its cost, are shown in Table 4.13. Fig. 4.17 shows a comparison between the power purchased from the WM in the single-level and bi-level models. According to Fig 4.17, until the arrival of the EVs, the purchasing power from the WM is the same. From 7:00, with the arrival of the EVs, this power will increase and will continue until 11:00. In these hours, purchasing the power from the WM in the single-level and bi-level models is slightly different. In fact, in the single-level model, when the price of selling energy to the EVs is high, the SDNO purchases more power. However, in the bi-level model, the SDNO purchases more power when the electricity price of the WM is low, i.e. at the off-peak hours. At 13:00 to 18:00 
due to the on-peak hours, the EVs are not charged through the SDNO. Therefore, at this time, the purchasing power from the WM is the same. From 19:00, due to the charging of some EVs, the power purchased will increase again. Furthermore, with the solar system, at 12:00 and 19:00 in two models (red and green line), no power is purchased from the WM.

Table 4.13. The energy purchased from the WM as well as its cost

\begin{tabular}{c|c|c}
\hline Program & The energy purchased $(\mathrm{MWh})$ & The cost of the energy purchased (\$) \\
\hline 1 & 192.938 & 19209.334 \\
\hline 2 & 191.767 & 19059.966 \\
\hline 3 & 192.870 & 19113.120 \\
\hline 4 & 191.714 & 18968.856 \\
\hline
\end{tabular}

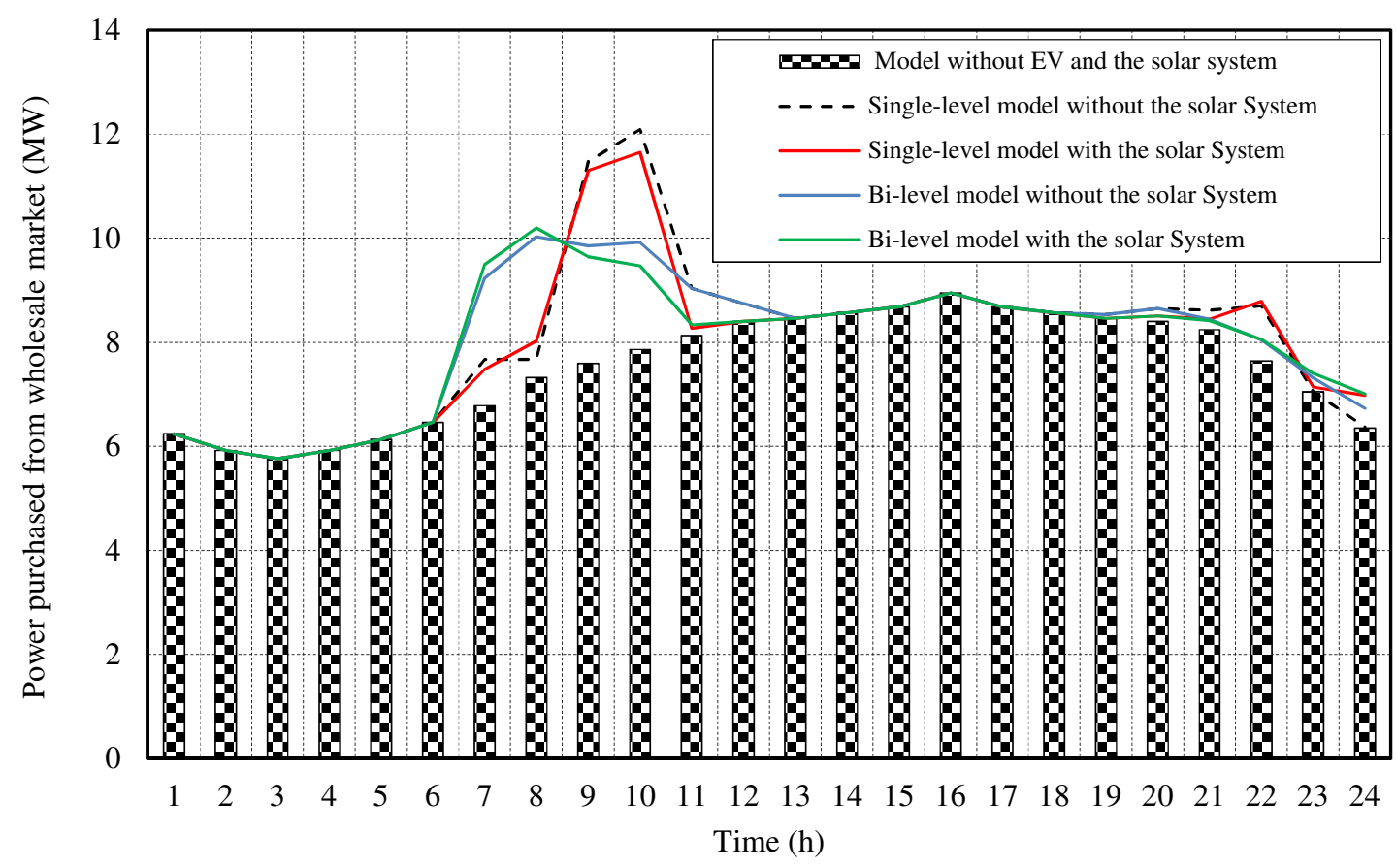

Fig.4.17. The power purchased from the WM in both models

\section{Evaluation of risk level}

To investigate the risk level, the system with the solar system is considered in the single-level and bi-level model. The revenue and cost of the SDNO are presented in separate sections in each of the three models of risk in Table 4.14. According to this table, the SDNO, taking into account the risk, gains less profit from the power sold to the EV owners or the PL owner. Also, Fig 4.18 illustrates the maximum profit of the SDNO by changing the risk aversion parameter, i.e. $\beta$. Increasing this amount leads to a reduction in the profit of the SDNO.

\section{Sensitivity analysis}

Finally, for investigation the affecting factors on the maximum profit of the SDNO in the risk-neutral model, sensitivity analysis is carried out according to Table 4.15 by changing some parameters such as the number of the EVs, the EVs' battery capacity and the rated power of the solar system in 6 modes for the single-level and bi-level model with the solar system. Based on Table 4.15, increasing the EVs' battery capacity, the number of the EVs as well as the rated power of the solar system will bring more profit to the SDNO due to increasing the energy sold to the EVs.

Additionally, for evaluating the effect of the PL sitting on the maximum profit of the SDNO, Table 4.16 is presented. In this regard, three buses are randomly selected considering the situation of first and sixth sensitivity 
analysis. With the changing of the PL sitting, the difference between maximum profit occurs in the single-level model and bi-level model.

Table 4.14. The revenue and cost of the SDNO in the three models of risk (\$)

\begin{tabular}{|c|c|c|c|}
\hline Income & Model & Bi-level model & Single-level model \\
\hline \multirow{3}{*}{ Energy sold to the customer } & Risk-seeker & 24256.64 & 24256.64 \\
\hline & Risk-neutral & 24256.64 & 24256.64 \\
\hline & Risk-averse & 24256.64 & 24256.64 \\
\hline \multirow{3}{*}{ Energy sold to the EV owners by the solar system } & Risk-seeker & - & 344.185 \\
\hline & Risk-neutral & - & 344.185 \\
\hline & Risk-averse & - & 344.185 \\
\hline \multirow{3}{*}{$\begin{array}{l}\text { Energy sold to the EV owners or the PL owner by } \\
\text { the SDNO }\end{array}$} & Risk-seeker & 1040.057 & 1063.127 \\
\hline & Risk-neutral & 937.547 & 1059.510 \\
\hline & Risk-averse & 893.792 & 1048.646 \\
\hline cost & Model & Bi-level model & Single-level model \\
\hline \multirow{3}{*}{ Energy purchased from the WM } & Risk-seeker & 18824.068 & 18951.786 \\
\hline & Risk-neutral & 18968.856 & 19059.966 \\
\hline & Risk-averse & 18967.328 & 19067.241 \\
\hline Profit & Model & Bi-level model & Single-level model \\
\hline \multirow{3}{*}{ Profit } & Risk-seeker & 6472.630 & 6712.166 \\
\hline & Risk-neutral & 6225.330 & 6600.368 \\
\hline & Risk-averse & 6183.103 & 6547.916 \\
\hline
\end{tabular}

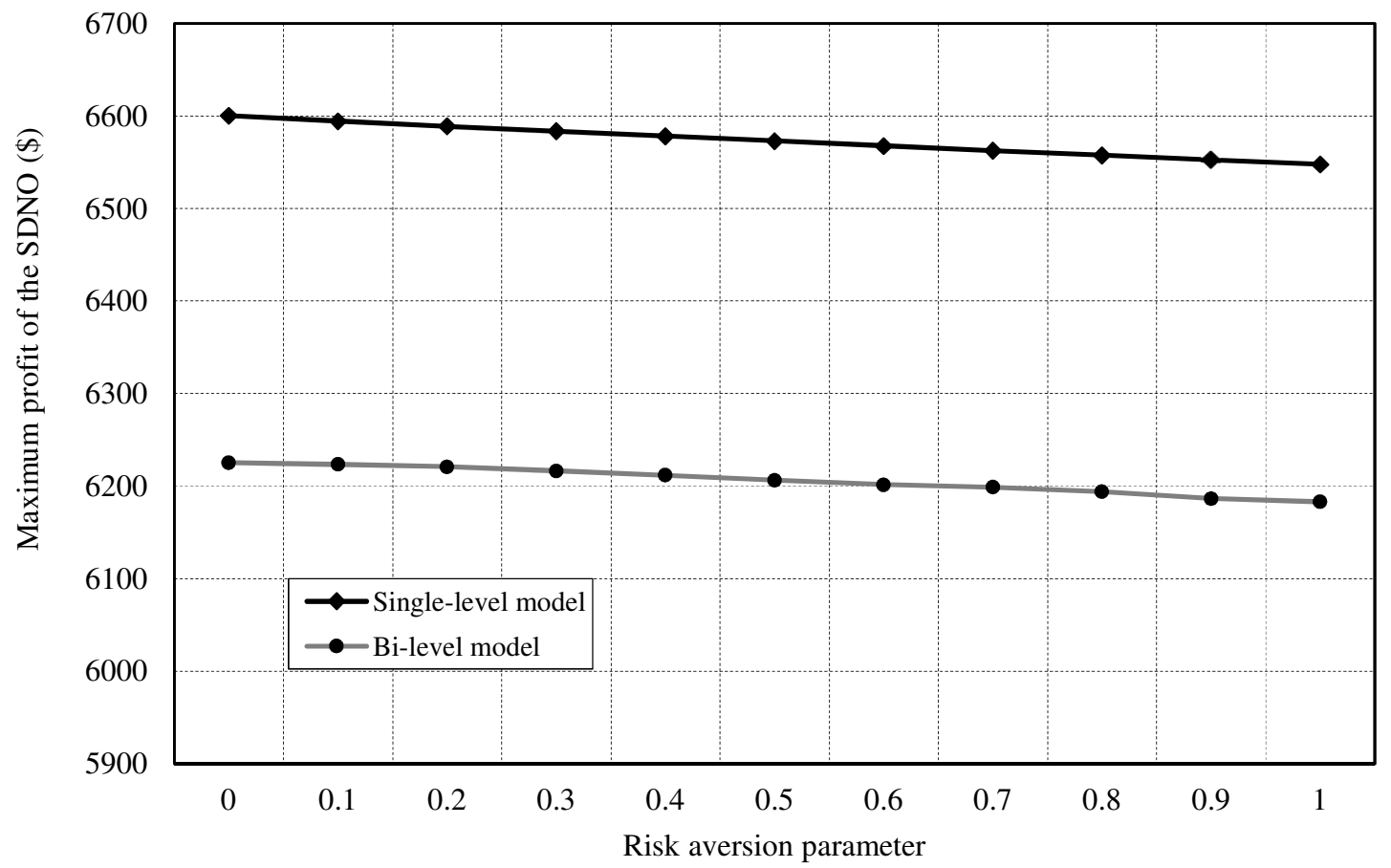

Fig.4.18. The effect of risk aversion parameter on the maximum profit of the SDNO in both models 
Table 4.15. Sensitivity analysis of the affecting factors on the maximum profit of the SDNO

\begin{tabular}{c|c|c|c|c|c}
\hline \multirow{2}{*}{ No } & \multirow{2}{*}{ EVs no. } & \multirow{2}{*}{$\begin{array}{c}\text { Battery capacity } \\
(\mathrm{kWh})\end{array}$} & $\begin{array}{c}\text { Rated power of the } \\
\text { solar system }(\mathrm{kW})\end{array}$ & \multicolumn{2}{|c}{ Maximum profit } \\
\cline { 5 - 6 } & & 50 & 400 & Single-level model & Bi-level model \\
\hline 1 & 500 & 24 & 400 & 6600.369 & 6225.330 \\
\hline 2 & 500 & 50 & 500 & 6326.914 & 6185.083 \\
\hline 3 & 500 & 400 & 7114.364 & 6367.970 \\
\hline 4 & 1000 & 40 & 400 & 6639.413 & 6589.192 \\
\hline 5 & 1000 & 24 & 500 & 7150.733 & 6373.397 \\
\hline 6 & 1000 & 50 & &
\end{tabular}

Table 4.16. Evaluation of the effect of the PL sitting on the maximum profit of the SDNO

\begin{tabular}{c|c|c|c}
\hline \multirow{2}{*}{ Sensitivity analysis No. } & \multirow{2}{*}{ The bus of the PL } & \multicolumn{2}{|c}{ Maximum profit } \\
\cline { 3 - 4 } & & Single-level model & Bi-level model \\
\hline 1 & 20 & 6600.369 & 6225.330 \\
\hline 1 & 4 & 6586.420 & 6315.722 \\
\hline 1 & 24 & 6565.793 & 6316.835 \\
\hline 6 & 20 & 7150.733 & 6629.801 \\
\hline 6 & 4 & 7110.169 & 6606.545 \\
\hline 6 & 24 & 6943.132 & 6429.363 \\
\hline
\end{tabular}

\subsubsection{The system with the EVs (charging/discharging) with/without the solar system}

In this section, the model is solved in the presence of the EVs with charging/discharging schedule as well as single-level and bi-level models. In the single-level model, the SDNO is the owner of the PL, so the price of the energy sold to the EV owners is equal to the price of the energy sold to the customers (see Table 4.9). Also, the maximum limit of the price of the energy purchased from the EV owners is $140 \$ / M W h$, i.e. the minimum electricity price of the WM. In the bi-level model, the price of the energy sold to the PL owner is the same as Table 4.10. The price of the energy purchased from the PL owner (in the bi-level model) is calculated by solving the problem. The maximum profit of SDNO, the charging/discharging power of the EVs and the power purchased from the WM are examined in both models. It should be noted that the customers' demand is the same as Fig. 4.13.

1. The maximum profit of SDNO

Table 4.17 shows the maximum profit of the SDNO in the single-level and bi-level models. In the single-level model, the SDNO gains more profit than the bi-level model. The reason can be seen in several factors. In the single-level model because of the power generated of the solar system, the SDNO purchases less power from the $\mathrm{WM}$ at the on-peak hours. Another reason is the price of the energy sold to the EV owners. In the single-level model, this price is equal to the price of the energy sold to the customer; however, in the bi-level model, this price is lower than the price of the energy sold to the customer. Moreover, in the bi-level model, the owner of the PL due to the minimization of cost purchases less power from the SDNO and therefore, has less power for selling to the SDNO during the on-peak hours. According to Table 4.18, the price of the energy purchased from the PL owner in the bi-level model is also lower than the single-level model. In addition, the solution times are presented in Table 4.17. With the presence of the EVs on the system, the solution time raise. Of course, in the bi-level model, due to the complexity of the problem, this time will be greatly increased.

Table 4.17. The maximum profit of the SDNO and solution time in all programs

\begin{tabular}{|c|c|c|}
\hline Program & Profit of the SDNO (\$) & Solution time $(\mathrm{s})$ \\
\hline 1. single-level model without the solar system & 6721.098 & 27.469 \\
\hline 2. single-level model with the solar system & 6961.287 & 78.984 \\
\hline 3. bi-level model without the solar system & 6645.461 & 243.67 \\
\hline 4. bi-level model with the solar system & 6684.246 & 574.56 \\
\hline
\end{tabular}


Table 4.18. The price of the energy purchased from the EV owners and the PL owner (\$/MWh)

\begin{tabular}{c|c|c}
\hline Hour & EV owners (single-level model) & PL owner (bi-level model) \\
\hline 13:00-18:00 & 140 & 133 \\
\hline
\end{tabular}

2. Charging/discharging power of the EVs

Due to the charging/discharging schedule of the EVs, during the off-peak and mid-peak hours, the EVs are charged and at the on-peak hours are discharged. As previously mentioned, the maximum power that can be imposed on the SDN for charging of the EVs can be up to $5 \mathrm{MWh}$. The same amount of power during the on-peak hours is available due to discharging power of the EVs. In this regard, the charging/discharging power of the EVs, as well as its cost and benefit are presented in Table 4.19 to 4.22 . The power generated of the solar system is also used for charging the EVs and supplying the customers' demand. According to these tables, In the bi-level model, the aim of PL owner is influenced in the charging/discharging power, and therefore, less power is exchanged between the SDNO and the PL.

Table 4.19. The power charged of the EVs in the single-level model (MW)

\begin{tabular}{c|c|c|c}
\hline Program & $\begin{array}{c}\text { Total charging power } \\
\text { of the EVs }\end{array}$ & $\begin{array}{c}\text { Charging power of the EVs } \\
\text { by the SDNO }\end{array}$ & $\begin{array}{c}\text { Charging power of the EVs } \\
\text { by the solar system }\end{array}$ \\
\hline 1 & 21.199 & 21.199 & - \\
\hline 2 & 20.610 & 19.131 & 1.479 \\
\hline 3 & 20.139 & 20.139 & - \\
\hline 4 & 18.174 & 16.658 & 1.516 \\
\hline
\end{tabular}

Table 4.20. The discharging power of the EVs in the single-level model (MW)

\begin{tabular}{c|c}
\hline Program & Total discharging power of the EVs \\
\hline 1 & 7.948 \\
\hline 2 & 7.444 \\
\hline 3 & 7.001 \\
\hline 4 & 6.505 \\
\hline
\end{tabular}

Table 4.21. The revenue of the energy sold to the EV owners and the PL owner for charging of the EVs $(\$)$

\begin{tabular}{c|c}
\hline Program & EV owners or PL owner \\
\hline 1 & 2444.292 \\
\hline 2 & 2233.900 \\
\hline 3 & 1927.175 \\
\hline 4 & 1826.865 \\
\hline
\end{tabular}

Table 4.22. The cost of the energy purchased from the EV owners and the PL owner (\$)

\begin{tabular}{c|c}
\hline Program & EV owners or PL owner \\
\hline 1 & 1112.806 \\
\hline 2 & 1042.281 \\
\hline 3 & 931.012 \\
\hline 4 & 865.213 \\
\hline
\end{tabular}

The Figs. 4.19 and 4.20 show the total charging/discharging power of the EVs through the SDNO in the single-level model. According to these Figs, the charging/ discharging schedule is properly done. At the off-peak and mid-peak hours, the EVs are charged and at the on-peak hours, the EVs are discharged. Since the discharging of the EVs occur at the on-peak hours, firstly, the EVs are fully charged, then they are discharged, and finally are again charged to achieve the desired SOE in the departure time. In accordance with Fig. 4.19, at 9:00 and 10:00 since the difference between the electricity price of the WM and the price of the energy sold to the EVs are high, so at these times, the SDNO sells more power. Also at the on-peak hours, the EVs do not charge. At 19:00, unlike the controlled charging mode, since most of the EVs participate in the discharging schedule and 
according to Table 4.4, about $50 \%$ of the EVs leave the PL, more power is sold for meeting the desired SOE. After that, considering the existing EVs, less power is sold for charging of the EVs.

The discharging of the EVs occurs at the on-peak hours according to Fig. 4.20. Based on this Fig, at 13:00, EVs do not discharge because at this time the discharging energy price is the same as the electricity price of the WM. In fact, the SDNO purchases the power discharged when the electricity price of the WM is very high, i.e. 17:00 and 16:00. At these times, the electricity price of the WM is 200 and $195 \$ / M W h$, respectively.

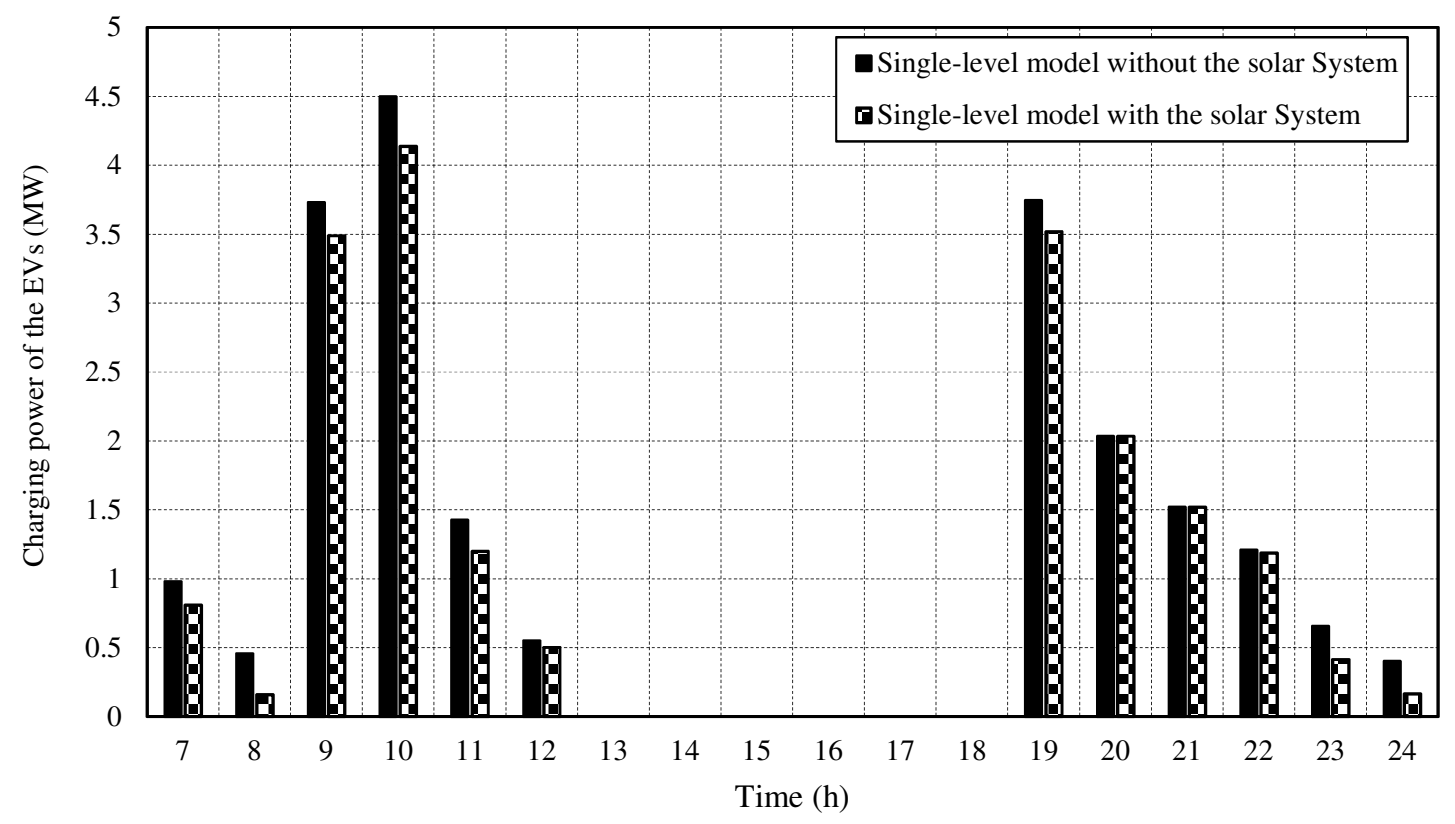

Fig. 4.19. The charging power of the all EVs by the SDNO in the single-level model

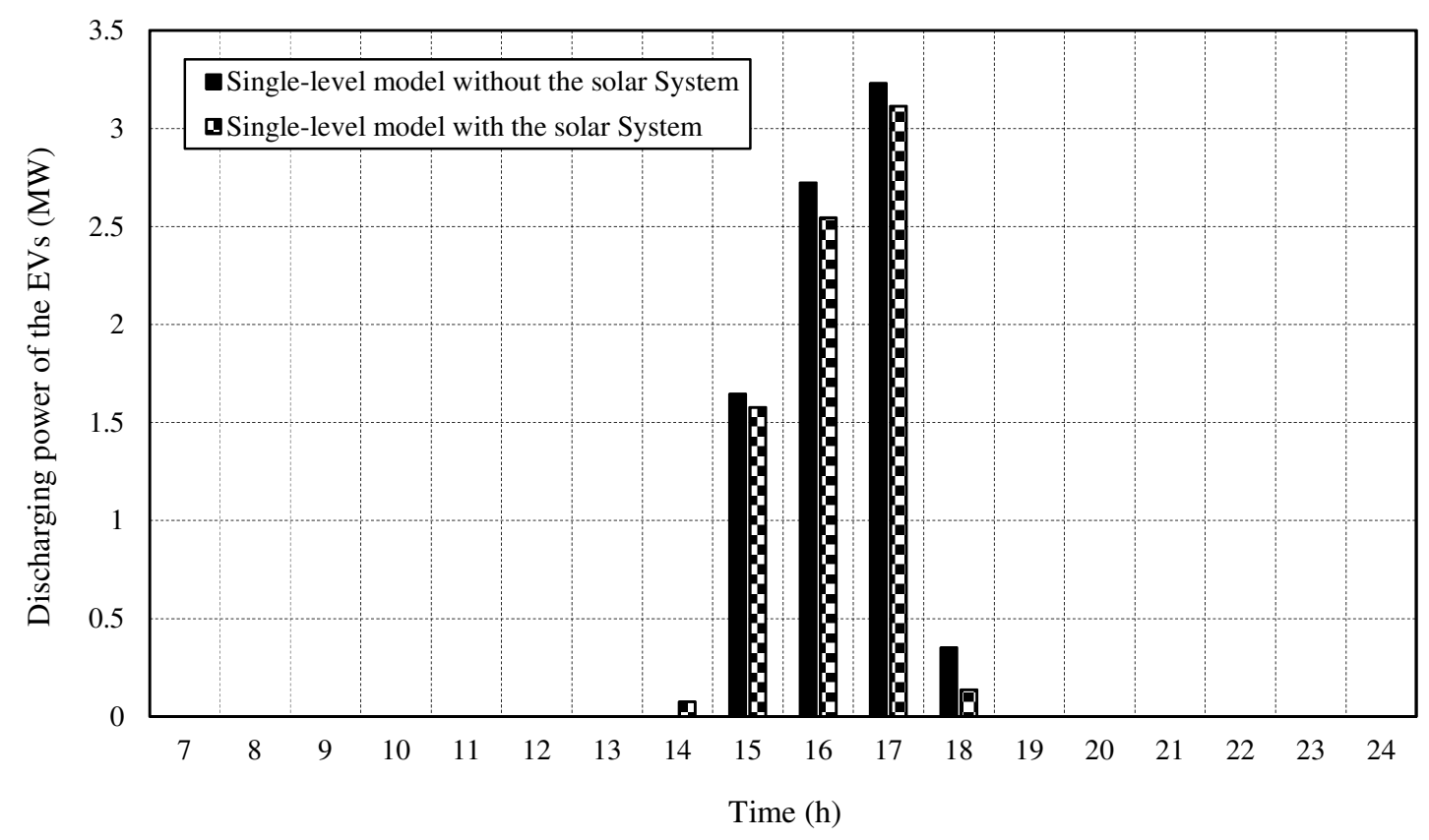

Fig. 4.20. The discharging power of the all EVs in the single-level model 
Also, Fig 4.21 shows the sharing of power generated by the solar system for charging of the EVs and feeding the customer in the single-level model. Based on Fig 4.21, during the on-peak hours, the SDNO uses most of this power for feeding the customer due to the high electricity price of the WM.

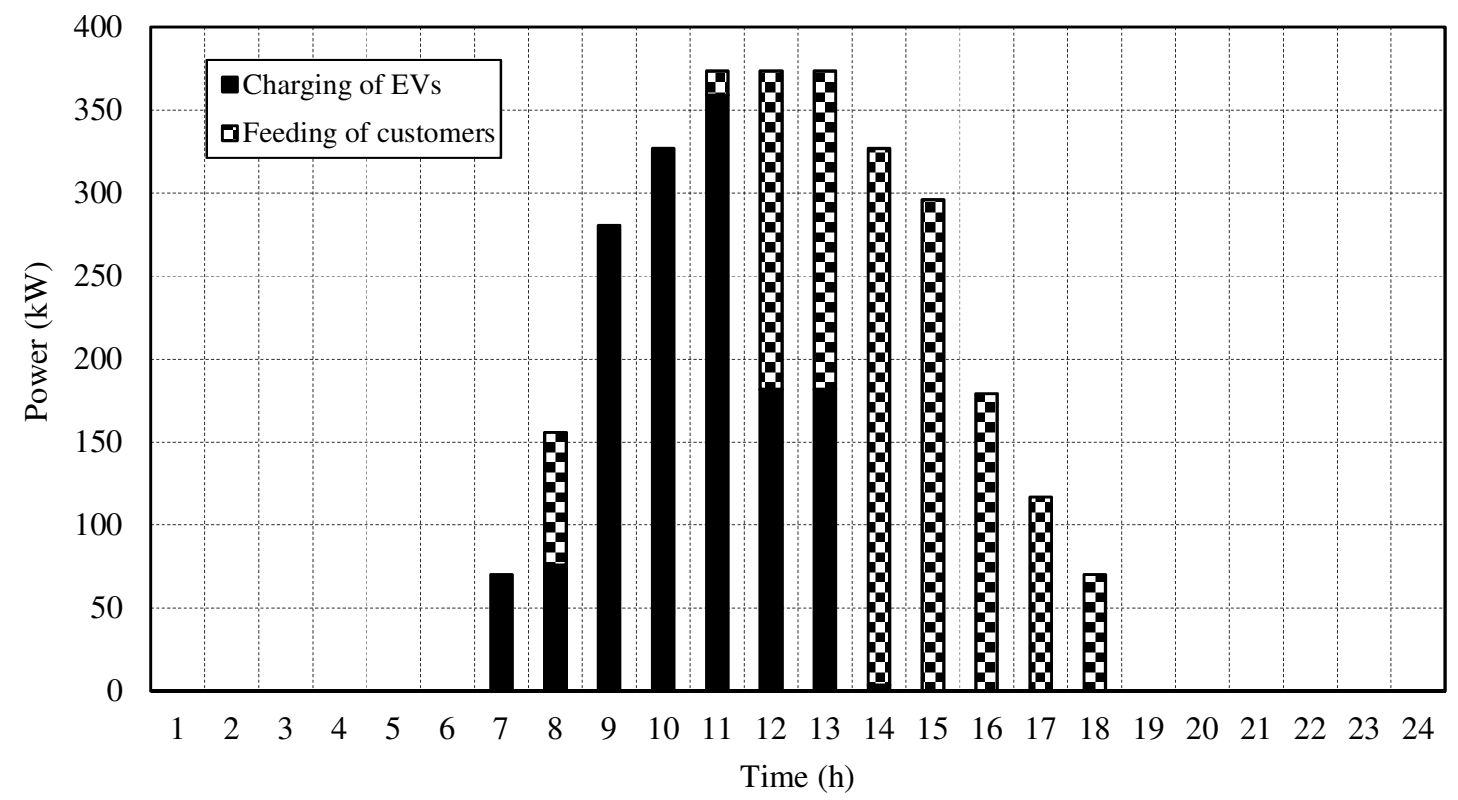

Fig.4.21. Sharing of power generated by the solar system for charging of the EVs and feeding of the customer in the single-level model

Fig 4.22 shows the charging power of the EVs in the bi-level model. Because of the aim of the PL owner, i.e. cost of minimization, the PL owner purchases more power from the SDNO when the electricity price of the WM is low, i.e. at 7:00 and 8:00. Fig 4.23, also shows the discharging power of the EVs in the bi-level model that is the same as the single-level model. Also, Fig 4.24 shows the sharing of power generated by the solar system for charging of the EVs and feeding the customer in the bi-level model.

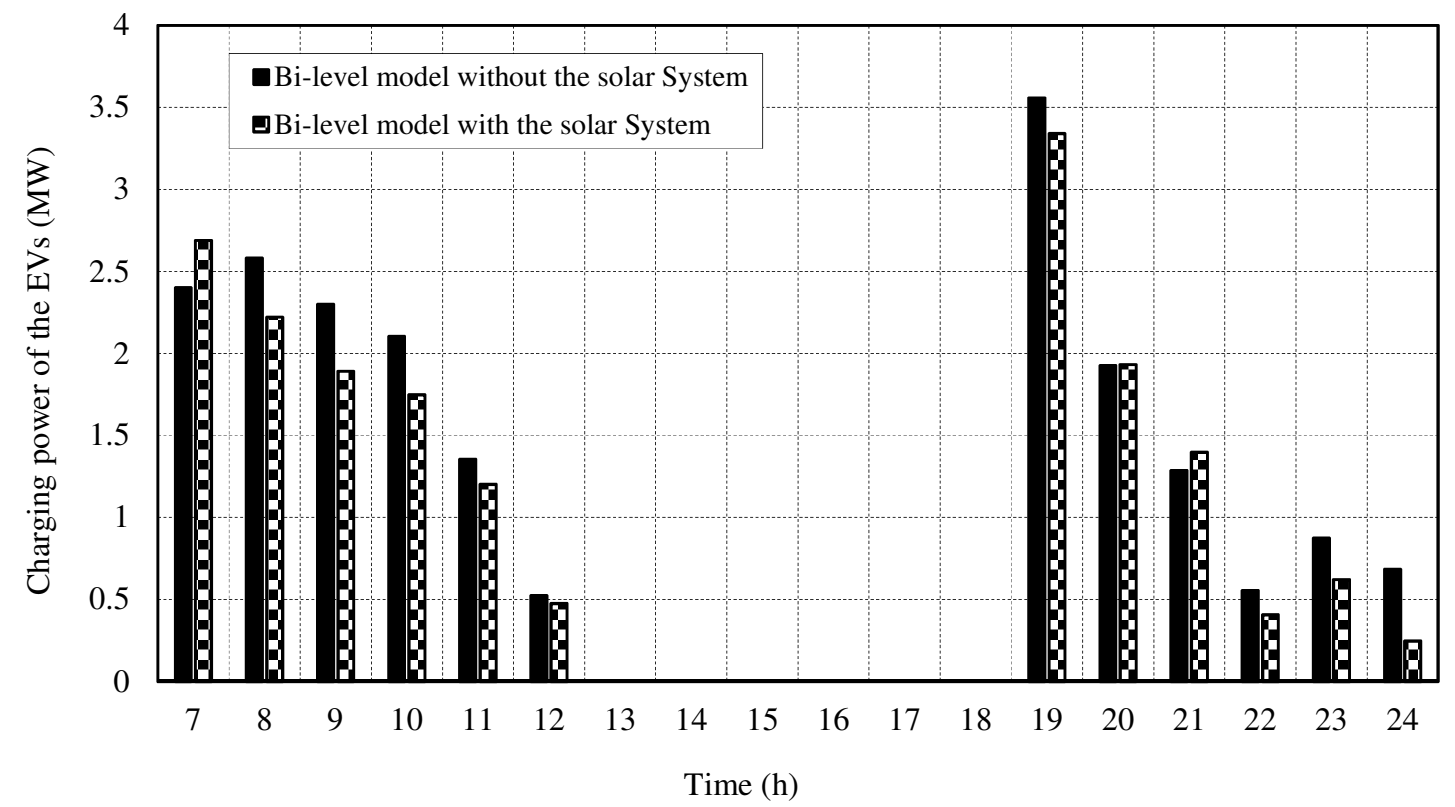

Fig. 4.22. The charging power of the all EVs by the SDNO in the bi-level model 


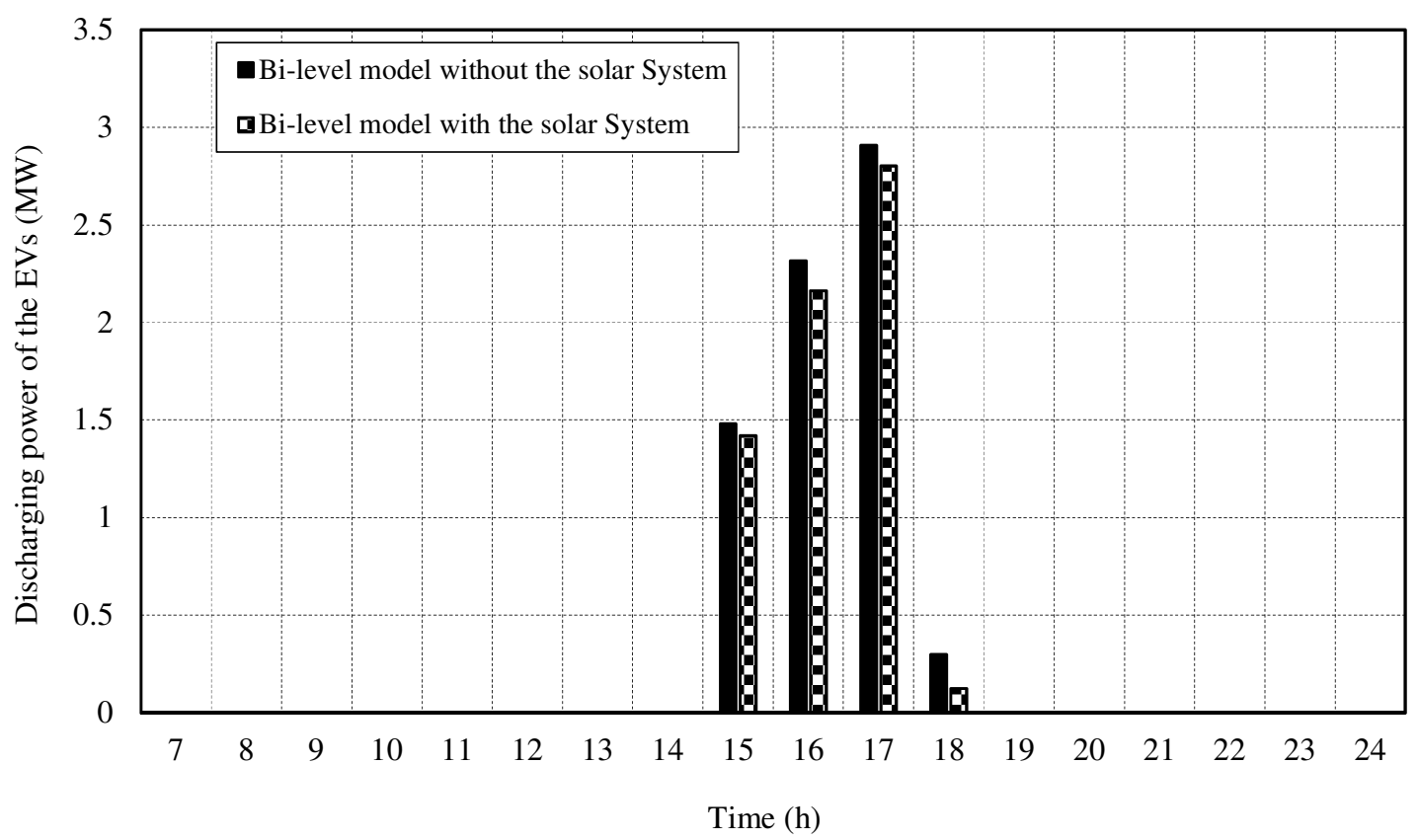

Fig. 4.23. The discharging power of the all EVs in the bi-level model

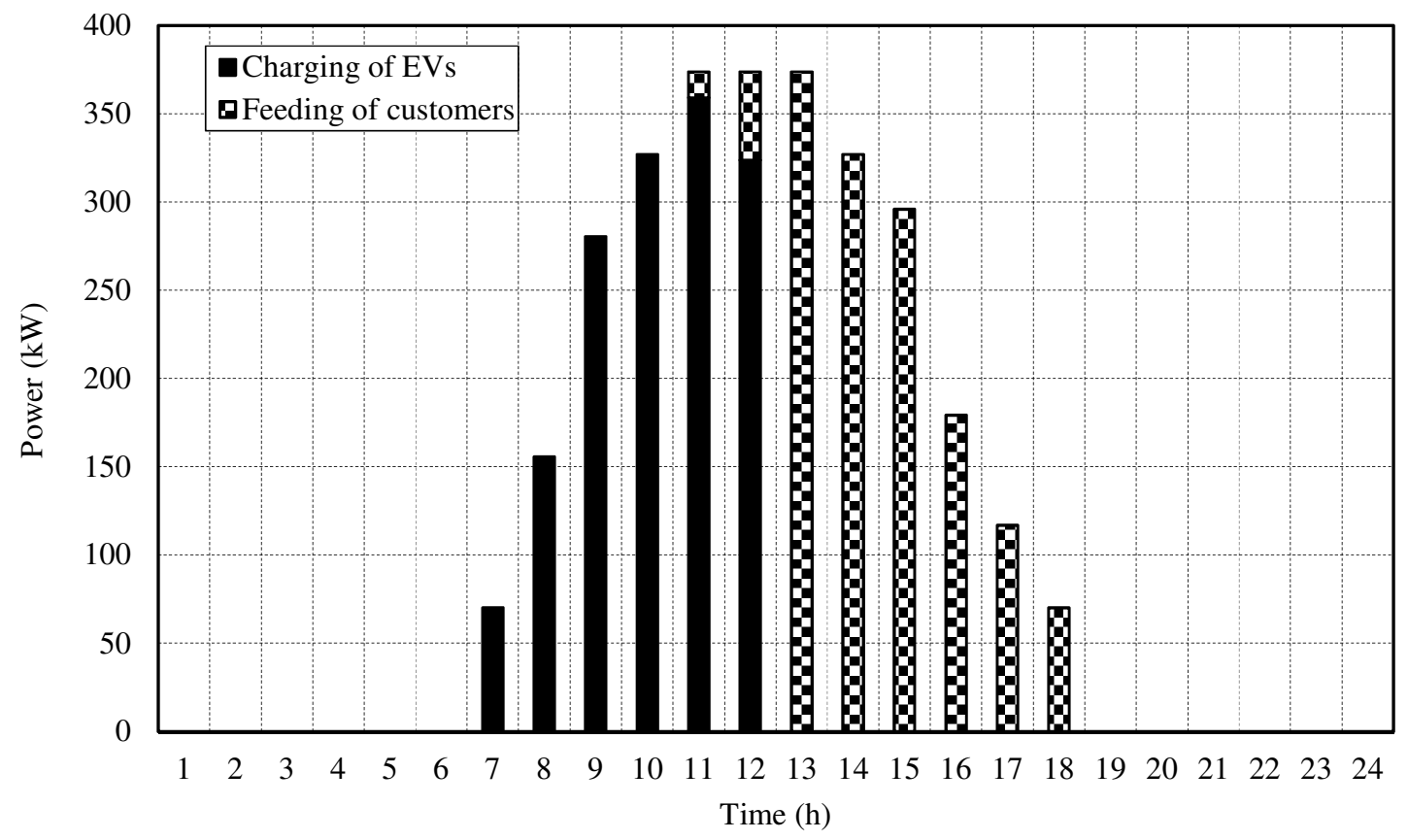

Fig.4.24. Sharing of power generated by the solar system for charging of the EVs and feeding of the customer in the bi-level model

\section{Power purchased from the WM}

Table 4.25 shows the power purchased from the WM and its cost. Also, Fig 4.24 shows a comparison between the power purchased from the WM in the single-level and bi-level models. Until the arrival of the EVs, i.e. 7:00, the power purchased from the WM is the same. Of course, this amount is slightly higher than the customers' demand due to network losses. From 7:00, with the arrival of the EVs, this power will increase and will continue 
until 11:00. In these hours, purchasing the power from the WM in the single-level and bi-level models is slightly different. From 13:00 to 18:00, discharging power of the EVs or power generated of the solar system are used for meeting the customers' demand. For this reason, at these hours, the purchasing power from the WM is reduced, so that the lowest power purchased from the WM is at 17:00. From 19:00, due to the departure of 50\% of the EVs from the PL and the satisfaction of the desired SOE, this power is increased. The power purchased from the WM after 19:00 is continued due to fewer numbers of the EVs in the PL and the customers' demand.

Table 4.23. The energy purchased from the WM as well as its cost

\begin{tabular}{c|c|c}
\hline Program & The energy purchased $(\mathrm{MWh})$ & The cost of the energy purchased $(\$)$ \\
\hline 1 & 194.572 & 18628.570 \\
\hline 2 & 193.409 & 18435.302 \\
\hline 3 & 194.503 & 18607.342 \\
\hline 4 & 193.356 & 18344.192 \\
\hline
\end{tabular}

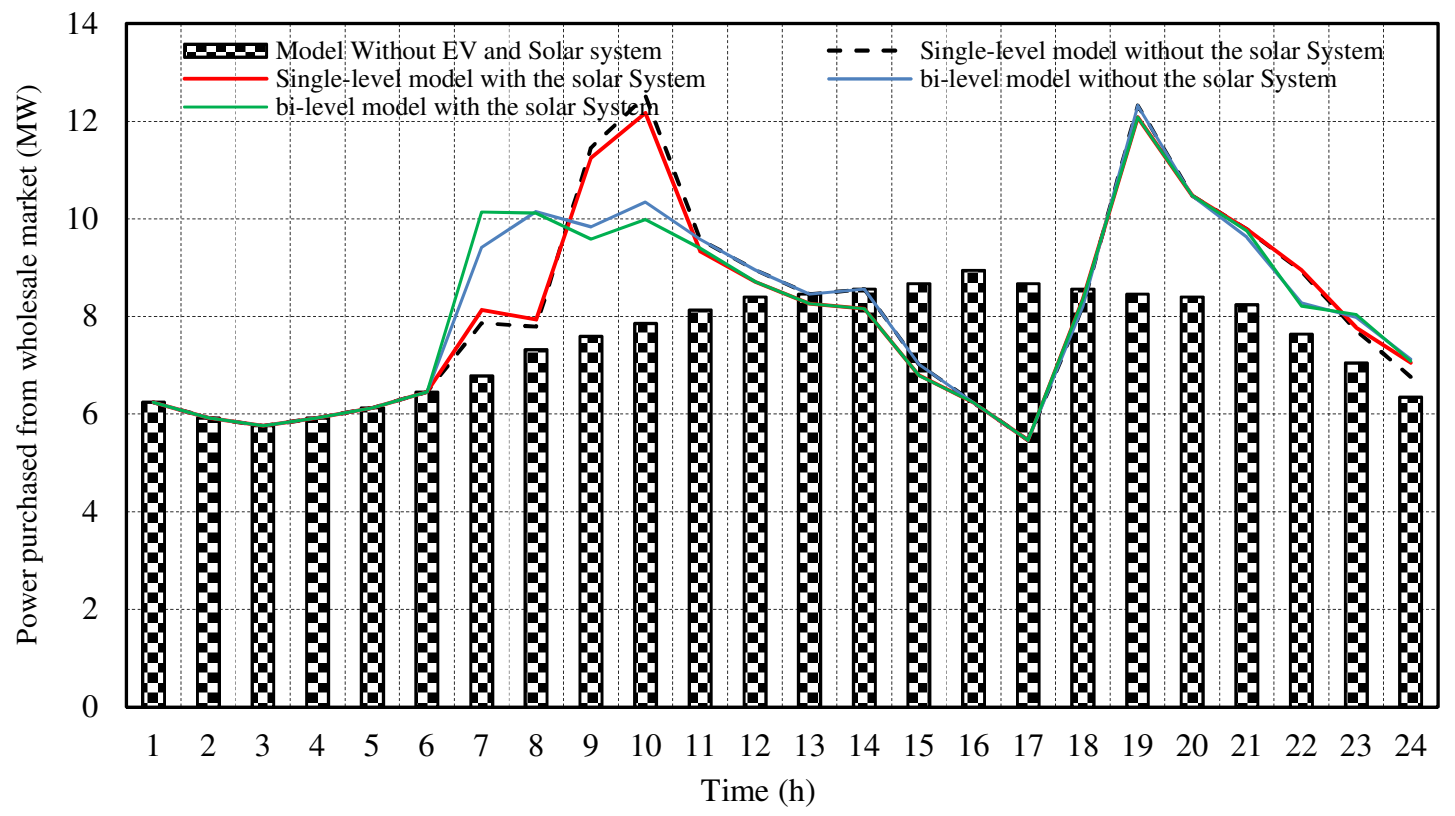

Fig.4.25. The power purchased from the WM in both models

4. Evaluation of risk level

In order to investigate the risk level, the system with the solar system is considered in the single-level and bi-level model. The revenue and cost of the SDNO are presented in separate sections in each of the three models of risk in Table 4.24. In the risk-seeker model, the SDNO purchases more power for EVs' charging in order to get more profit, but in the risk-averse model, purchase less power for EVs' charging. Also, in the risk-seeker model, the SDNO by using discharging power to meeting the customers' demand at the on-peak hours, purchase less power from the WM. For this reason, in this model, the power purchased's cost of the EVs is the highest. So, in the riskseeker model, the SDNO gains the most profit. Furthermore, Fig 4.26 illustrates the maximum profit of the SDNO by changing the risk aversion parameter, i.e. $\beta$. Increasing this amount leads to a reduction in the profit of SDNO. 
Table 4.24. The revenue and cost of the SDNO in the three models of risk (\$)

\begin{tabular}{|c|c|c|c|}
\hline Income & Model & Bi-level model & Single-level model \\
\hline \multirow{3}{*}{ Energy sold to customer } & Risk-seeker & 24256.64 & 24256.640 \\
\hline & Risk-neutral & 24256.64 & 24256.640 \\
\hline & Risk-averse & 24256.64 & 24256.640 \\
\hline \multirow{3}{*}{ Energy sold to the EV owners by the solar system } & Risk-seeker & - & 149.803 \\
\hline & Risk-neutral & - & 171.676 \\
\hline & Risk-averse & - & 282.169 \\
\hline \multirow{3}{*}{$\begin{array}{l}\text { Energy sold to the EV owners or the PL owner by } \\
\text { the SDNO }\end{array}$} & Risk-seeker & 1906.865 & 2300.071 \\
\hline & Risk-neutral & 1826.865 & 2233.900 \\
\hline & Risk-averse & 1807.415 & 2223.475 \\
\hline cost & Model & Bi-level model & Single-level model \\
\hline \multirow{3}{*}{ Energy purchased from the WM } & Risk-seeker & 18154.402 & 18191.885 \\
\hline & Risk-neutral & 18344.192 & 18435.302 \\
\hline & Risk-averse & 18326.522 & 18431.262 \\
\hline \multirow{3}{*}{ Battery depreciation } & Risk-seeker & - & 243.123 \\
\hline & Risk-neutral & - & 223.345 \\
\hline & Risk-averse & - & 249.266 \\
\hline \multirow{3}{*}{$\begin{array}{l}\text { Energy purchased from the EV owners or the PL } \\
\text { owner (discharging power) }\end{array}$} & Risk-seeker & 955.103 & 1134.576 \\
\hline & Risk-neutral & 865.213 & 1042.280 \\
\hline & Risk-averse & 936.124 & 1163.243 \\
\hline \multirow{3}{*}{$\begin{array}{l}\text { Energy purchased from the PL owner } \\
\text { (power generated of the solar system) }\end{array}$} & Risk-seeker & 215.413 & - \\
\hline & Risk-neutral & 189.853 & - \\
\hline & Risk-averse & 170.093 & - \\
\hline Profit & Model & Bi-level model & Single-level model \\
\hline \multirow{3}{*}{ Profit } & Risk-seeker & 6838.587 & 7136.930 \\
\hline & Risk-neutral & 6684.246 & 6961.287 \\
\hline & Risk-averse & 6631.316 & 6894.798 \\
\hline
\end{tabular}

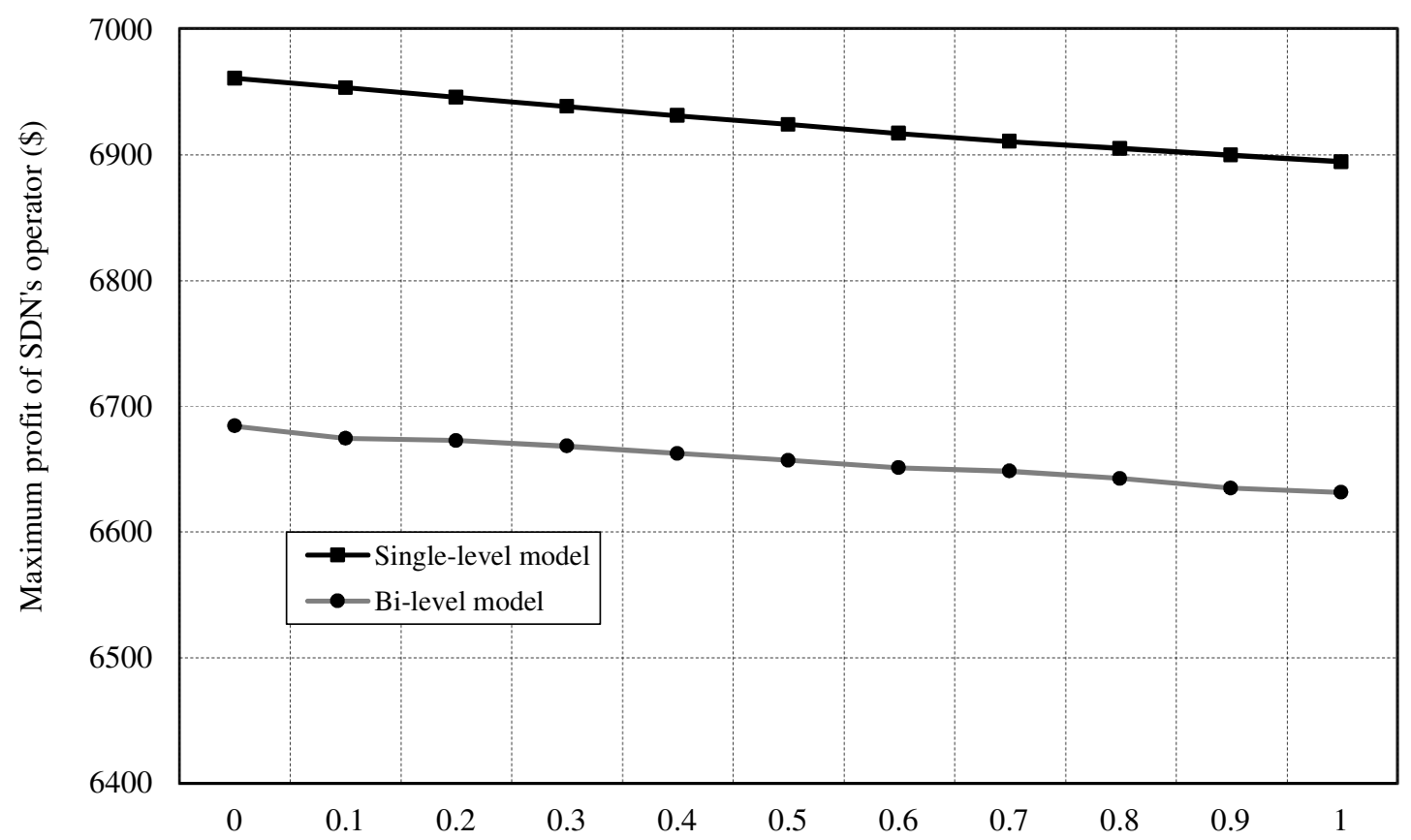

Risk aversion parameter

Fig.4.26. The effect of risk aversion parameter on the maximum profit of the SDNO in both models 


\section{Sensitivity analysis}

Finally, for investigation the affecting factors on the maximum profit of the SDNO in the risk-neutral model, sensitivity analysis is carried out by changing some parameters such as the number of the EVs, the EVs' battery capacity and rated power of the solar system in 6 modes for both models, i.e. single-level and bi-level model with the solar system according to Table 4.25. Based on Table 4.15, increasing the EVs' battery capacity, number of the EVs as well as the rated power of the solar system will bring more profit to the SDNO due to increasing the energy sold to the EVs

Also, for evaluating the effect of the PL sitting on the maximum profit of the SDNO, Table 4.26 is presented. In this regard, three buses are randomly selected considering the situation of first and sixth sensitivity analysis. With the changing of the PL sitting, the difference between maximum profit occurs in the single-level model and bilevel model.

Table 4.25. Sensitivity analysis of the affecting factors on the maximum profit of the SDNO

\begin{tabular}{c|c|c|c|c|c}
\hline \multirow{2}{*}{ No } & \multirow{2}{*}{ EVs no. } & \multirow{2}{*}{$\begin{array}{c}\text { Battery capacity } \\
(\mathrm{kWh})\end{array}$} & $\begin{array}{c}\text { Rated power of the } \\
\text { solar system }(\mathrm{kW})\end{array}$ & \multicolumn{2}{|c}{ Maximum profit } \\
\cline { 5 - 6 } & & 50 & 400 & Single-level model & Bi-level model \\
\hline 1 & 500 & 24 & 400 & 6961.287 & 6684.246 \\
\hline 2 & 500 & 50 & 500 & 6564.702 & 6303.117 \\
\hline 3 & 500 & 400 & 7016.687 & 6751.966 \\
\hline 4 & 1000 & 50 & 400 & 6962.344 & 7440.848 \\
\hline 5 & 1000 & 24 & 500 & 7721.598 & 6693.670 \\
\hline 6 & 1000 & 50 & & \\
\hline
\end{tabular}

Table 4.26. Evaluation of the effect of the PL sitting on the maximum profit of the SDNO

\begin{tabular}{c|c|c|c}
\hline \multirow{2}{*}{ Sensitivity analysis No. } & \multirow{2}{*}{ The bus of the PL } & \multicolumn{2}{|c}{ Maximum profit } \\
\cline { 3 - 4 } & & Single-level model & Bi-level model \\
\hline 1 & 20 & 6961.287 & 6684.246 \\
\hline 1 & 4 & 6999.619 & 6707.128 \\
\hline 1 & 24 & 6943.316 & 6645.155 \\
\hline 6 & 20 & 7721.598 & 7490.227 \\
\hline 6 & 4 & 7813.149 & 7549.778 \\
\hline 6 & 24 & 7237.194 & 7150.823 \\
\hline
\end{tabular}

\subsection{Conclusions}

With modeling the EVs and the solar system and considering the private owner for the PLs (with two programs, i.e. controlled charging mode and smart charging/discharging mode), a new non-linear bi-level model was suggested for the operational scheduling of the SDN. The profit maximization of the SDNO and minimizing the cost of the PLs owner were the objective functions of each level. By using of KKT condition and the dual theory as well as the Fortuny-Amat and McCarl linearization method, the non-linear bi-level model was converted to single-level and linear models. Further, by supposing that the SDNO is the owner of the PLs, the single-level model was also proposed with the goal of profit maximization of the SDNO. Also, due to the uncertainties, three different strategies for risk management were introduced to evaluate the effect of the risk on the operational scheduling of the SDN. By introducing a Conditional Value-at-Risk (CVaR) index, the risk-based model was defined.

After presenting these models, the simulations on the IEEE 33-bus distribution system were tested over a 24-hours for proving the effectiveness of the model. The maximum profit of the SDNO, the customers' demand, charging/discharging power of the EVs and the power purchased from the WM were evaluated in each mode. Also, for investigation of risk level, the amount of revenue and cost of the SDNO in three models of risk were presented. Finally, the sensitivity analysis was performed by changing some parameters. The main results were achieved from the case studies as follows: 
1. The maximum profit of the SDNO in the single-level model was higher than the bi-level model. The reason in controlled charging and charging/discharging schedule can be seen in several factors:

- The higher price of the energy sold to the EV owners in the single-level model (in both section)

- More revenue from the energy sold to the EV owners during the off-peak/mid-peak hours due to power generated of the solar system in the single-level model (in both section)

- More revenue from the less power purchased from the WM during the on-peak hours due to power generated of solar in the single-level model (in the charging/discharging schedule)

- Less revenue from the energy sold to the PL owner in the bi-level model due to minimizing the cost (in the charging/discharging schedule)

2. The charging schedule and even charging/discharging schedule of the EVs were correctly done. So that the EVs' charging happened during the off-peak/mid-peak hours. Moreover, the EVs' discharging occurred during the on-peak hours. Of course, during the off-peak/mid-peak hours when the difference between the electricity price of the WM and the energy sold to the EV owners or the PL owner was negative or zero, discharging did not happen. Also, during the on-peak hours, the electricity price of the WM and the purchasing energy price from the EV owners or the PL owner were the main reason for the decision of the SDNO for purchasing energy. Therefore, most of the energy purchased from the EV owners or the PL owner was performed at 16:00 or 17:00. At this time, the energy purchased from the WM was the highest value.

3. By increasing the level of risk, the SDNO was more conservative done the charging/discharging schedule, so the SDNO was obtained the lowest profit in the risk-averse model. In fact, in the risk-averse model, since the EVs were less involved in charging/discharging schedule, the SDNO more power was purchased from the WM, and less profit was achieved.

4. Increasing the EV's battery capacity and increasing the number of EVs as well as the rated power of the solar system was brought more profit to the SDNO. Also, with the changing of sitting of PL, in some cases, there was a difference between the profit of the SDNO.

5. The results of the single-level and bi-level models were proved the effectiveness of these models. For solving the bi-level model, the dual theory, the KKT conditions, and the Fortuny-Amat and McCarl methods were applied. So, the non-linear bi-level model was transformed into a single-level and linear model that can be easily solved by the optimization solver.

\section{Appendix-1. A. Linear Power Flow}

In this chapter, a linear power flow is used based on [20,31]. This power flow is used only in radial distribution networks. For this purpose, a term is considered as a block to avoid nonlinearities. Note that the EVs in the PLs act as a source at the on-peak hours and as a load at the off-peak or mid-peak hours. The active and reactive power balance in this power flow is shown in Eqs. (A.1) and (A.2). Of course in the single-level model, instead of the expected value of the charging/discharging power and the output power of the solar system in Eq. (A.1), their scenario values are replaced.

$$
\begin{aligned}
& P_{s b, t}^{W h 2 G} \times \eta^{\text {Trans }}+\hat{P}_{P L, t}^{\text {Solar }}+\sum_{E V} \hat{P}_{P L, E V, t}^{d c h}-\sum_{E V} \hat{P}_{P L, E V, t}^{c h}-\sum_{b^{\prime}}\left[\left(P_{b, b^{\prime}, t, s}^{+}-P_{b, b^{\prime}, t, s}^{-}\right)+R_{b, b^{\prime}} I 2_{b, b^{\prime}, t, s}\right] \\
& +\sum_{b^{\prime}}\left(P_{b^{\prime}, b, t, s}^{+}-P_{b^{\prime}, b, t, s}^{-}\right)-P_{b, t}^{\mathrm{L}}=0 \quad \forall \mathrm{t}, \mathrm{s} \\
& Q_{s b, t}^{W h 2 G}-\sum_{b^{\prime}}\left[\left(Q_{b, b^{\prime}, t, s}^{+}-Q_{b, b^{\prime}, t, s}^{-}\right)+X_{b, b^{\prime}} I 2_{b, b^{\prime}, t, s}\right]+\sum_{b^{\prime}}\left(Q_{b^{\prime}, b, t, s}^{+}-Q_{b^{\prime}, b, t, s}^{-}\right)-Q_{b, t}^{\mathrm{L}}=0 \quad \forall \mathrm{t}, \mathrm{s}
\end{aligned}
$$

Note that I2 refers to an auxiliary variable linearly representing the squared current flow I2 in a given branch. At most one of these two positive auxiliary variables, i.e., $\mathrm{P}_{\mathrm{b}, \mathrm{b}, \mathrm{t}, \mathrm{s}}$ and $\mathrm{Q}_{\mathrm{b}, \mathrm{b}, \mathrm{t}, \mathrm{s}}$, can be different from zero at a time. This condition is again implicitly enforced by optimality. Moreover, Eqs. (A.3) and (A.4) limit these variables by the maximum apparent power for the sake of completeness. 


$$
\begin{aligned}
& 0 \leq\left(P_{b, b^{\prime}, t, s}^{+}+P_{b, b^{\prime}, t, s}^{-}\right) \leq V^{\text {Rated }} \times I^{\max , b, b^{\prime}} \\
& 0 \leq\left(Q_{b, b^{\prime}, t, s}^{+}+Q_{b, b^{\prime}, t, s}^{-}\right) \leq V^{\text {Rated }} \times I^{\max , b, b^{\prime}}
\end{aligned}
$$

Eq. (A.5) is presented for the balancing of voltage between two nodes. It should be noted that V2 in Eq. (A.5) is an auxiliary variable representing the squared voltage relation.

$$
V 2_{b, t, s}-V 2_{b^{\prime}, t, s}-Z_{b, b^{\prime}}^{2} I 2_{b, b^{\prime}, t, s}-2 R_{b, b^{\prime}}\left(P_{b, b^{\prime}, t, s}^{+}-P_{b, b^{\prime}, t, s}^{-}\right)-2 X_{b, b^{\prime}}\left(Q_{b, b^{\prime}, t, s}^{+}-Q_{b, b^{\prime}, t, s}^{-}\right)=0
$$

Eq. (A.6) is employed for linearizing the active and reactive power flows that appear in the apparent power expression.

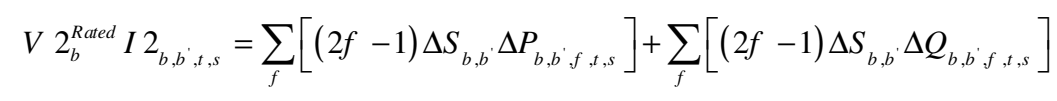

For the piecewise linearization, Eqs. (A.7) - (A.11) are represented. The number of blocks required to linearize the quadratic curve is set to ten according to [20], which strikes the right balance between accuracy and computational requirements. Further descriptions, justifications, and derivations of the network model used in this chapter can be found in [31].

$$
\begin{aligned}
& P_{b, b^{\prime}, t, s}^{+}+P_{b, b^{\prime}, t, s}^{-}=\sum_{f} \Delta P_{b, b^{\prime}, f, t, s} \\
& Q_{b, b^{\prime}, t, s}^{+}+Q_{b, b^{\prime}, t, s}^{-}=\sum_{f} \Delta Q_{b, b^{\prime}, f, t, s} \\
& 0 \leq \Delta P_{b, b^{\prime}, f, t, s} \leq \Delta S_{b, b^{\prime}} \\
& 0 \leq \Delta Q_{b, b^{\prime}, f, t, s} \leq \Delta S_{b, b^{\prime}} \\
& \Delta S_{b, b^{\prime}}=\frac{V^{\text {Rated }} \times I^{\max , b, b^{\prime}}}{f}
\end{aligned}
$$

\section{Appendix-1. B. Converting the bi-level model to the single-level model}

The presented non-linear bi-level model by using the KKT conditions and the dual theory is converted into a linear single-level model. Firstly, by using of KKT optimization conditions (which a series of equal and unequal constraints that are inherently non-linear) a single-level model will be achieved. The presence of complementary constraints is caused by the model to be non-linear. These series of constraints by the Fortuny-Amat and McCarl method which include binary variables, and a very large positive integer will be linear. Then, by using dual theory, the non-linear objective function becomes linear. When the bi-level model is converted to a single-level model, the main objective function of the final model is the linearly objective function of the upper level. Also the constraints of this model are the upper and lower level constraints, KKT's optimization constraints and linearly KKT's complementary constraints.

\section{Converting controlled charging the bi-level model to the single-level model}

At first, the constraints of the lower-level are described as Eqs. (I.1) - (I.9):

$$
\begin{aligned}
& C_{1}=S O E_{E V}^{\max }-S O E_{P L, E V, t, s} \geq 0 \\
& \forall \mathrm{PL}, \mathrm{EV}, \mathrm{t}, \mathrm{s} \\
& C_{2}=P_{P L, E V, t^{\text {mid loff-peak }}, s}^{\text {ch-grid }}+P_{P L, E V, t^{\text {mid loff }- \text { peak }}, s}^{\text {ch-Solar }} \geq 0 \\
& \forall \mathrm{PL}, \mathrm{EV}, t^{\text {midloff-peadk }}, \mathrm{s} \quad \lambda_{\mathrm{PLEV}, t^{\text {midloff-peak }}, \mathrm{s}}^{2}
\end{aligned}
$$

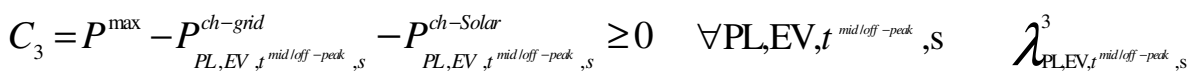




$$
\begin{aligned}
& C_{4}=P_{P L, E V, t^{\text {on-paed }}, s}^{c h-\text { solar }} \geq 0 \\
& \forall \mathrm{PL}, \mathrm{EV}, t^{\text {on-peak }}, \mathrm{s} \quad \lambda_{\mathrm{PL}, \mathrm{EV}, t^{\text {on-peak }}, \mathrm{s}}^{4} \\
& C_{5}=P^{\max }-P_{P L, E V, t^{\text {on-peak }}, s}^{c h-\text { solar }} \geq 0 \\
& \forall \mathrm{PL}, \mathrm{EV}, t^{\text {on-peak }}, \mathrm{s} \quad \lambda_{\mathrm{PL}, \mathrm{EV}, t^{\text {on-peak }}, \mathrm{s}}^{5} \\
& S O E_{\mathrm{PL}, \mathrm{EV}, \mathrm{t}, \mathrm{s}}-S O E_{\mathrm{PL}, \mathrm{EV}, \mathrm{t}-1, \mathrm{~s}} \\
& -\left(\left(P_{P L, E V, t, s}^{c h-\text { grid }}+P_{P L, E V, t, s}^{c h-\text { Solar }}\right) \times \eta^{c h}\right)=0 \\
& S O E_{\mathrm{PL}, \mathrm{EV}, \mathrm{t,s}}-\mathrm{SOE}_{E V}^{\mathrm{arv}} \\
& \forall \mathrm{PL}, \mathrm{EV}, \mathrm{t} \succ \mathrm{t}^{a v}, \mathrm{~s} \quad \lambda_{\mathrm{PL}, \mathrm{EV}, \mathrm{t} \succ \mathrm{t}^{a v}, \mathrm{~s}}^{6} \\
& -\left(\left(P_{P L, E V, t, s}^{c h-g i d}+P_{P L, E V, t, s}^{c h-\text { Solar }}\right) \times \eta^{c h}\right)=0 \\
& S O E_{P L, E V, t, s}-S O E_{E V}^{d e p}=0 \\
& \sum_{E V} P_{P L, E V, t, s}^{c h-S o l a r}-P_{P L, t, s}^{\text {Solar }}=0 \\
& \forall \mathrm{PL}, \mathrm{EV}, \mathrm{t}^{a v}, \mathrm{~s} \quad \lambda_{\mathrm{PL}, \mathrm{EV}, \mathrm{t}^{a v}, \mathrm{~s}}^{7} \\
& \forall \text { PL,EV, } \mathrm{t}^{\text {dep }}, \mathrm{s} \quad \lambda_{\mathrm{PL}, \mathrm{EV}, \mathrm{t}^{d e p}, \mathrm{~s}}^{8} \\
& \forall \mathrm{PL}, \mathrm{EV}, \mathrm{t}, \mathrm{s} \quad \lambda_{\mathrm{PL}, \mathrm{EV}, \mathrm{t}, \mathrm{s}}^{9}
\end{aligned}
$$

So, the Lagrangian function can be achieved by Eq. (I.10):

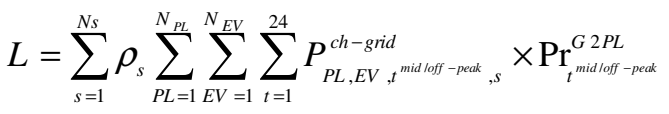

$$
\begin{aligned}
& -\left(S O E_{E V}^{\max }-S O E_{P L, E V, t, s}\right) \lambda_{P L, E V, t, s}^{1}
\end{aligned}
$$

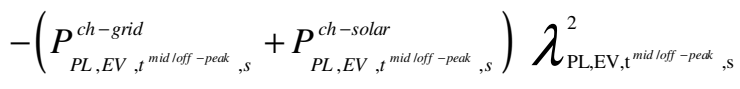

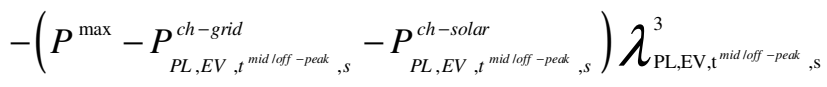

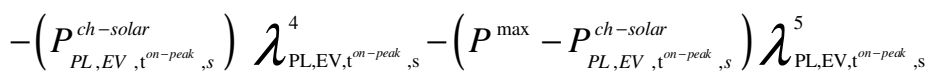

$$
\begin{aligned}
& -\left(S O E_{P L, E V, t, s}-S O E_{P L, E V, t-1, s}-\left(P_{P L, E V, t, s}^{c h-g i d} \times \eta^{c h}\right)-\left(P_{P L, E V, t, s}^{c h-s o l a r} \times \eta^{c h}\right)\right) \lambda_{\mathrm{PL}, \mathrm{EV}, \mathrm{t}, t^{a v}, \mathrm{~s}}^{6} \\
& -\left(\operatorname{SOE}_{P L, E V, t, s}-\mathrm{SOE}_{E V}^{\mathrm{arv}}-\left(P_{P L, E V, t, s}^{c h-\text { grid }} \times \eta^{c h}\right)-\left(P_{P L, E V, t, s}^{c h-\text { solar }} \times \eta^{c h}\right)\right) \lambda_{\mathrm{PL}, \mathrm{EV}, \mathrm{t}^{a v}, \mathrm{~s}}^{7} \\
& -\left(S O E_{P L, E V, t, s}-\mathrm{SOE}_{E V}^{\mathrm{dep}}\right) \lambda_{\mathrm{PL}, \mathrm{EV}, t^{d t p}, \mathrm{~s}}^{8}-\left(\sum_{E V} P_{P L, E V, t, s}^{c h-s o l a r}-P_{P L, t, s}^{\text {solar }}\right) \lambda_{\mathrm{PL}, \mathrm{EV}, \mathrm{t}, \mathrm{s}}^{9}
\end{aligned}
$$

Due to the decision variable in this model, KKT conditions are explained in Eqs. (I.11) - (I.13):

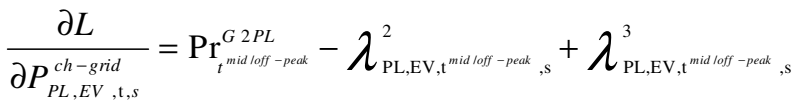

$$
\begin{aligned}
& +\left(\eta^{c h} \times\left.\lambda_{\mathrm{PL}, \mathrm{EV}, \mathrm{t}, \mathrm{s}}^{6}\right|_{\mathrm{t}>\mathrm{tav}}\right)+\left(\eta^{c h} \times\left.\lambda_{\mathrm{PL}, \mathrm{EV}, \mathrm{t}, \mathrm{s}}^{7}\right|_{t=t a v}\right)=0
\end{aligned}
$$

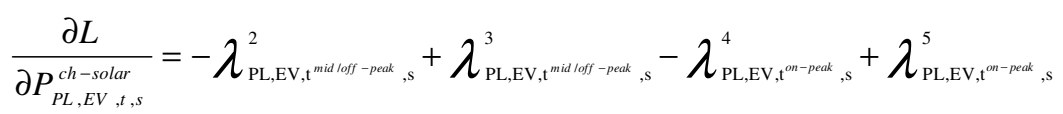

$$
\begin{aligned}
& +\left(\eta^{c h} \times\left.\lambda_{\mathrm{PL}, \mathrm{EV}, \mathrm{t}, \mathrm{s}}^{6}\right|_{\mathrm{t} \succ \mathrm{tav}}\right)+\left(\eta^{c h} \times\left.\lambda_{\mathrm{PL}, \mathrm{EV}, \mathrm{t}, \mathrm{s}}^{7}\right|_{t=t a v}\right)-\lambda_{\mathrm{PL}, \mathrm{EV}, \mathrm{t}, \mathrm{s}}^{9}=0 \\
& \frac{\partial L}{S O C_{P L, E V, t, s}}=\lambda_{\mathrm{PL}, \mathrm{EV}, \mathrm{t}, \mathrm{s}}^{1}+\lambda_{\mathrm{PL}, \mathrm{EV}, \mathrm{t}+1, \mathrm{~s}, \mathrm{t} \succ \mathrm{tav}}^{6}-\lambda_{\mathrm{PL}, \mathrm{EV}, \mathrm{ts}, \mathrm{t} \succ \mathrm{t}^{\mathrm{arV}}}^{6} \\
& -\left.\lambda_{\mathrm{PL}, \mathrm{EV}, \mathrm{ts}}^{7}\right|_{\mathrm{t}=\mathrm{t}^{\mathrm{arV}}}-\left.\lambda_{\mathrm{PL}, \mathrm{EV}, \mathrm{ts}}^{8}\right|_{\mathrm{t}=\mathrm{t}^{\mathrm{dep}}}=0
\end{aligned}
$$


The dual variables of unequal constraints are equal or greater than zero, and the dual variables whose constraints are equal to zero are unrestricted in sign. For Eqs. (I.1) to (I.5), the complementary constraints are as follows, i.e. Eqs. (I.14) to (I.18).

$$
\begin{aligned}
& 0 \leq S O E_{E V}^{\max }-S O E_{P L, E V, t, s} \perp \lambda_{\mathrm{PL}, \mathrm{EV}, \mathrm{t}, \mathrm{s}}^{1} \geq 0 \\
& 0 \leq P_{P L, E V, t^{\text {mid loff }- \text { peak }}, s}^{\text {ch-grid }}+P_{P L, E V, t^{\text {mid loff - peak }, s}}^{\text {ch-solar }} \perp \lambda_{\mathrm{PL}, \mathrm{EV}, \mathrm{t}^{\text {mid loff }- \text { peak }}, \mathrm{s}}^{2} \geq 0 \\
& 0 \leq P^{\max }-P_{P L, E V, t^{\text {mid loff-peak }}, s}^{\text {ch-grid }}+P_{P L, E V, t^{\text {mid loff -peak }, s}}^{c h-S \text { Slar }} \perp \lambda_{\mathrm{PL}, \mathrm{EV}, \mathrm{t}^{\text {mid loff- - peak }}, \mathrm{s}}^{3} \geq 0 \\
& 0 \leq P_{P L, E V, t^{\text {on-peak }}, \mathrm{s}}^{\text {ch-solar }} \perp \lambda_{\mathrm{PL}, \mathrm{EV}, \mathrm{t}, \mathrm{s}}^{4} \geq 0 \\
& 0 \leq P^{\max }-P_{P L, E V, t^{\text {on-peak }}, s}^{c h-\text { solar }} \perp \lambda_{\mathrm{PL}, \mathrm{EV}, \mathrm{t}, \mathrm{s}}^{5} \geq 0
\end{aligned}
$$

The linearization of complementary constraints is performed by Fortuny-Amat and McCarl linearization method by Eq. (I.19) [21]. Then, Eqs. (I.20) - (I.24) are obtained.

$$
\begin{aligned}
& 0 \leq F_{1} \perp F_{2} \geq 0 \\
& 0 \leq F_{1} \leq U \times M \\
& 0 \leq F_{2} \leq(1-U) \times M \\
& U \varepsilon[0,1] \\
& 0 \leq S O E_{E V}^{\max }-S O E_{P L, E V, t, s} \leq U_{P L, E V, t, s}^{1} \times M^{1} \\
& 0 \leq \lambda_{P L, E V, t, s}^{1} \leq\left(1-U_{P L, E V, t, s}^{1}\right) \times M^{2} \\
& 0 \leq P_{P L, E V, \mathrm{t}^{\text {mid loff - peak }}, s}^{c h-\text { gird }}+P_{P L, E V, \mathrm{t}^{\text {mid loff-peak }, s}}^{\text {ch-solar }} \leq U_{P L, E V, \mathrm{t}^{\text {midl loff }- \text { peak }}, s}^{2} \times M^{1} \\
& 0 \leq \lambda_{\mathrm{PL}, \mathrm{EV}, \mathrm{t}^{\text {mid loff }- \text { peak }}, \mathrm{S}}^{2} \leq\left(1-U_{P L, E V, \mathrm{t}^{\text {mid loff }- \text { peak }}, \mathrm{s}}^{2}\right) \times M^{2} \\
& 0 \leq P^{\text {max }}-P_{P L, E V, \mathrm{t}^{\text {mid loff-peak }}, s}^{c h-\text { grid }}-P_{P L, E V, \mathrm{t}^{\text {mid loff }-p e a k}, s}^{c h-\text { solar }} \leq U_{P L, E V, \mathrm{t}^{\text {mid loff - peak }}, s}^{3} \times M^{1} \\
& 0 \leq \lambda_{\mathrm{PL}, \mathrm{EV}, \mathrm{t}^{\text {mid loff - peak }}, \mathrm{S}}^{3} \leq\left(1-U_{P L, E V, \mathrm{t}^{\text {mid loff - peak }}, s}^{3}\right) \times M^{2} \\
& 0 \leq P_{P L, E V, \mathrm{t}^{\text {on-peak }}, s}^{\text {ch-solar }} \leq U_{P L, E V, \mathrm{t}^{\text {on-peak }}, s}^{4} \times M^{1} \\
& 0 \leq \lambda_{\mathrm{PL}, \mathrm{EV}, \mathrm{t}^{\text {on-peak }}, \mathrm{s}}^{4} \leq\left(1-U_{P L, E V, \mathrm{t}^{\text {on-peak }}, \mathrm{s}}^{4}\right) \times M^{2} \\
& 0 \leq P^{\max }-P_{P L, E V, \mathrm{t}^{\text {on-peak }}, s}^{c h-\text { solar }} \leq U_{P L, E V, \mathrm{t}^{\text {on-peak }}, \mathrm{s}}^{5} \times M^{1} \\
& 0 \leq \lambda_{\mathrm{PL}, \mathrm{EV}, \mathrm{t}^{\text {on-peak }}, \mathrm{s}}^{5} \leq\left(1-U_{P L, E V, \mathrm{t}^{\text {on-pead }}, \mathrm{s}}^{5}\right) \times M^{2}
\end{aligned}
$$

The obtained model is a non-linear single-level model, which must be linearized using the dual theory. So, firstly, the dual objective function of the lower-level model is formed as Eq. (I.25): 
Maximize

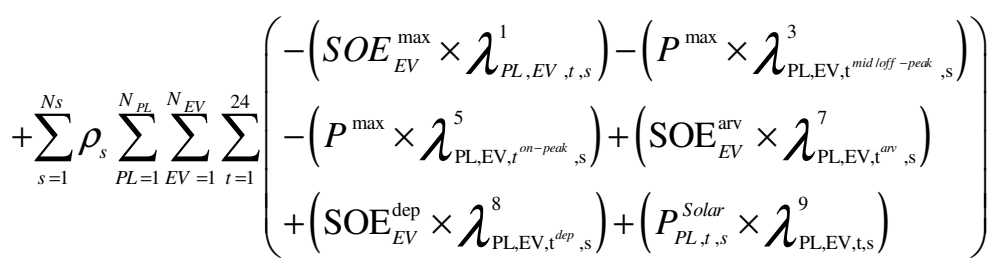

According to the strong dual theory, the objective functions of the original and dual problems are equal at the optimal point of the decision variables of the two problems; therefore, the non-linear section of the objective function is linear according to Eq. (I.26).

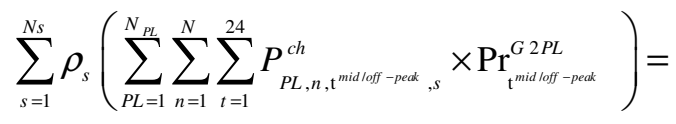

$$
\begin{aligned}
& \sum_{P L=1}^{N_{P L}} \sum_{E V=1}^{N_{E V}} \sum_{t=1}^{24}\left(\hat{P}_{P L, E V, t^{\text {mid loff }- \text { peeak }}}^{c h-\text { gid }} \times \operatorname{Pr}_{t^{\text {mid loff }}}^{G \text { 2Peak }}\right)=
\end{aligned}
$$

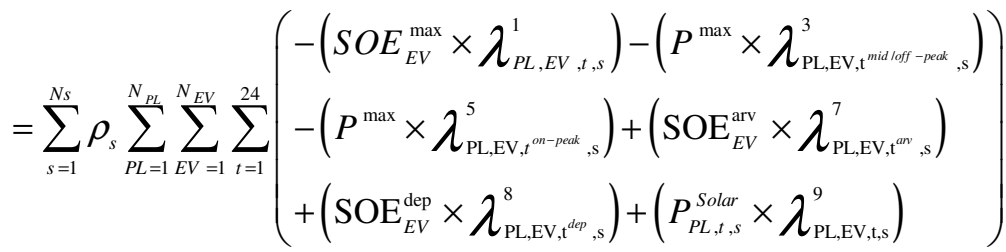

\section{Converting charging/discharging schedule the bi-level model to the single-level model}

At first, the constraints of the lower-level are described as Eqs. (II.1) - (II.10):

$$
\begin{aligned}
& C_{1}=S O E_{P L, E V, t, s}-S O E_{E V}^{\min } \geq 0 \quad \forall \mathrm{PL}, \mathrm{EV}, \mathrm{t}, \mathrm{S} \quad \lambda_{\mathrm{PLEV}, \mathrm{t}, \mathrm{S}}^{1} \\
& C_{2}=S O E_{E V}^{\max }-S O E_{P L, E V, t, s} \geq 0 \quad \forall \mathrm{PL}, \mathrm{EV}, \mathrm{t}, \mathrm{s} \quad \lambda_{\mathrm{PL}, \mathrm{EV}, \mathrm{ts}}^{2}
\end{aligned}
$$

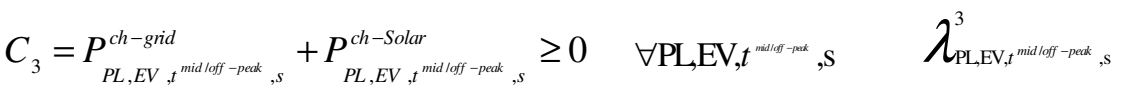

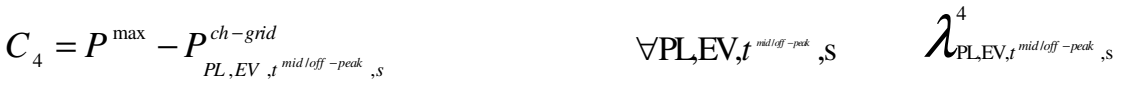

$$
\begin{aligned}
& -P_{P L, E V, t^{\text {mid } h \text { off }- \text { peat }}, s}^{\text {ch-Solar }} \geq 0 \\
& C_{5}=P_{P L, E V, t^{\text {on-pecec }}, s}^{d c h} \geq 0 \\
& \forall \mathrm{PL}, \mathrm{EV}, t^{\text {an-peak }}, \mathrm{s} \quad \lambda_{\mathrm{PL}, \mathrm{EV}, t^{\text {on-peak }}, \mathrm{s}}^{5} \\
& C_{6}=P^{\max }-P_{P L, E V, t^{\text {on-peak }}, s}^{d c h} \geq 0 \quad \forall \mathrm{PLEV}, t^{\text {on- peak }}, \mathrm{s} \quad \lambda_{\mathrm{PL}, \mathrm{EV}, t^{\text {on-peak }}, \mathrm{s}}^{6}
\end{aligned}
$$




$$
\begin{aligned}
& S O E_{\mathrm{PL}, \mathrm{EV}, \mathrm{t}, \mathrm{s}}-S O E_{\mathrm{PL}, \mathrm{EV}, \mathrm{t}-1, \mathrm{~s}}+\left(\frac{P_{P L, E V, t, s}^{d c h}}{\eta^{d c h}}\right) \quad \forall \mathrm{PL}, \mathrm{EV}, \mathrm{t} \succ \mathrm{t}^{a v}, \mathrm{~s} \quad \lambda_{\mathrm{PL}, \mathrm{EV}, \mathrm{t} \succ \mathrm{t}^{a v}, \mathrm{~s}}^{7} \\
& -\left(\left(P_{P L, E V, t, s}^{c h-\text { grid }}+P_{P L, E V, t, s}^{c h-S o l a r}\right) \times \eta^{c h}\right)=0 \\
& S O E_{\mathrm{PL}, \mathrm{EV}, \mathrm{ts}}-\mathrm{SOE}_{E V}^{\mathrm{arv}}+\left(\frac{P_{P L, E V, t, s}^{d c h}}{\eta^{d c h}}\right) \quad \forall \mathrm{PL}, \mathrm{EV}, \mathrm{t}^{a v}, \mathrm{~s} \quad \lambda_{\mathrm{PL}, \mathrm{EV}, \mathrm{t}^{a v}, \mathrm{~s}}^{8} \\
& -\left(\left(P_{P L, E V, t, s}^{c h-\text { grid }}+P_{P L, E V, t, s}^{c h-S o l a r}\right) \times \eta^{c h}\right)=0 \\
& S O E_{P L, E V, t, s}-S O E_{E V}^{d e p}=0 \quad \forall \mathrm{PL}, \mathrm{EV}, \mathrm{t}^{d e p}, \mathrm{~s} \quad \lambda_{\mathrm{PL}, \mathrm{EV}, \mathrm{t}^{d e p}, \mathrm{~s}}^{9}
\end{aligned}
$$

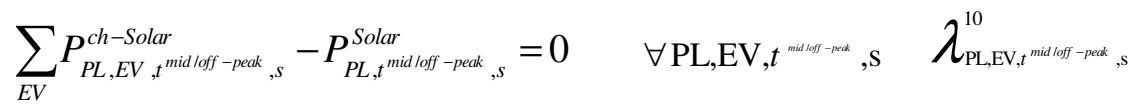

Based on the previous part, Eqs. (II.11) to (II.27) is showing the single-level steps:

$$
\begin{aligned}
& L=
\end{aligned}
$$

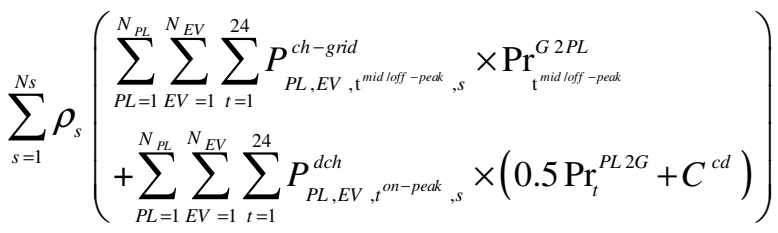

$$
\begin{aligned}
& -\left(S O E_{P L, E V, t, s}-S O E_{E V}^{\min }\right) \lambda_{P L, E V, t, s}^{1} \\
& -\left(S O E_{E V}^{\max }-S O E_{P L, E V, t, s}\right) \lambda_{P L, E V, t, s}^{2}
\end{aligned}
$$

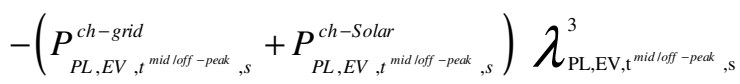

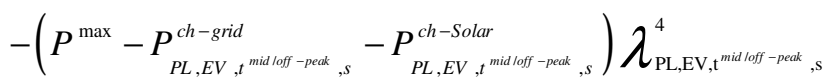

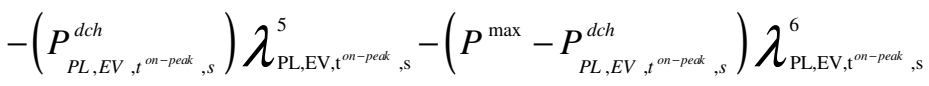

$$
\begin{aligned}
& -\left(\begin{array}{l}
\operatorname{SOE}_{P L, E V, t, s}-S O E_{P L, E V, t-1, s}-\left(P_{P L, E V, t, s}^{c h-g r i d} \times \eta^{c h}\right) \\
-\left(P_{P L, E V, t, s}^{c h-S o l a r} \times \eta^{d h}\right)+\left(\frac{P_{P L, E V, t, s}^{d c h}}{\eta_{d c h}}\right)
\end{array}\right) \lambda_{\mathrm{PL}, \mathrm{EV}, t \succ^{a v,}, s}^{7} \\
& -\left(\begin{array}{l}
S O E_{P L, E V, t, s}-\operatorname{SOE}_{E V}^{\mathrm{arv}}-\left(P_{P L, E V, t, s}^{c h-g r i d} \times \eta^{d h}\right) \\
-\left(P_{P L, E V, t, s}^{c h-S o l a r} \times \eta^{c h}\right)+\left(\frac{P_{P L, E V, t, s}^{d c h}}{\eta^{d c h}}\right)
\end{array}\right) \lambda_{\mathrm{PL}, \mathrm{EV}, t^{a v}, s}^{8} \\
& -\left(S O E_{P L, E V, t, s}-\mathrm{SOE}_{E V}^{\mathrm{dep}}\right) \lambda_{\mathrm{PL}, \mathrm{EV}, t^{d p}, \mathrm{~s}}^{9}
\end{aligned}
$$

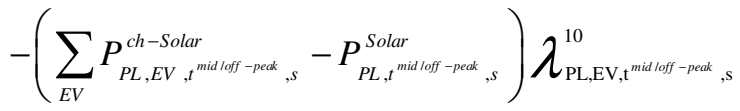




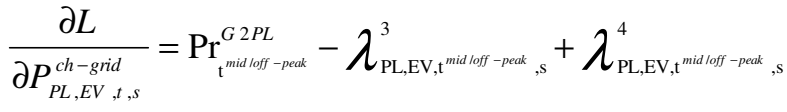

$$
\begin{aligned}
& +\left(\eta^{c h} \times\left.\lambda_{\mathrm{PL}, \mathrm{EV}, \mathrm{t}, \mathrm{s}}^{7}\right|_{\mathrm{t} \succ \mathrm{t}^{\mathrm{av}}}\right)+\left(\eta^{c h} \times\left.\lambda_{\mathrm{PL}, \mathrm{EV}, \mathrm{ts},}^{8}\right|_{t=t^{a v}}\right)=0
\end{aligned}
$$

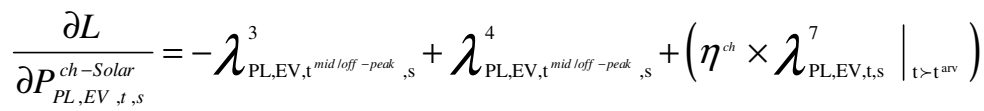

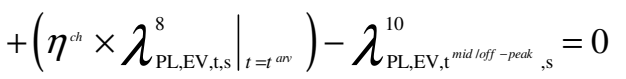

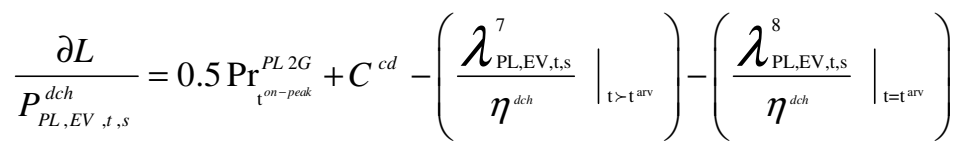

$$
\begin{aligned}
& -\lambda_{\mathrm{PL}, \mathrm{EV}, t^{\text {on }} \text {-peak }, \mathrm{s}}^{5}+\lambda_{\mathrm{PL}, \mathrm{EV}, t^{\text {on-peat }}, \mathrm{s}}^{6}=0 \\
& \frac{\partial L}{S O C_{P L, E V, t, s}}=\left.\lambda_{\mathrm{PL}, \mathrm{EV}, \mathrm{t}+1, s}^{7}\right|_{\mathrm{t} \succ \mathrm{t}^{\mathrm{arv}}}-\left.\lambda_{\mathrm{PL}, \mathrm{EV}, \mathrm{t}, \mathrm{s}}^{7}\right|_{\mathrm{t} \succ \mathrm{t}^{\mathrm{arv}}}-\left.\lambda_{\mathrm{PL}, \mathrm{EV}, \mathrm{ts}}^{8}\right|_{\mathrm{t}=\mathrm{t}^{\mathrm{av}}} \\
& -\left.\lambda_{\mathrm{PL}, \mathrm{EV}, \mathrm{t}, \mathrm{s}}^{9}\right|_{\mathrm{t}=\mathrm{t}^{\mathrm{dep}}}-\lambda_{\mathrm{PL}, \mathrm{EV}, \mathrm{t}, \mathrm{s}}^{1}+\lambda_{\mathrm{PL}, \mathrm{EV}, \mathrm{t}, \mathrm{s}}^{2}=0 \\
& 0 \leq S O E_{P L, E V, t, s}-\mathrm{SOE}_{E V}^{\min } \perp \lambda_{\mathrm{PL}, \mathrm{EV}, \mathrm{t}, \mathrm{S}}^{1} \geq 0 \\
& 0 \leq \mathrm{SOE}_{E V}^{\max }-S O C_{P L, E V, t, s} \perp \lambda_{\mathrm{PL}, \mathrm{EV}, \mathrm{t}, \mathrm{s}}^{2} \geq 0
\end{aligned}
$$

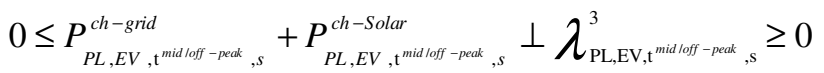

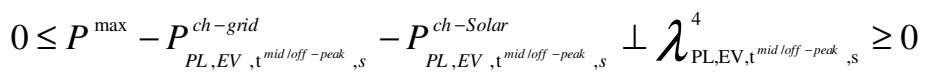

$$
\begin{aligned}
& 0 \leq P_{P L, E V, t^{o n-p e a k}, s}^{d c h} \perp \lambda_{\mathrm{PL}, \mathrm{EV}, t^{\text {on-pead }}, \mathrm{s}}^{5} \geq 0 \\
& 0 \leq P^{\max }-P_{P L, E V, t^{o n-p e a k}, s}^{d c h} \perp \lambda_{\mathrm{PL}, \mathrm{EV}, \mathrm{t}^{\text {on }} \text {-peak }, \mathrm{s}}^{6} \geq 0 \\
& 0 \leq S O E_{P L, E V, t, s}-\mathrm{SOE}_{E V}^{\min } \leq U_{P L, E V, t, s}^{1} \times M^{1} \\
& 0 \leq \lambda_{P L, E V, t, s}^{1} \leq\left(1-U_{P L, n, t, s}^{1}\right) \times M^{2} \\
& 0 \leq S O E_{E V}^{\max }-S O E_{P L, E V, t, s} \leq U_{P L, n, t, s}^{2} \times M^{1} \\
& 0 \leq \lambda_{P L, E V, t, s}^{2} \leq\left(1-U_{P L, n, t, s}^{2}\right) \times M^{2}
\end{aligned}
$$

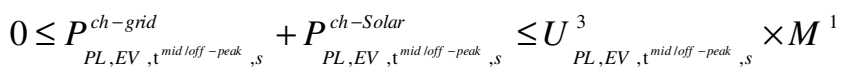

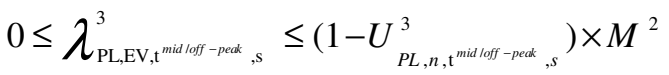




$$
\begin{aligned}
& 0 \leq P^{\text {max }}-P_{P L, E V, \mathrm{t}^{\text {mid loff }- \text { peak }}, s}^{\text {ch-grid }}-P_{P L, E V, \mathrm{t}^{\text {mid loff }- \text { peak }}, s}^{\text {ch-Solar }} \leq U_{P L, E V, \mathrm{t}^{\text {mid loff }- \text { peak }}, s}^{4} \times M^{1} \\
& 0 \leq \lambda_{\mathrm{PL}, \mathrm{EV}, \mathrm{t}^{\text {mid loff }- \text { peak }}, \mathrm{S}}^{4} \leq\left(1-U_{P L, E V, \mathrm{t}^{\text {mid loff - peak }}, s}^{4}\right) \times M^{2} \\
& 0 \leq P_{P L, E V, \mathrm{t}^{\text {on-peak }}, s}^{d c h} \leq U_{P L, E V, \mathrm{t}^{\text {on-peak }}, s}^{5} \times M^{1} \\
& 0 \leq \lambda_{\mathrm{PL}, \mathrm{EV}, \mathrm{t}^{\text {on-peak }}, \mathrm{s}}^{5} \leq\left(1-U_{P L, E V, \mathrm{t}^{\text {on-peak }}, s}^{5}\right) \times M^{2} \\
& 0 \leq P^{\text {max }}-P_{P L, E V, \mathrm{t}^{\text {on-peak }}, s}^{d c h} \leq U_{P L, E V, \mathrm{t}^{\text {on-peak }}, s}^{6} \times M^{1} \\
& 0 \leq \lambda_{\mathrm{PL}, \mathrm{EV}, \mathrm{t}^{\text {on-peak }}, \mathrm{s}}^{6} \leq\left(1-U_{P L, E V, \mathrm{t}^{\text {on-peak }}, \mathrm{s}}^{6}\right) \times M^{2}
\end{aligned}
$$

The non-linear part of the objective function can be converted to a linear part with two Eqs. i.e. (II.28) and (II.29).

\section{Maximize}

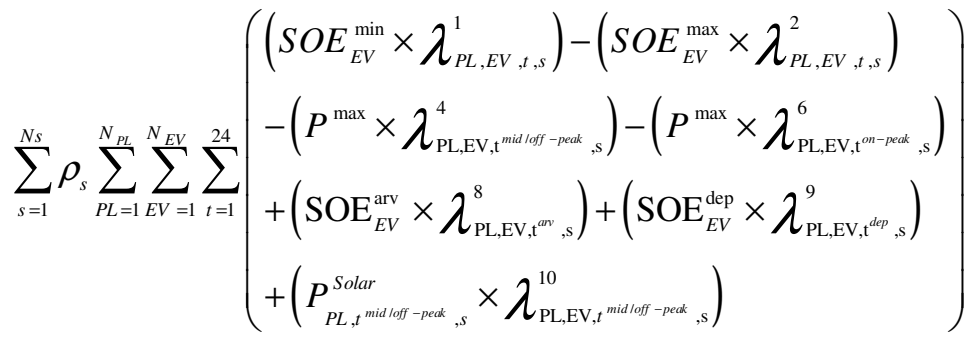




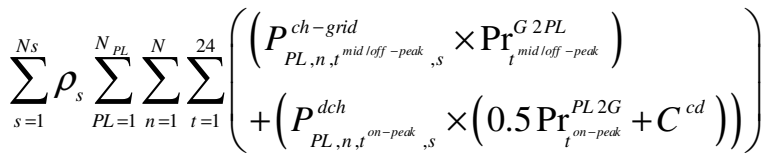

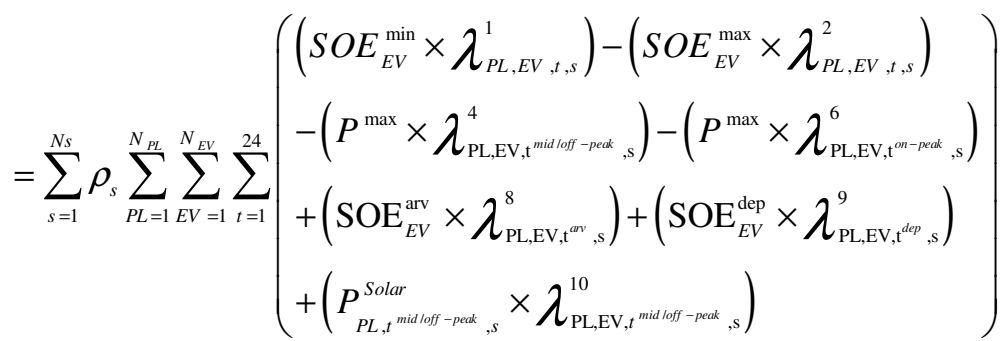

So :

$$
\begin{aligned}
& \sum_{s=1}^{N s} \rho_{s} \sum_{P L=1}^{N_{P L}} \sum_{E V=1}^{N_{E V}} \sum_{t=1}^{24} P_{P L, E V, t^{\text {on-peak }}, s}^{d c h} \times \operatorname{Pr}_{t^{\text {on-peak }}}^{P L 2 G}=\sum_{P L=1}^{N_{P L}} \sum_{E V=1}^{N_{E V}} \sum_{t=1}^{24}\left(\hat{P}_{P L, E V, t^{\text {mid } \text { off }- \text { peak }}}^{d c h} \times \operatorname{Pr}_{t^{\text {mid loff }}}^{G \text {-peak }}\right)=
\end{aligned}
$$

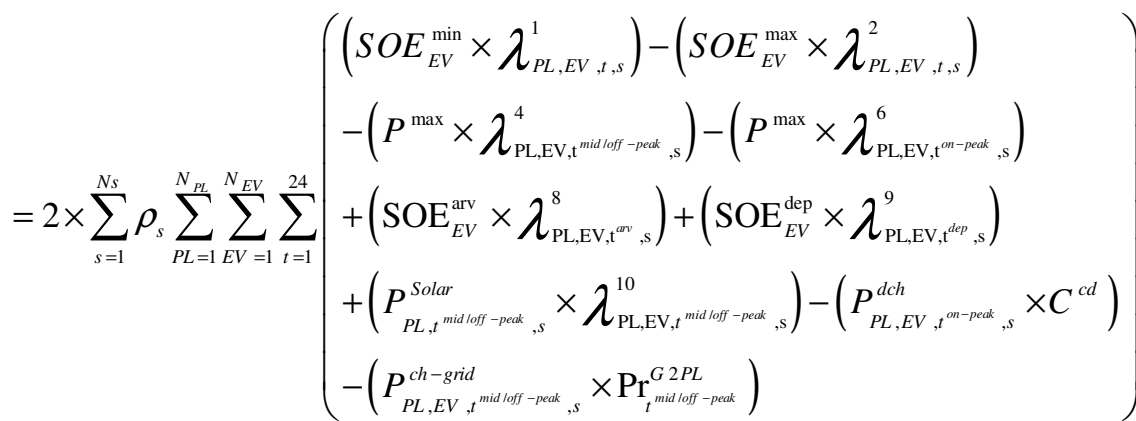

\section{Appendix-1.C}

\begin{tabular}{|c|c|}
\hline \multicolumn{2}{|l|}{ Indices } \\
\hline $\mathrm{b}, \mathrm{b}$ & Index for branch or bus \\
\hline EV & Index for EV number \\
\hline $\mathrm{F}$ & Index for linear partitions in linearization \\
\hline $\mathrm{s}$ & Index for scenarios \\
\hline $\mathrm{sb}$ & Index for slack bus \\
\hline $\mathrm{t}, \mathrm{t}$ & Index for time (hour) \\
\hline \multicolumn{2}{|c|}{ Parameters } \\
\hline $\mathrm{C}^{\mathrm{cd}}$ & Cost of equipment depreciation $(\$ / \mathrm{kWh})$ \\
\hline $\mathrm{I}^{\max }$ & Upper limit of branches' current (A) \\
\hline$I^{\max , b, b^{\prime}}$ & Maximum current of branch $b, b^{\prime}$ (A) \\
\hline M & Sufficiently large constants \\
\hline $\mathrm{P}^{\mathrm{L}}$ & The demand of customers $(\mathrm{kW})$ \\
\hline $\mathrm{P}^{\max }$ & Nominal rate of charging/discharging of EVs $(\mathrm{kWh})$ \\
\hline $\mathrm{P}^{\text {Solar }}$ & Power generated of the solar system $(\mathrm{kW})$ \\
\hline $\operatorname{Pr}^{\mathrm{L}}$ & Electricity price for the customer $(\$ / \mathrm{kWh})$ \\
\hline $\operatorname{Pr}^{\mathrm{Wh} 2 \mathrm{G}}$ & The wholesale market electricity price $(\$ / \mathrm{kWh})$ \\
\hline $\mathrm{R}_{\mathrm{b}, \mathrm{b}^{\prime}}$ & Resistance between branch b , b' $(\Omega)$ \\
\hline $\mathrm{Q}^{\mathrm{L}}$ & Customer's reactive power (kVAR) \\
\hline SOE $^{\text {arv }}$ & Initial SOE of the EVs (kWh) \\
\hline $\mathrm{SOE}^{\mathrm{dep}}$ & Desired SOE of the EVs (kWh) \\
\hline $\mathrm{SOE}^{\max }$ & Upper limit of SOE (kWh) \\
\hline $\mathrm{SOE}^{\min }$ & lower limit of SOE (kWh) \\
\hline
\end{tabular}

The nomenclature is shown below. 


\begin{tabular}{|c|c|}
\hline $\mathrm{t}^{\mathrm{arv}}$ & Arrival time of the EVs to the PL \\
\hline$t^{\text {dep }}$ & Departure time of the EVs from the PL \\
\hline V Rated & Nominal voltage $(\mathrm{V})$ \\
\hline$V^{\max }$ & Maximum allowable voltage $(\mathrm{V})$ \\
\hline $\mathrm{V}^{\min }$ & Minimum allowable voltage (V) \\
\hline $\mathrm{X}_{\mathrm{b}, \mathrm{b}^{\prime}}$ & Reactance between branch b, b $(\Omega)$ \\
\hline$Z$ & Impedance $(\Omega)$ \\
\hline$\eta^{\text {ch }}$ & Charging efficiency $(\%)$ \\
\hline$\eta^{\mathrm{dch}}$ & Discharging efficiency $(\%)$ \\
\hline$\eta^{\text {Trans }}$ & Transformer efficiency $(\%)$ \\
\hline$\rho$ & Probability of each scenario \\
\hline$\alpha$ & Confidence level \\
\hline$\beta$ & Risk aversion parameter \\
\hline$\Delta S$ & Upper limit in the discretization of quadratic flow terms (kVA) \\
\hline \multicolumn{2}{|l|}{ Variables } \\
\hline B & Profit in each scenario \\
\hline $\mathrm{I}, \mathrm{I} 2$ & Current flow (A), Squared current flow (A2) \\
\hline$P^{\text {ch-grid }}$ & Charging power of the EVs by the SDNO $(\mathrm{kW})$ \\
\hline $\mathrm{P}^{\text {ch-solar }}$ & Charging power of the EVs by the power generated of the solar system $(\mathrm{kW})$ \\
\hline$\hat{P}^{\text {ch-grid }}$ & The expected value of charging power of the EVs by the SDNO $(\mathrm{kW})$ \\
\hline$\hat{P}^{\text {solar }}$ & The expected value of the power generated of the solar system $(\mathrm{kW})$ \\
\hline$P^{d c h}$ & Discharging power of the EVs $(\mathrm{kW})$ \\
\hline$\hat{P}^{d c h}$ & The expected value of discharging power of the EVs $(\mathrm{kW})$ \\
\hline $\mathrm{P}^{\text {Loss }}$ & SDN's losses $(\mathrm{kW})$ \\
\hline $\mathrm{P}^{\mathrm{Wh} 2 \mathrm{G}}$ & Purchasing power from the wholesale by the SDNO $(\mathrm{kW})$ \\
\hline $\mathrm{P}^{+}$ & Active power flows in downstream directions $(\mathrm{kW})$ \\
\hline $\mathrm{P}^{-}$ & Active power flows in upstream directions $(\mathrm{kW})$ \\
\hline $\operatorname{Pr}{ }^{\mathrm{G} 2 \mathrm{PL}}$ & Charging tariff of the EVs $(\$ / \mathrm{kWh})$ \\
\hline $\operatorname{Pr}^{\mathrm{PL} 2 \mathrm{G}}$ & Discharging tariff of the EVs $(\$ / \mathrm{kWh})$ \\
\hline $\mathrm{Q}^{\mathrm{Wh} 2 \mathrm{G}}$ & SDN's reactive power (kVAR) \\
\hline $\mathrm{Q}^{+}$ & Reactive power flows in downstream directions (kVAR) \\
\hline $\mathrm{Q}^{-}$ & Reactive power flows in upstream directions (kVAR) \\
\hline SOE & State of energy $(\mathrm{kWh})$ \\
\hline $\mathrm{U}$ & Binary variable \\
\hline$\lambda$ & dual variable $(\$ / \mathrm{kWh})$ \\
\hline$\eta$ & Auxiliary variable for calculating $\mathrm{CVaR}$ \\
\hline$\xi$ & Value-at-risk \\
\hline
\end{tabular}

\section{References}

[1] Fernandez, L.P.; San Román, T.G.; Cossent, R.; Domingo, C.M.; Frias, P. Assessment of the impact of plugin electric vehicles on distribution networks. IEEE Trans. Power Syst. 2011, 26, pp. 206-213.

[2] ElNozahy, M.S.; Salama, M.M.A. A comprehensive study of the impacts of PHEVs on residential distribution networks. IEEE Trans. Sustain. Energy 2014, 5, pp. 332-342.

[3] Weiller, C. Plug-in hybrid electric vehicle impacts on hourly electricity demand in the United States. Energy Policy 2011, 39, pp. 3766-3778.

[4] Mullan, J.; Harries, D.; Bräunl, T.; Whitely, S. Modelling the impacts of electric vehicle recharging on the Western Australian electricity supply system. Energy Policy 2011, 39, pp. 4349-4359.

[5] Yong, J.Y.; Ramachandaramurthy, V.K.; Tan, K.M.; Mithulananthan, N. A review on the state-of-the-art technologies of electric vehicle, its impacts and prospects. Renew. Sustain. Energy Rev. 2015, 49, pp. 365385. 
[6] Jiménez, A.; García, N. Voltage unbalance analysis of distribution systems using a three-phase power flow ans a Genetic Algorithm for PEV fleets scheduling. In Proceedings of the Power and Energy Society General Meeting, San Diego, CA, USA, 22-26 July 2012; pp. 1-8.

[7] Shareef, H.; Islam, M.M.; Mohamed, A. A review of the stage-of-the-art charging technologies, placement methodologies, and impacts of electric vehicles. Renew. Sustain. Energy Rev. 2016, 64, pp. 403-420.

[8] Salman, H.; Muhammad, K.; Umar, R. Impact analysis of vehicle-to-grid technology and charging strategies of electric vehicles on distribution networks-A review. J. Power Sources 2015, 277, pp. 205-214.

[9] Moses, P.S.; Deilami, S.; Masoum, A.S.; Masoum, M.A. Power quality of smart grids with plug-in electric vehicles considering battery charging profile. In Proceedings of the 2010 IEEE PES Innovative Smart Grid Technologies Conference Europe (ISGT Europe), Chalmers Lindholmen Gothenburg, Sweden, 11-13 October 2010; pp. 1-7.

[10] Razeghi, G.; Zhang, L.; Brown, T.; Samuelsen, S. Impacts of plug-in hybrid electric vehicles on a residential transformer using stochastic and empirical analysis. J. Power Sources 2014, 252, pp. 277-285.

[11] Akhavan-Rezai, E.; Shaaban, M.F.; El-Saadany, E.F.; Zidan, A. Uncoordinated charging impacts of electric vehicles on electric distribution grids: Normal and fast charging comparison. In Proceedings of the Power and Energy Society General Meeting, San Diego, CA, USA, 22-26 July 2012; pp. 1-7.

[12] Sortomme, E., \& El-Sharkawi, M. A. Optimal scheduling of vehicle-to-grid energy and ancillary services. IEEE Transactions on Smart Grid, 2012, 3(1), pp. 351-359.

[13] Wang, Z., \& Wang, S. Grid power peak shaving and valley filling using vehicle-to-grid systems. IEEE Transactions on Power Delivery,2013, 28(3), pp. 1822-1829.

[14] López, M. A., De la Torre, S., Martín, S., \& Aguado, J. A. Demand-side management in smart grid operation considering electric vehicles load shifting and vehicle-to-grid support. International Journal of Electrical Power \& Energy Systems,2015, 64, pp. 689-698.

[15]Zakariazadeh, A., Jadid, S., \& Siano, P. Multi-objective scheduling of electric vehicles in smart distribution system. Energy Conversion and Management,2014, 79, pp. 43-53.

[16] Fazelpour, F., Vafaeipour, M., Rahbari, O., \& Rosen, M. A. Intelligent optimization to integrate a plug-in hybrid electric vehicle smart parking lot with renewable energy resources and enhance grid characteristics. Energy Conversion and Management,2014, 77, pp. 250-261.

[17] Marra, F., Yang, G. Y., Træholt, C., Larsen, E., Østergaard, J., Blažič, B., \& Deprez, W. EV charging facilities and their application in LV feeders with photovoltaics. IEEE Transactions on Smart Grid,2013, 4(3), pp. 1533-1540.

[18] Amini, M. H., Moghaddam, M. P., \& Karabasoglu, O. Simultaneous allocation of electric vehicles’ parking lots and distributed renewable resources in smart power distribution networks. Sustainable Cities and Society,2017, 28, pp. 332-342.

[19] Mohammadi-Hosseininejad, S. M., Fereidunian, A., \& Lesani, H. Reliability improvement considering plugin hybrid electric vehicles parking lots ancillary services: a stochastic multi-criteria approach. IET Generation, Transmission \& Distribution,2017, 12(4), pp. 824-833.

[20] Sadati, S. M. B., Moshtagh, J., Shafie-khah, M., \& Catalão, J. P. Smart distribution system operational scheduling considering electric vehicle parking lot and demand response programs. Electric Power Systems Research,2018, 160, pp. 404-418.

[21] Sadati, S. M. B., Moshtagh, J., Shafie-khah, M., Rastgou, A., \& Catalão, J. P. Operational scheduling of a smart distribution system considering electric vehicles parking lot: A bi-level approach. International Journal of Electrical Power \& Energy Systems,2019, 105, pp. 159-178.

[22] Sioshansi, R., \& Miller, J. Plug-in hybrid electric vehicles can be clean and economical in dirty power systems. Energy Policy,2011, 39(10), pp. 6151-6161.

[23] Weiller, C. Plug-in hybrid electric vehicle impacts on hourly electricity demand in the United States. Energy Policy,2011, 39(6), pp. 3766-3778.

[24]ElNozahy, M. S., \& Salama, M. M. A. Studying the feasibility of charging plug-in hybrid electric vehicles using photovoltaic electricity in residential distribution systems. Electric Power Systems Research,2014, 110, pp. 133-143. 
[25] Ghofrani, M., Arabali, A., \& Ghayekhloo, M. Optimal charging/discharging of grid-enabled electric vehicles for predictability enhancement of PV generation. Electric Power Systems Research,2014, 117, pp. 134-142.

[26] Hennings, W., Mischinger, S., \& Linssen, J. Utilization of excess wind power in electric vehicles. Energy policy,2013, 62, pp.139-144.

[27] Borba, B. S. M., Szklo, A., \& Schaeffer, R. Plug-in hybrid electric vehicles as a way to maximize the integration of variable renewable energy in power systems: the case of wind generation in northeaster Brazil. Energy, 37(1), pp. 469-481.

[28] Dallinger, D., Gerda, S., \& Wietschel, M. Integration of intermittent renewable power supply using gridconnected vehicles-A 2030 case study for California and Germany. Applied Energy,2013,104, pp. 666-682.

[29] Jin, C., Sheng, X., \& Ghosh, P. Optimized electric vehicle charging with intermittent renewable energy sources. IEEE Journal of Selected Topics in Signal Processing,2014, 8(6), pp. 1063-1072.

[30] Conejo, A. J., Carrión, M., \& Morales, J. M. Decision making under uncertainty in electricity markets, (Vol. 1), 2010, New York: Springer.

[31] Shafie-khah, M., Siano, P., Fitiwi, D. Z., Mahmoudi, N., \& Catalão, J. P. An Innovative Two-Level Model for Electric Vehicle Parking Lots in Distribution Systems with Renewable Energy. IEEE Trans. Smart Grid, 2017.

[32] Bahramara, S., Moghaddam, M. P., \& Haghifam, M. R. Modelling hierarchical decision making framework for operation of active distribution grids. IET Generation, Transmission \& Distribution, 2015, 9(16), pp. 25552564.

[33] Esmaeeli, M., Kazemi, A., Shayanfar, H., Haghifam, M. R., \& Siano, P. Risk-based planning of distribution substation considering technical and economic uncertainties. Electric Power Systems Research,2016, 135, pp. 18-26.

[34] Mazidi, M., Monsef, H., \& Siano, P. Incorporating price-responsive customers in day-ahead scheduling of smart distribution networks. Energy Conversion and Management,2016, 115, pp. 103-116.

[35] Talari, S., Yazdaninejad, M., \& Haghifam, M. R. Stochastic-based scheduling of the microgrid operation including wind turbines, photovoltaic cells, energy storages and responsive loads. IET Generation, Transmission \& Distribution,2015, 9(12), pp. 1498-1509.

[36] Zakariazadeh, A., Jadid, S., \& Siano, P. Stochastic multi-objective operational planning of smart distribution systems considering demand response programs. Electric Power Systems Research, 2014, 111, pp. 156-168. 